\title{
GDNF SIGNALING REGULATES YBX1/mRNA INTERACTIONS IN MOUSE SPERMATOGONIA
}

by

\section{Bart Tyler Phillips}

[BS, Missouri Western State University, 2005]

Submitted to the Graduate Faculty of

The School of Medicine in partial fulfillment

of the requirements for the degree of

Doctor of Philosophy

University of Pittsburgh 


\section{UNIVERSITY OF PITTSBURGH \\ SCHOOL OF MEDICINE}

This thesis was presented

by

Bart Tyler Phillips

It was defended on

August 9, 2012

and approved by

J. Richard Chaillet, Professor, Cellular and Molecular Pathology

Eric Lagasse, Associate Professor, Cellular and Molecular Pathology

Christine Milcarek, Professor, Molecular Genetics and Developmental Biology

William H. Walker, Associate Professor, Molecular Genetics and Developmental Biology

Thesis Advisor: Kyle Orwig, Assistant Professor, Molecular Genetics and Developmental Biology 
Copyright (C by Bart Phillips

2012 


\section{GDNF SIGNALING REGULATES YBX1/mRNA INTERACTIONS IN MOUSE SPERMATOGONIA}

Bart Phillips, PhD

University of Pittsburgh, 2012

Spermatogenesis is a highly coordinated and productive process that maintains continuous sperm production in post-pubertal males. Spermatogonial stem cells (SSCs) are the basis of spermatogenesis and balance self-renewal with differentiation to maintain the stem cell pool while producing differentiating progenitors that give rise, through several transit-amplifying mitotic divisions, two meiotic divisions and morphological differentiation to sperm. The molecular mechanisms driving these fate decisions are poorly understood, though numerous RNA regulatory pathways are thought to be critical. We used microarray analysis of distinct testis models to identify genes whose expression correlates with SSC activity. Fourteen RNA binding proteins were identified, and their testis expression was validated using RT-PCR and immunohistochemistry. The multi-functional RNA regulator YBX1 was expressed only by cells located on the basement membrane of seminiferous tubules, consistent with the location of SSCs. YBX1 was of special interest because of its heretofore unexplored role in the testis, as well as its possible phosphorylation by AKT. The AKT signaling pathway is activated in mouse SSCs by GDNF, a factor essential for SSC survival and self-renewal. We hypothesized that YBX1 was phosphorylated by AKT signaling downstream of GDNF, and that this phosphorylation would affect YBX1 interaction with target messenger RNAs (mRNAs). We show that YBX1 is phosphorylated in spermatogonia, and that GDNF signaling modulates YBX1 phosphorylation. Inhibiting either PI3K or AKT in SSC cultures also causes a loss of YBX1 phosphorylation, suggesting that GDNF works through the PI3K/AKT signaling pathway to phosphorylate YBX1. To identify mRNA targets of YBX1, we immunoprecipitated YBX1 from SSC cultures grown in the presence or absence of GDNF, and isolated co-immunoprecipitated mRNAs. In normal growth conditions (containing GDNF), YBX1 associated with mRNA for genes expressed by all 
germ cells ( $D a z l$ and $D d x 4$ ), but not those expressed specifically by more undifferentiated germ cells (GFRal, Ngn3 and Plzf). Furthermore, association of YBX1 with a specific mRNA correlates with an increase in protein levels for that gene. These data collectively lead us to conclude that YBX1 mediates GDNF-dependent translational regulation of specific transcripts that may be important for coordinating SSC maintenance, renewal and/or differentiation. 
TABLE OF CONTENTS

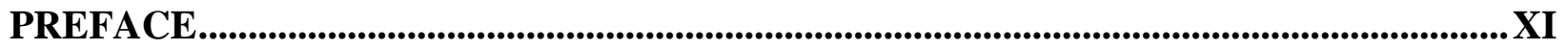

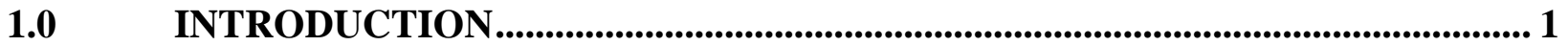

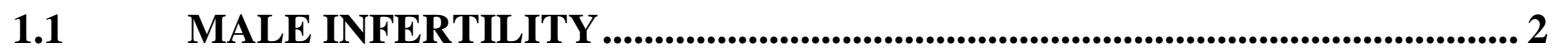

1.2 SPERMATOGONIAL STEM CELLS AND SPERMATOGENESIS ............ 2

1.3 REGULATION OF SPERMATOGONIAL STEM CELLS ............................ 8

1.4 EXPERIMENTAL TOOLS FOR STUDYING SPERMATOGONIA .......... 10

1.5 RNA REGULATION IN THE MALE GERMLINE ...................................... 16

1.6 IDENTIFYING SPERMATOGONIAL GENES............................................ 23

2.0 CHARACTERIZING RNA BINDING PROTEINS IN THE MOUSE TESTIS. 28

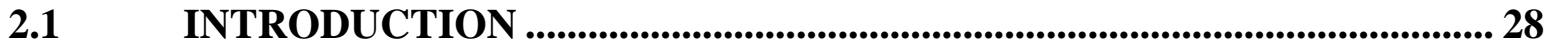

2.2 MATERIALS AND METHODS......................................................................... 29

$2.3 \quad$ RESULTS AND DISCUSSION .......................................................................... 32

2.3.1 Testis RNA Binding Proteins....................................................................... 32

2.3.2 Characterization of the 14 RNA Binding Proteins of Interest ................... 32

$\begin{array}{llllll}3.0 & \text { GDNF } & \text { SIGNALING THROUGH } & \text { PI3K/AKT } & \text { REGULATES } & \text { YBX1 }\end{array}$

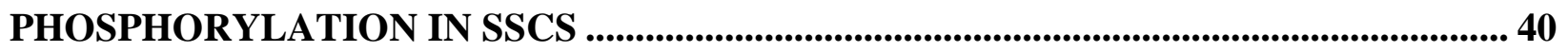

INTRODUCTION ..................................................................................................... 40

MATERIALS AND METHODS............................................................... 42 
R.3 RESULTS AND DISCUSSION ........................................................................... 44

3.3.1 YBX1 is Expressed in Mouse SSC Cultures...................................................... 44

3.3.2 YBX1 is Phosphorylated in vivo and in vitro................................................... 46

3.3.3 GDNF Directs YBX1 Phosphorylation....................................................... 48

4.0 GROWTH FACTOR STIMULI DIRECT YBX1/MRNA INTERACTION ........ 53

INTRODUCTION ................................................................................................ 53

4.2 MATERIALS AND METHODS ..................................................................... 55

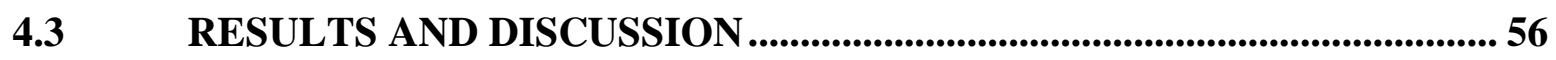

4.3.1 Growth Factor Mediated YBX1 Association with mRNA.......................... 56

4.3.2 YBX1 Association with RNA Correlates with Protein Levels ..................... 59

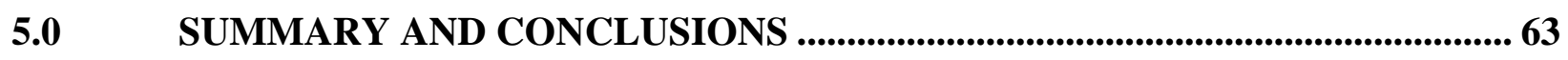

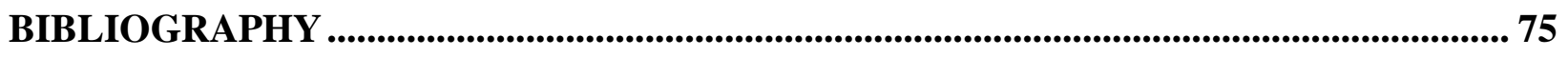




\section{LIST OF TABLES}

Table 1: Forward and reverse primers for RNA binding protein encoding genes....................... 30

Table 2: RNA Binding Proteins Identified in Differential Testis Microarray ........................... 33

Table 3: Forward and reverse primers for PCR and nested PCR (denoted with N).................. 54 


\section{LIST OF FIGURES}

Figure 1: Stem, progenitor and differentiating spermatogonia nomenclature ............................ 3

Figure 2: Mouse spermatogenic lineage. ..................................................................... 4

Figure 3: Mouse spermatogenic clone development by stage ......................................... 7

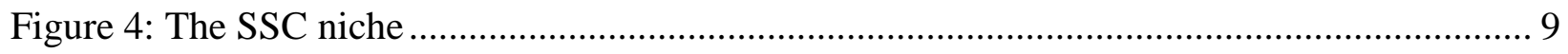

Figure 5: Spermatogonial stem cell (SSC) transplant assay. .............................................. 11

Figure 6: PLZF marks mouse undifferentiated spermatogonia. .......................................... 16

Figure 7: RBMY1A1 is expressed by undifferentiated spermatogonia................................... 19

Figure 8: In vivo testis models have variable SSC activity................................................ 24

Figure 9: Functional annotation of gene list from microarray.......................................... 26

Figure 10: RNA binding protein expression in testis models ............................................ 34

Figure 11: RNA binding protein expression in the testis................................................ 36

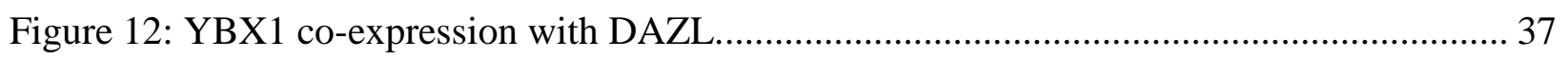

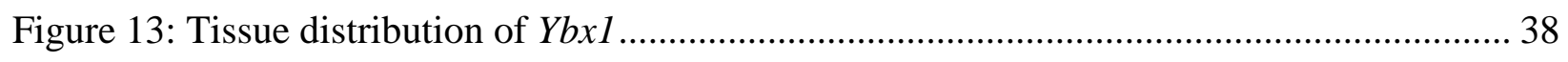

Figure 14: YBX1 protein is detected in mouse SSC culture.. ............................................... 45

Figure 15: YBX1 mRNA is detected in mouse SSC culture. .............................................. 46

Figure 16: Phospho-YBX1 is expressed in adult mouse testis and SSCs in vitro.................... 47

Figure 17: YBX1 phosphorylation is mediated by GDNF signaling in mSSCs cultures............ 49 
Figure 18: YBX1 phosphorylation is mediated by PI3K signaling in SSCs cultures................. 50

Figure 19: YBX1 phosphorylation is mediated by PI3K signaling in SSCs cultures.................. 51

Figure 20: YBX1 association with mRNA is mediated by growth factor stimuli..................... 57

Figure 21: Protein levels correlate with YBX1 association with mRNA................................ 60

Figure 22: Model of GDNF/bFGF action on YBX1 in SSCs............................................ 70 


\section{PREFACE}

During my final thesis committee meeting, the one where I asked for permission to begin writing my dissertation, the committee sent me out of the room to decide my fate. I had great anxiety coming into the meeting, devoting sleepless nights to agonizing over how they would respond. My watershed moment came while I was waiting for them to decide. My $\mathrm{PhD}$ would not be earned while standing at a podium convincing my thesis committee to let me head for the finish line. My PhD would not be earned having the same conversations with my advisor. No, my advisor and thesis committee hold the keys to my receiving a diploma, but I earned it over the last few years. I earned it in long days and nights, early mornings and weekends spent in the lab. I earned it traveling to meetings, designing posters and giving presentations. I earned it studying data, thinking through models and planning the next experiments. The earning of this degree has been a long, multi-faceted, challenging and rewarding journey. I have many people to thank, for I did not make the journey on my own.

First and foremost, I need to acknowledge Dr. Kyle Orwig, my advisor and mentor, in whose lab I performed my thesis research. More than being simply the source of materials and space to experiment, Kyle has been a sounding board, an encouragement and a driving force behind this work. He has allowed me to take up afternoons sitting in his office discussing my research, recent publications and the intricacies of lab life. He has pushed me to plan 
experiments thoughtfully, speak and write carefully, accurately and concisely. He provided me great freedom in developing a research project I was excited about and gave me words of wisdom that I'll carry with me. After all, "extraordinary claims require extraordinary proof” isn’t the kind of thing you hear everywhere.

One of the most valuable things Kyle provided as a mentor was a diversely talented group of co-workers. Jen kept the lab running, acting as a sort of laboratory mother to oversee everything that needed to happen to keep the lab running. Meena helped me perform my first animal surgeries. Yi Sheng, Brian and Chih-Cheng were my molecular biology teachers. Kathrin's encyclopedic knowledge of the field made our co-authored review significantly easier. Hanna, my fellow graduate student, helped keep my in line with paperwork and classes, not to mention being my reference for human germ cell biology. Julia kept me in mice and Karen helped keep me in mouse cultures. Any number of other researchers (like Min), medical fellows (Melanie, Serena, Gosia) and various rotation and summer students have all contributed to my research or the personality of the lab. The 'work hard and have fun' environment is one that was proactively established, and is one that I hope to find again in future work settings.

The other great work experience that I will walk away from my formal education with is the value of organic collaboration. It was over cigars that Chas and I worked out any number of details related to marrying our independent research strengths into what became a solid project. Meanwhile, Pawan initially came to us for help with germ cell culture, but I learned as much from him as he quickly became a reference and sounding board. Both of these guys gave me not only a broader research experience, but they have given me unique perspectives on everything from grants and experiments, to balancing personal and professional life as a post-doc. 
And speaking of the personal life, I must acknowledge the people outside of the lab who have encouraged and supported me through the years. I suppose this begins with my parents who told me I could do whatever I wanted when I grew up, though they probably did not foresee this path. I greatly value my brother Drew, my friends in the program who I could converse with, and my friends from church and those outside of biology who I could converse to about the joys and struggles of school and labwork. All helped me keep perspective, keep focus and have some fun. I thank too my friend and love, my fiancé Victoria for her support, her patient understanding, her excitement over my success and sympathy over failures, her encouragement to do things like bathe regularly and have meals. I could fill books extolling the others, from my first research advisor to my thesis committee and many in between who have contributed to my work. Though I will cut myself off here. I will conclude with thanks to my Creator for allowing me to use my gifts in the investigation of the smallest parts of life. I hear that God is in the details, and it has been my pleasure to study those biological details. RNA regulation is surely what that idiom describes, right? 


\subsection{INTRODUCTION}

Spermatogenesis is the process by which male germ cells proliferate and differentiate to produce haploid gametes. The integrity of this system is critical for the survival and evolution of metazoan species. The basis of spermatogenesis is an evolutionarily conserved adult tissue stem cell: the spermatogonial stem cell (SSC). Like all stem cells, the SSC resides in a niche where it balances self-renewal with differentiation. During differentiation an SSC leaves the stem cell pool and commits to a differentiation pathway which includes numerous mitotic and meiotic divisions as well as morphological changes, ultimately producing fully differentiated spermatozoa. In self-renewing division, a parent SSC reproduces two daughter SSCs to replenish the stem cell pool, thus preventing its exhaustion, and providing a mechanism for continual germ cell production. The mechanisms driving SSC fate decisions, self-renewal vs. differentiation, are poorly understood, although many forms of RNA regulation play major roles. The research presented in this thesis first screened for RNA binding proteins in mouse SSCs and identified one protein, YBX1 that was further analyzed in its regulation and function in mouse SSCs. 


\subsection{MALE INFERTILITY}

Sexual reproduction is the mechanism by which two members of a species combine genetic material to produce a new species member containing heritable traits of each parent. This process is responsible for producing novel genotypes, which in turn produces ever-increasing species variability, and is thus responsible for much of the diversity we see in life. In many species, including our own, sexual reproduction commences during fertilization, when the male and female haploid gametes fuse.

Fertility is the natural capability of producing offspring. Approximately $15 \%$ of couples worldwide experience infertility, and as many as half of the cases are due to male specific pathologies [54]. The specific causes of male infertility are numerous, and include genetic factors in germ or somatic cells of the testis, age, medical treatment, endocrine system disruption, post-testicular disorders and environmental factors [55-58]. Many cases of male infertility are idiopathic (unknown cause) and are the impetus for further investigation into molecular mechanisms that maintain healthy steady state spermatogenesis.

\subsection{SPERMATOGONIAL STEM CELLS AND SPERMATOGENESIS}

Spermatogenesis is the basis of male fertility. It is a complex system, depending on somatic cells and comprised of the continual production of the male gamete, spermatozoa, from differentiating precursor cells. The unique cells comprising the spermatogenic compartment have different gene expression profiles, physical and functional characteristics due to the specific role of each 


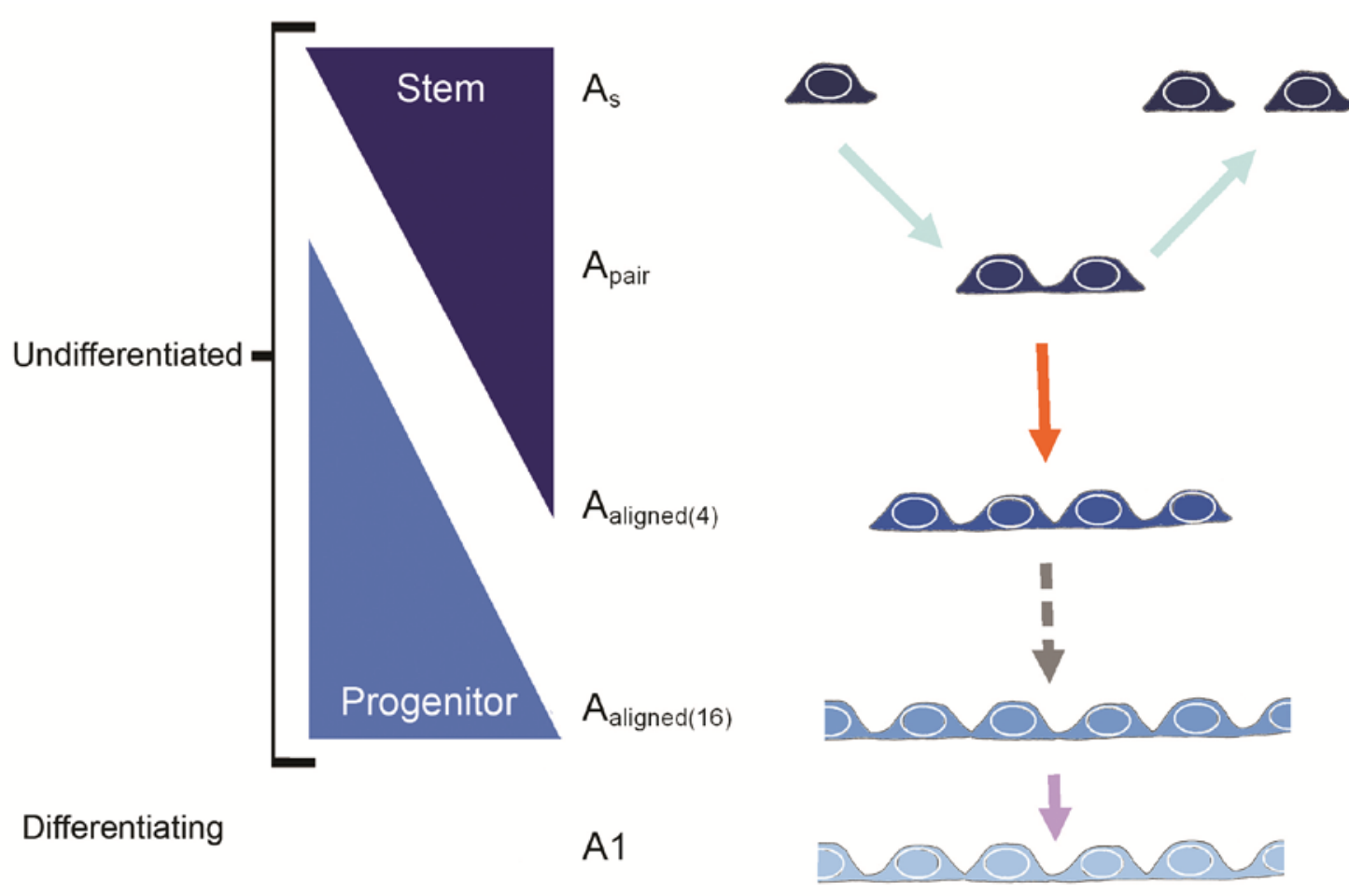

Figure 1: Stem, progenitor and differentiating spermatogonia nomenclature. The $A_{s}$, seen at the top of the diagram, is responsible for self-renewal and differentiation. Self-renewal is represented here by the $A_{\text {pair }}$ dividing to form two $A_{s}$. Differentiation is indicated by color change (from dark to light) and the lengthening chain of germ cells. While stem cell activity is considered to reside in the pool of $A_{s}$ spermatogonia, the tapered triangle on the left indicates that stem cell activity may extend to $A_{p r}$ and some $A_{a l}$ spermatogonia. Republished with permission from: Phillips, B., Gassei, K., Orwig, K. Philos Trans R Soc Lond B Biol Sci, 2010. 365(1546):1663-1678.

cell in spermatogenesis. The spermatogonial stem cell (SSC) is the cell that in an adult is responsible for maintaining the continual production of sperm. Because it represents the foundation of spermatogenesis, understanding SSCs could provide insights into idiopathic male infertility, as well as yield clinical relevance for preserving and restoring male fertility and offering the potential for a reversible contraceptive [59].

The developmental origin of SSCs is the primordial germ cell (PGC). PGCs are first observed in the mouse embryo about 7 days post coitum (dpc). They then migrate out of the embryo, and re-enter via the hindgut ultimately coming to rest in the indifferent gonad between 

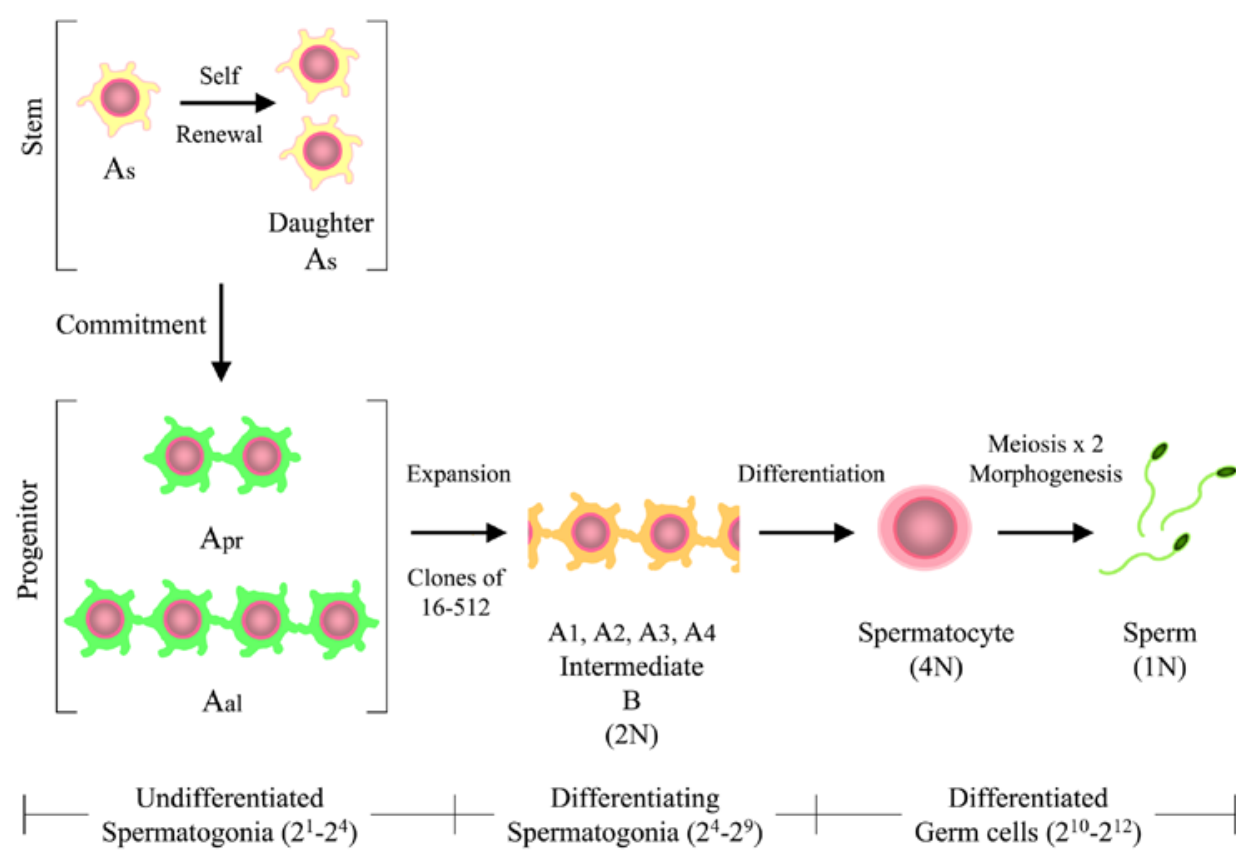

Figure 2: Mouse spermatogenic lineage. When a spermatogonial stem cell (type $A_{s}$ spermatogonia) divides, daughter cells can remain type $A_{s}$ spermatogonia (self-renewal) or commit to differentiation, giving rise through 12 amplifying divisions (212) to a clone of spermatogenesis that could theoretically contain 4,096 spermatozoa. Once committed to differentiation, an $A_{s}$ spermatogonial stem cell gives rise to a pair of undifferentiated spermatogonia $\left(A_{p r}\right)$ that are connected by a cytoplasmic bridge. Incomplete cytokinesis is a hallmark of germ cell proliferation. The first four population doubling divisions $\left(2^{1}-2^{4}\right)$ generate chains of undifferentiated $A_{p r}$ and $A_{a l}$ spermatogonia; $A_{p r}, A_{a l 4}, A_{a l 8}, A_{a 16}$, which collectively make up the pool of progenitor spermatogonia. Differentiation becomes evident morphologically when a chain of $\mathrm{A}_{\text {al16 }}$ spermatogonia becomes a chain of type $\mathrm{A}_{16}$ spermatogonia. The next five population doubling divisions $\left(2^{5}-2^{9}\right)$ generate types A2, A3, A4, intermediate, and B differentiating spermatogonia. The 10th division $\left(2^{10}\right)$ produces primary spermatocytes $(4 \mathrm{~N})$ and is followed by two meiotic divisions $\left(2^{11}-2^{12}\right)$ and spermiogenesis to produce $1 \mathrm{~N}$, terminally differentiated spermatozoa. Abbreviations: $A_{a l}, A_{\text {aligned }} ; A_{p r}, A_{\text {paired }} ; A_{s}, A_{\text {single }}$. Republished with permission from: Orwig, K., Ryu, B., Master, S., Phillips, B., Mack, M., Avarbock, M. Chodosh, L., Brinster, R. Stem Cells, 2008. 26(4):927-938.

8.5 and $12.5 \mathrm{dpc}$ [60]. At day $13.5 \mathrm{dpc}$ in males, PGCs give rise to gonocytes which are surrounded by somatic cells, Sertoli cell precursors, to form testicular cords [61]. In the first 
postnatal week, gonocytes travel to the basement membrane of the cords, which at this point have transitioned to seminiferous tubules of the testis. Once there, the gonocytes establish the pool of SSCs responsible for spermatogenic maintenance [62-64].

Like all adult tissue stem cells, SSCs balance self-renewing divisions that maintain the stem cell pool with differentiating divisions that produce clones of spermatogenesis. The balance of self-renewing and differentiating divisions is regulated at least in part by signals emanating from the SSC niche and is necessary for tissue homeostasis[65-67]. The hierarchy of spermatogonial development begins with the $A_{\text {single }}\left(A_{s}\right)$ spermatogonia, initially identified by whole mount analysis as isolated cells located on the basement membrane of mouse seminiferous tubules [68]. When an $A_{s}$ divides, it produces a pair of spermatogonia $\left(A_{p a i r e d}\right.$ or $\left.A_{p r}\right)$ that either completes cytokinesis to produce two new $\mathrm{A}_{\mathrm{s}}$ spermatogonia (self-renewal) or remains connected and produces chains of 4, 8, 16 and sometimes 32 cells known as $A_{\text {aligned }}\left(A_{a l}\right)$ spermatogonia.

SSC activity is generally considered to reside in the pool of $A_{s}$ spermatogonia, but may also extend $A_{p r}$ and $A_{a l 4}[65,69-72]$. Chains of spermatogonia share protein, mRNA and other intracellular components, which facilitates coordinated progression through discrete stages of development [73, 74]. Collectively these earliest germ cell divisions are known as stem and progenitor spermatogonia, or undifferentiated spermatogonia, while cells proceeding from these stages are known as differentiating germ cells (Figures 1 and 2). The larger chains of $A_{a l 8-32}$ spermatogonia give rise to differentiating type A1 spermatogonia, followed by successive divisions to produce types A2, A3, A4, Intermediate and B spermatogonia. Type B spermatogonia then transition into primary spermatocytes which progress with two meiotic divisions and morphological differentiation to ultimately produce haploid spermatids (Figure 2) [75]. 
Because spermatogenesis is perpetual, with SSCs continually committing to differentiate, there are concomitant waves of spermatogenesis occurring concurrently and sequentially. Therefore multiple distinct cell types from different phases of germ cell development (spermatogonia, spermatocytes and spermatids), representing multiple independent waves of spermatogenesis, are observed in each cross-section of the seminiferous epithelium. These distinct combinations can be dissected into unique stages of spermatogenesis, of which there are 12 in the mouse (labeled I-XII) [75, 76]. Figure 3 follows the development of two undifferentiated clones (green and red) and one differentiating clone (blue) through one complete cycle of the seminiferous epithelium, including all 12 stages. Note that clonal development can be observed in whole mount preparations of seminiferous tubules, but not cross sections or longitudinal sections. In contrast, cross-sections and longitudinal sections depict complete spermatogenesis (spermatogonia to sperm) that cannot be observed in whole mount.

In addition to being highly ordered, spermatogenesis is a highly proliferative process. For every mouse SSC that commits to differentiation there is the theoretical potential to produce over 4,000 sperm from the amplifying divisions [77]. There are few, if any, molecular markers able to unequivocally distinguish SSCs from their immediate progeny, which have similar morphology and localization in the seminiferous tubules. All germ cells, beginning with $\mathrm{A}_{\text {single }}$ through primary spermatocytes are located on the basement membrane of the seminiferous epithelium. The lack of clear molecular, morphological or topographical SSC phenotypes, make a functional assay, the SSC transplant assay, the only definitive way to identify SSCs (for more detail, see section 1.4). 


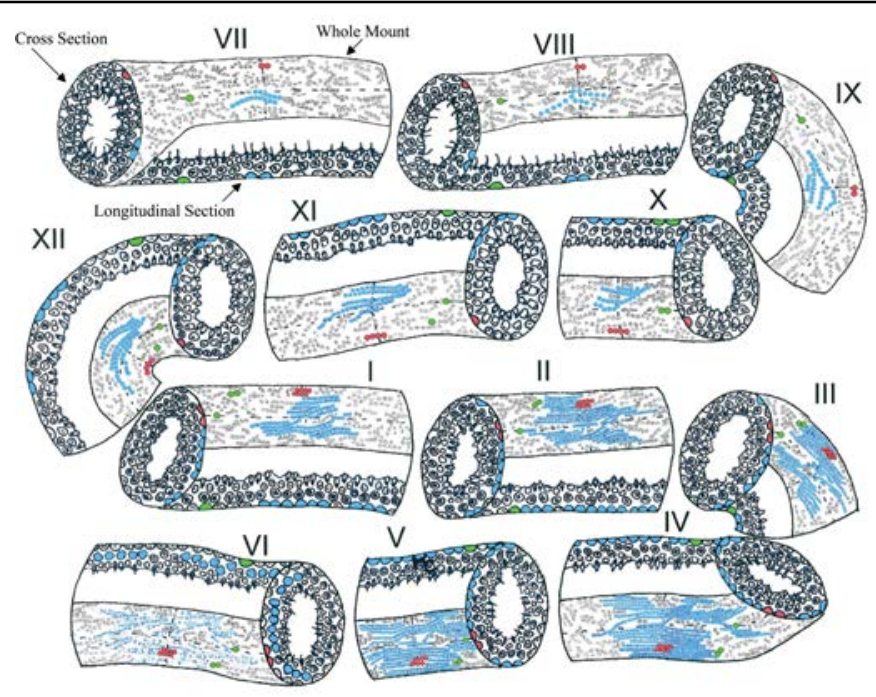

Figure 3: Mouse spermatogenic clone development by stage. The mouse spermatogenic cycle contains twelve stages (I-XII). Each stage is temporally unique, and the stages in the diagram represent the relative time each stage lasts in the mouse. Each stage in the diagram is shown in cross-sectional, longitudinal and whole-mount perspectives (labeled in stage VII). Three putative spermatogonial clones are highlighted in blue, red and green. The dotted lines in the whole-mount perspective indicate the planes of the cross section and longitudinal section views. For example, in stage VII, the red cell is in the vertical line and therefore appears in the cross-sectional view. A green cell is in the horizontal line, so is observed in the longitudinal section view. The development of three putative clones (blue, red and green) through one cycle of the seminiferous epithelium is shown. Stage VII: $\mathrm{A}_{\mathrm{al}-16}$ (blue); $\mathrm{A}_{\text {pair }}(\mathrm{red}) ; \mathrm{A}_{\text {single }}$ (green); stage VIII: A1 (clone of 16) (blue); $\mathrm{A}_{\text {pair }}$ (red); $\mathrm{A}_{\text {single }}$ (green); stage IX: A2 (clone of 32) (blue); $\mathrm{A}_{\text {pair }}$ (red); $\mathrm{A}_{\text {single }}$ (green); stage X: A2 (clone of 32) (blue); $\mathrm{A}_{\mathrm{al}-4}$ (red); $\mathrm{A}_{\text {pair }}$ (green); stage XI: A3 (clone of 64) (blue); $\mathrm{A}_{\mathrm{al}-4}(\mathrm{red}) ; \mathrm{A}_{\text {single }}$ (x2) (green); stage XII: A3 (clone of 64) (blue); $\mathrm{A}_{\mathrm{al}-4}$ (red); $\mathrm{A}_{\text {single }}(\mathrm{x} 2)$ (green); stage I: A4 (clone of 128) (blue); $\mathrm{A}_{\mathrm{al}-8}$ (red); $\mathrm{A}_{\text {single }}$ and $\mathrm{A}_{\text {pair }}$ (green); stage II: intermediate spermatogonia (clone of 256) (blue); $A_{\text {al-8 }}(r e d) ; A_{\text {single }}$ and $A_{\text {pair }}$ (green); stage III: intermediate spermatogonia (clone of 256) (blue); $A_{\text {al-8 }}$ (red); $A_{\text {single }}$ and $A_{\text {pair }}$ (green); stage IV: Type B Spermatagonia (clone of 512) (blue); $\mathrm{A}_{\mathrm{al}-8}(\mathrm{red}) ; \mathrm{A}_{\text {single }}$ and $\mathrm{A}_{\text {pair }}$ (green); stage V: Type B Spermatagonia (clone of 512) (blue); $A_{\text {al-8 }}$ (red); $A_{\text {single }}$ and $A_{\text {pair }}$ (green); stage VI: primary spermatocytes (lifting off the basement membrane) (blue); $\mathrm{A}_{\mathrm{al}-8}$ (red); $\mathrm{A}_{\text {single }}$ and $\mathrm{A}_{\text {pair }}$ (green). Republished with permission from: Phillips, B., Gassei, K., Orwig, K. Philos Trans R Soc Lond B Biol Sci, 2010. 365(1546):1663-1678. 


\section{$1.3 \quad$ REGULATION OF SPERMATOGONIAL STEM CELLS}

The spermatogonial stem cell resides in the niche, a combination of extracellular components, factors and cells. This environment provides the extracellular cues that most likely influence the balance between SSC self-renewal and differentiation in the adult testis. SSCs rest on the seminiferous tubule basement membrane and are surrounded by columnar somatic cells known as Sertoli cells (Figure 4A) [78]. Sertoli cells establish a unique environment for SSCs that is distinct from meiotic and post-meiotic germ cells due to the formation of tight intracellular junctions known as the blood testis barrier (BTB) that separates the basal from the adluminal compartment of the seminiferous tubules [79]. Sertoli cells are necessary for normal spermatogenesis, as many problems in the Sertoli cell compartment can result in an agametic testis. Disruption of the BTB, and subsequently the niche itself can result in loss of spermatogenesis as evidenced by spermatogenic defects in the absence of specific proteins in Sertoli cells, such as ERM, Claudin 11 and Androgen Receptor (AR) [80-82]. Furthermore, transplantation of functioning Sertoli cells in a mouse can recover fertility in mice with genetic Sertoli cell defects [83]. These data demonstrate the necessity of a functional niche in maintaining healthy spermatogenesis.

There are many additional components of the SSC niche, some of which are shown in Figure 4B. Peritubular myoid cells exist in the interstitial space outside the basal lamina [78]. They contribute directly to SSC function through the production of CSF1 (colony-stimulating factor 1), whose receptor is expressed on undifferentiated germ cells [84]. Another interstitial cell type, the Leydig cell, also produces CSF1, making it another cellular constituent of the SSC niche [84]. Additionally, Leydig cells may have indirect roles on SSC maintenance, as their testosterone release acts as an important signaling molecule in Sertoli cells, which, as described, 

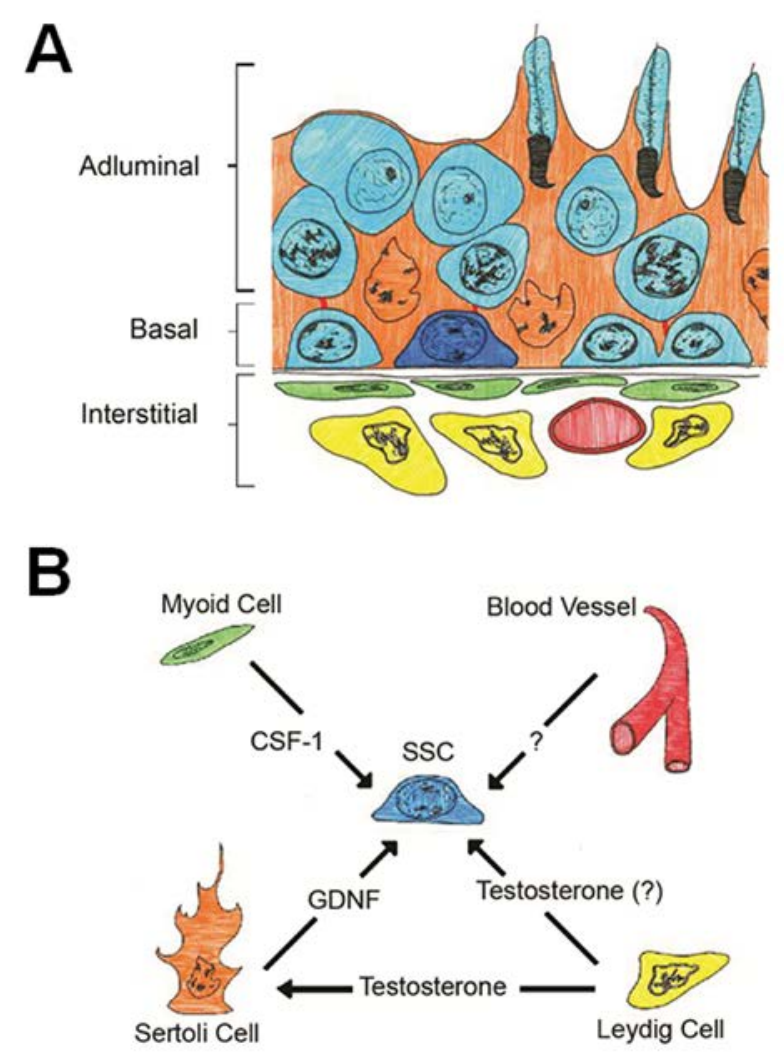

Figure 4: The SSC niche. The SSC (dark blue) is diagrammed in its physical niche (A) surrounded by Sertoli cells (orange) and differentiating germ cells (light blue) within the seminiferous tubule. Niche components outside the tubule itself include myoid cells (green), blood vessels (red) and Leydig cells (yellow). The components of the niche and the some factors known to be provided by each are shown in (B). While some factors are known to act directly on the SSC, such as GDNF, others, like testosterone are important for spermatogenesis but may not act directly on the SSC. Republished with permission from: Phillips, B., Gassei, K., Orwig, K. Philos Trans R Soc Lond B Biol Sci, 2010. 365(1546):1663-1678.

act as mediators of signals to direct germ cell differentiation [79]. Blood vessels in the interstial space are also considered an important component of the SSC niche because SSCs preferentially localize to regions of seminiferous tubule adjacent to blood vessels [85] (Figure 1.4B).

Of the paracrine signaling necessary for SSCs, the most crucial identified thus far is Glial cell line-derived neurotrophic factor (GDNF). GDNF is secreted by Sertoli cells in a process governed by follicle-stimulating hormone (FSH), a hormone produced by the anterior pituitary 
gland [86]. In vivo studies in mice show that over-expression of GDNF causes undifferentiated spermatogonia to proliferate without differentiating, causing undifferentiated germ cell masses in the seminiferous tubules [66]. Conversely, loss of GDNF expression causes germ cell depletion and a Sertoli cell only phenotype [66]. Furthermore, SSCs can be maintained in culture for prolonged periods only in the presence of GDNF [87, 88]. Collectively, these data show that GDNF is necessary for maintenance of SSCs and helping balance their fate decisions of selfrenewal and differentiation.

GDNF signals through its receptor complex: GFR $\alpha 1$ and co-receptor Ret receptor tyrosine kinase [89]. This receptor complex is found on the undifferentiated germ cells $\left(A_{s}, A_{p r}\right.$ and $A_{a l}$ ). Downstream activators of GDNF signaling include members of the Src family of kinases and the Ras/Erk1/2 signaling pathway. Phosphoinositide 3-kinase (PI3K) and AKT (also known as protein kinase B, or PKB) are constituents of a pathway activated by GDNF, as shown in cultured mouse SSCs [90-92]. Upon withdrawal of GDNF, or upon drug-mediated inhibition of PI3K, total AKT levels are unchanged, but its phosphorylation is lost. The downstream activities of this pathway in SSCs are poorly understood and illuminating such mechanisms is one of the focuses of the research herein.

\subsection{EXPERIMENTAL TOOLS FOR STUDYING SPERMATOGONIA}

Morphology has helped dissect the spermatogenic lineage based on the size and location of germ cell clones. However, as discussed, morphology is not sufficient for SSC identification (see Figure 3), nor are there markers that uniquely and completely identify this rare cell population, because of heterogeneity of gene expression in SSCs and incomplete understanding of whether 


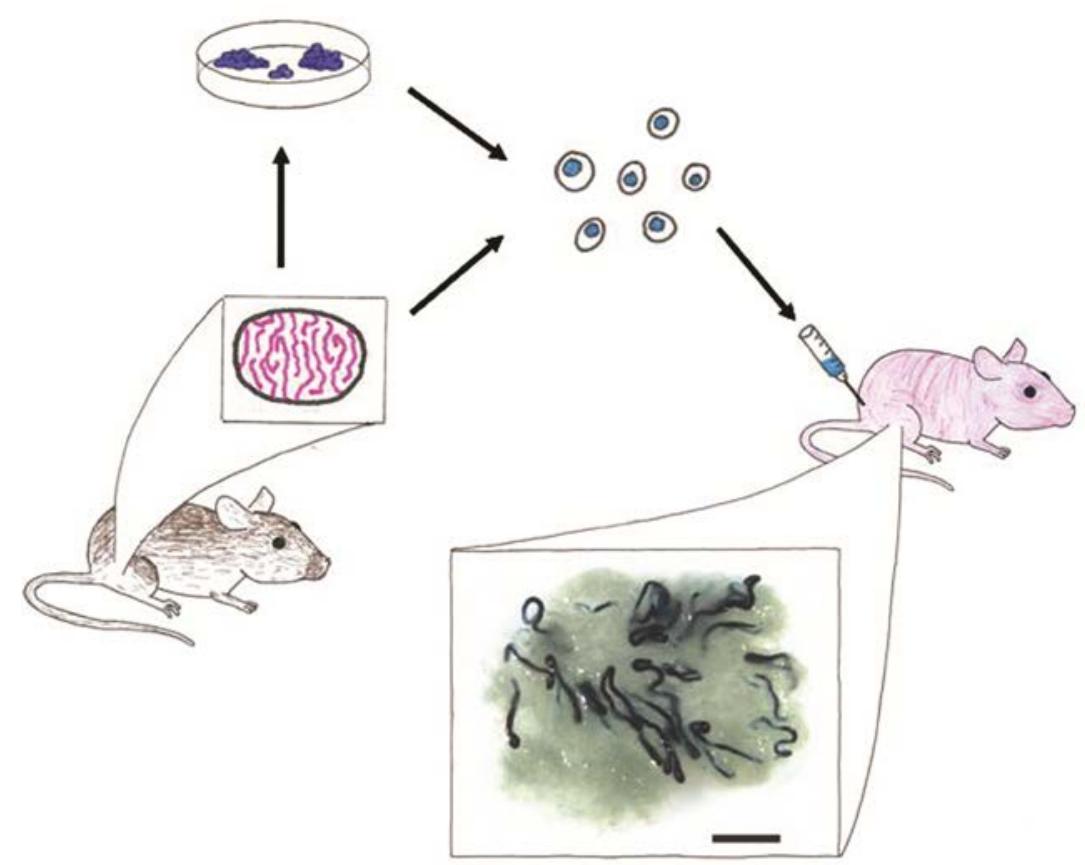

Figure 5: Spermatogonial stem cell (SSC) transplant assay. The functional analysis of SSCs is a retrospective assay of spermatogenic function. In this example, cells are isolated from a lacZ donor mouse testis and digested to produce a single cell suspension. Cells can then be maintained in culture or injected into the testes of an infertile recipient mouse. Recipient testes are typically analysed two to three months after transplantation for donor spermatogenesis (blue colonies in this example). A typical recipient testis is shown with blue colonies of donor-derived spermatogenesis (scale bar, 2 mm). Republished with permission from: Phillips, B., Gassei, K., Orwig, K. Philos Trans R Soc Lond B Biol Sci, 2010. 365(1546):1663-1678.

stem cell activity exists in some or all undifferentiated spermatogonia $\left(A_{s}, A_{p r}, A_{a l}\right)$ [69-71]. As a result, SSCs are only definitively identified by their biological potential to produce and maintain spermatogenesis in vivo using the SSC transplant assay.

First described in 1994, the SSC transplant assay functions by injecting populations of cells containing SSCs into the testes of infertile recipient animals where stem cells engraft niches on the seminiferous tubule basement membrane and establish spermatogenesis [93] (Figure 5). This is most easily performed when using transgenic transplants so that identification of donor 
spermatogenesis can be visualized (eg. GFP or lacZ). To optimize the donor testis for receiving transplanted cells, it is necessary to deplete donor spermatogenesis [94].

Multiple mouse models exist without native spermatogenesis, including genetically infertile recipients containing intact somatic compartments (including SSC niches), or chemically induced infertility. $W$ mice, for instance have a mutation that disrupts cKit signaling in germ cells. Because the receptor is mutated, it cannot respond to Kit ligand signaling from cKit (produced by Sertoli cells), which directs the germ cells to differentiate [95]. The resultant animal is devoid of spermatogenesis because of the germ cell-specific defect, but the somatic environment is normal making an ideal candidate for receiving transplanted SSCs.

Busulfan treatment is another way to deplete endogenous spermatogenesis. Busulfan is an alkylating chemotherapeutic agent with specificity for highly proliferative cells, including germ cells. Mice treated with busulfan become infertile through death of germ cells, though like the $W$ mouse, its somatic cells are competent to support spermatogenesis from transplanted cells. By depleting the testis of spermatogenesis using busulfan, niches become available to accept transplanted SSCs [93]. In any recipient transplant model, the ability of SSCs to find the niches and establish the homeostatic balance of self-renewal and differentiation to produce and maintain complete spermatogenesis demonstrates stem cell function.

Another advantage to the SSC transplant assay is that it is quantitative. When an SSC is transplanted and establishes residence in a niche, it begins clonogenic proliferation and differentiation, which is visualized as a colony of spermatogenesis (see Figure 5). Especially when transgenic SSCs are transplanted into an infertile recipient, as discussed, the colony is easily visualized as a discrete section of the seminiferous epithelium thick with multiple germ cell layers indicating complete spermatogenesis. Individual colonies arise from a single SSC 
which has found a niche and established the balance of differentiation and self-renewal leading to spermatogenesis [96, 97]. Each discrete colony can be counted, and because the efficiency of the technique is about $5 \%$, the number of SSCs can be calculated from the transplanted starting population of cells [98, 99].

A number of technical drawbacks to the SSC transplant assay make it difficult to use in addressing all SSC related questions. First of all, to test the true regenerative capabilities of transplanted SSCs, 2-3 months are required to differentiate through the spermatogenic lineage and complete waves of sperm production. Second, because it is a retrospective assay, lineage tracing and dissecting specific mechanisms of SSC function are challenging. Some of the most significant data to date about SSC phenotypes have come from coupling the SSC transplant assay with other experiments, such as those described below.

Various forms of cell sorting can be used to characterize phenotypes of SSCs. FACS (fluorescence-activated cell sorting) and MACS (magnetic-activated cell sorting) are both used to sort testis cell populations based on cell surface markers, and when coupled with the transplant assay, can define the molecular signature of SSCs [100-107]. While it should be noted that, to date, there is no known marker that is specific to SSCs, characterizing cell-surface markers does facilitate the sorting and enrichment of SSCs. This is critical because of how scarce they are in the testis. Germ cells represent about $95 \%$ of the cellular population in the testis, and SSCs represent about one in 3,000 germ cells [72]. Because of this, enrichment schemes are necessary for the facilitating many experiments with SSCs.

Some of the more efficient SSC enriching methods employ knowledge learned about the cell surface phenotype, based on FACS/MACS and transplant experiments. For instance, almost all SSCs are contained in Thy1+ populations of testis cells; though this is far from a pure 
population (only 6\% of Thy1+ cells have SSC activity) [102]. There are numerous additional options for SSC enrichment, and some of the technically easier ones are biological. SSCs can be isolated from both adult and pup testis, but pups have yet to complete waves of spermatogenesis $[87,108]$. Since the vast majority of the adult testis is composed of differentiating germ cells, by simply starting with a population devoid of these cells, there is tremendous enrichment proportionally of the SSCs. Likewise, cryptorchid mice are a biological model enriched for SSCs because of the depletion of differentiating germ cells [109]. Further techniques for enrichment depend on the physical characteristics of the cell, in methods like differential plating (where somatic cells stick to plastic plates and germ cells float and can be removed), and Percoll separation (whereby cells, including SSCs, are separated based on their density) [101, 109, 110]. Because no enrichment strategy is capable of specifically and efficiently isolating a pure population of SSCs, multiple strategies are often employed in combination to maximize the SSC enrichment of the starting population of cells to culture.

One of the most useful applications for SSC enrichment, and an experimental paradigm that necessitates it, is SSC culture. Only established in the last decade, mouse SSC culture provides a unique tool for analyzing intracellular and extracellular mechanisms of SSC regulation in a more easily manipulated paradigm than the in vivo testis. This is possible because stable primary SSC lines can be established which can be amplified and maintained through large passage number [87]. Establishing these lines though, requires the enrichment schemes facilitated by phenotyping, especially as the initial steps in SSC culture establishment have proven critical $[88,111]$. The stem cell activity of cultured SSCs has been confirmed by the transplantation assay $[87,88,108]$. Further, as discussed, because of the quantifiable nature of 
the SSC transplant assay, it is possible to test the efficiency of SSC enrichment through initial purification steps, or after passages, or after in vitro manipulations by comparative transplant.

Once enriched, the SSCs have specific conditional requirements for maintenance and expansion. Two major mechanisms exist for maintaining cells. First, they can be grown under feeder cell-free conditions in the presence of media containing serum [112]. However, serum contains unknown components that may complicate interpretation of experimental manipulations. Therefore, SSCs are commonly maintained in serum free, defined media on feeder cells [87, 88, 108, 111]. That defined media contains many components, but GDNF was identified as the critical factor required for their maintenance and expansion of SSCs in vitro [108]. This is not necessarily surprising, knowing the necessity of properly regulated GDNF signaling in vivo for mouse SSC maintenance (see Section 1.3 and [66]). Other factors, including GDNF's soluble receptor (GFR 1 1), bFGF (FGF2) and EGF have all been proposed to contribute to SSC maintenance in vitro, but GDNF remains the critical signaling factor in the long term maintenance of mouse SSCs [108, 113].

Molecular phenotpying is useful in identifying factors necessary to isolate or maintain SSCs in vitro, but can also be used to identify undifferentiated spermatogonia in the testis through antibody-mediated labeling. While SSCs themselves cannot be definitively identified via marker analysis, the lineage of the male germline can be dissected through such observation. Specifically, $A_{s}, A_{p r}$ and $A_{a l}$ spermatogonia, in which the SSCs are thought to reside, can be identified based on their distance from one another when staining whole seminiferous tubules, or whole mount staining [68]. For instance PLZF (promyelocytic leukemia zinc finger protein) is a transcriptional regulator necessary for maintenance of spermatogonia [114, 115]. It is also recognized as a marker of stem and progenitor spermatogonia, expressed uniquely by the 

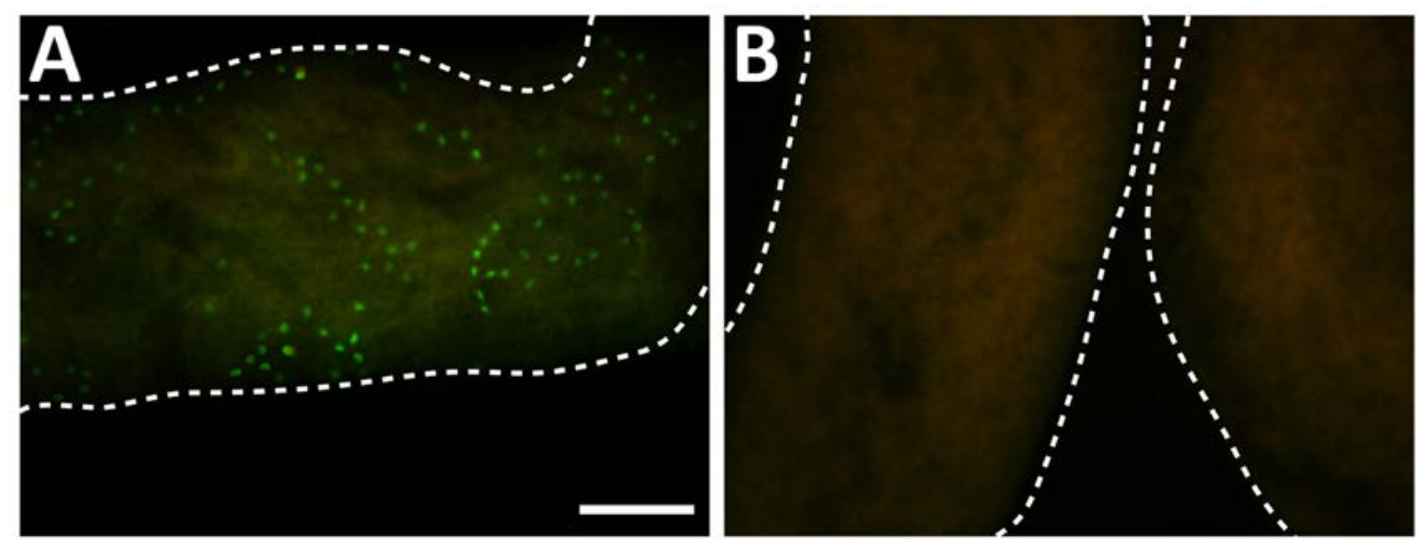

Figure 6: PLZF marks mouse undifferentiated spermatogonia. A. Whole mount immunohistochemistry of adult mouse seminiferous tubules was performed with PLZF. Positive cells (green) are observed in small chains evenly and sparsely distributed throughout the tubules. B. Isotype controlled experiment serves as negative control. Scale bar, $100 \mu \mathrm{m}$.

undifferentiated germ cells in the testis, enabling the visualization of $A_{s}, A_{p r}$ and $A_{a l}$ spermatogonia in whole mount staining of mouse seminiferous tubules (Figure 6). Since we cannot know if all undifferentiated germ cells are labeled with PLZF, we cannot determine from whole mount staining alone if SSCs express PLZF. However, natural or induced mutations of the PLZF locus in mice results in infertility that appears to result from depletion of the SSC pool [115, 116]. Therefore, PLZF is considered an excellent marker of stem and progenitor spermatogonia and will be used accordingly in these studies.

\subsection{RNA REGULATION IN THE MALE GERMLINE}

Transcription factors, such as PLZF, OCT4 and SOHLH2, which are unique to undifferentiated germ cells, have all been studied as facilitators of SSC function [115-120]. Furthermore, many 
groups have used microarray analysis to identify SSC transcripts in vivo and in SSC culture [121-124]. However, the focus of the current study is on what happens to mRNAs in SSCs after they are produced by the transcriptional machinery and before they are translated into functional proteins. During transcription, as RNAs are being produced but before they are completed, elongating mRNAs are bound by multiple proteins responsible for splicing, polyadenylating the tail (3') and capping the head (5'). The new transcript is then actively transported out of the nucleus into the cytoplasm where it can then be translated, stored or degraded [125]. Every step in each mRNA's lifespan can be regulated to alter the final protein isoform, adjust the rate of translation, and control the timing of translation. RNA binding proteins provide the mechanism for these regulatory steps. Furthermore, many RNA binding proteins serve multiple functions in RNA regulation, or at least work in concert, so that many of the steps do not necessarily function independently [126].

One of the first mRNA processing steps is to splice out non-coding intronic sequences, and splicing together protein coding exons of mRNA. One of the great surprises of the human genome project was in the finding that there are many fewer human genes than were predicted, roughly 20,000-25,000 [127, 128]. Much of the protein diversity observed from such a relatively small number of genes can be explained by alternative splicing, some data indicating that greater than $70 \%$ of human multi-exon genes are alternatively spliced [129]. Alternative splicing has distinct mechanisms, each capable of producing unique proteins from single genes. There are generally thought to be five general forms of alternative splicing including intron retention, exon skipping, mutually exclusive exons and alternative acceptor or donor sites [130, 131]. Through alternative splicing, multiple protein products can be produced from a single gene, and the "cellular splicing code," or what gets spliced specifically in each tissue, is in large part 
determined by the unique splicing machinery components present in each cellular milieu [132]. Thus, identifying specific RNA binding proteins and their targets of splicing in germ cells could help unlock mysteries specific to SSC fate decisions.

In comparative tissue studies, only the brain was found to have as many alternatively spliced transcripts as the testis $[133,134]$. So, while mRNA splicing is generally important across cell types, we know that alternative splicing plays an important and specific mechanistic role in spermatogenesis. One example is CREM (cyclic-AMP responsive element regulator), which is a protein that is a transcriptional repressor early in germ cell development until the spermatocyte stage. In later stage germline development, CREM mRNA is alternatively spliced, and this unique isoform is an active transcriptional regulator [135]. It is alternative splicing that turns one crucial spermatogenic gene, CREM, from a negative regulator of transcription to a positive one as germ cells develop to coordinate gene expression with differentiation.

Also involved in RNA processing is the testis-specific splicing regulator, RBMY1A1 (RNA binding motif protein, Y-linked, family 1, member A1), which regulates genes specific to spermatogenesis, and it is expressed solely by germ cells located on the basement membrane of seminiferous tubules, including PLZF+ spermatogonia [136-138] (Figure 7). This well conserved protein is also linked to male infertility, and it specifically associates with the mRNA of proteins necessary for spermatogenesis further establishing the role of RMBY1A1 and male germline specific splicing as critical to spermatogenic function [139-141]. Identifying other mRNA regulatory proteins, and their target mRNAs, will extend our basic biological understanding of SSCs and spermatogenesis beyond the transcriptome.

Once transcribed and spliced, mRNAs are transported out of the nucleus, although this step can also be regulated. Nuclear sequestration of transcripts is a mechanism for controlling 

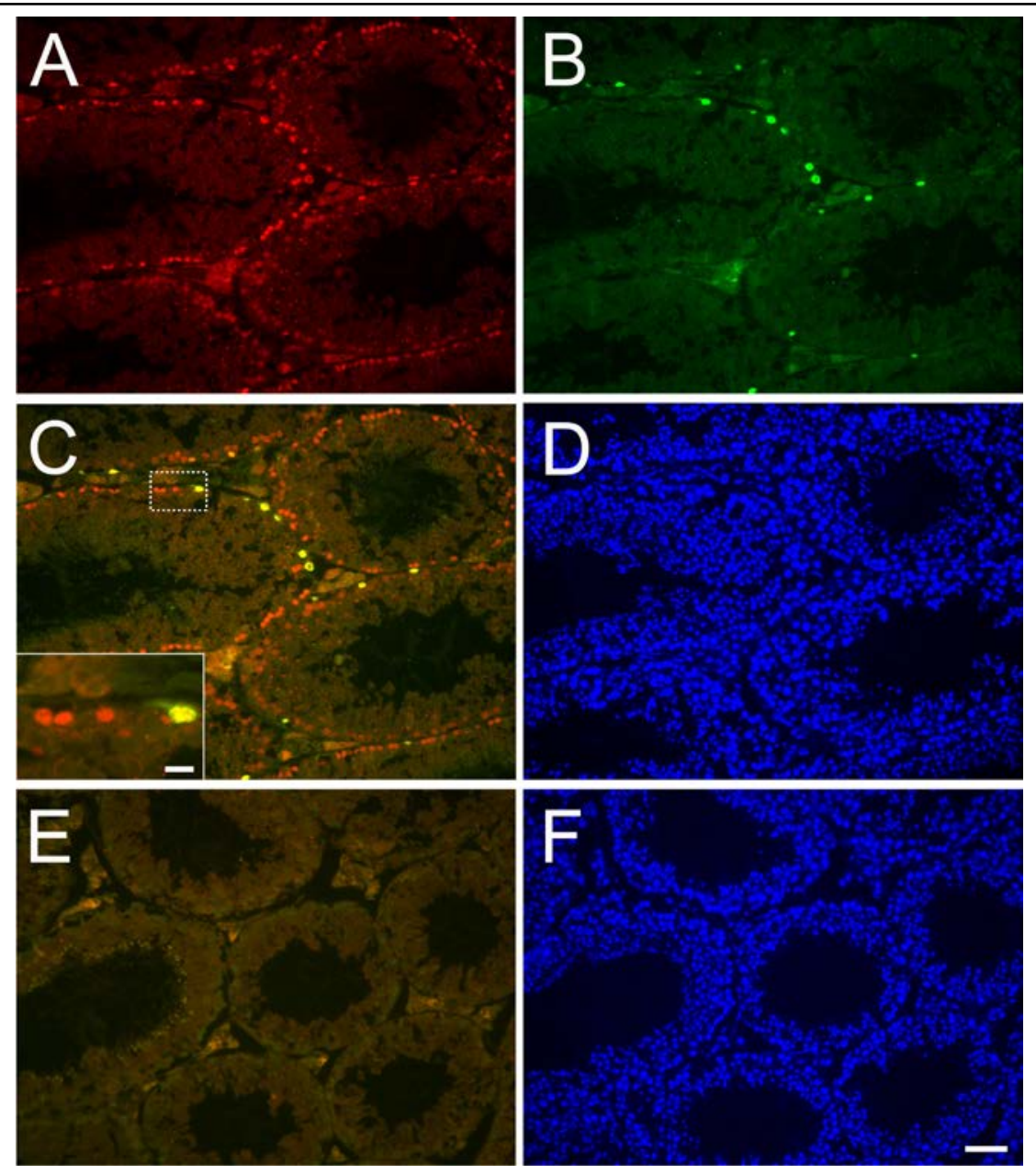

Figure 7: RBMY1A1 is expressed by undifferentiated spermatogonia. (A) RBMY1A1 immunoreactivity (red) was restricted to cells on the basement membrane of adult mouse seminiferous tubules. (B) Immunofluorescent staining for PLZF (green) is expressed by rare cells on the basement membrane of mouse seminiferous tubules. (C) Overlay of PLZF and RBMY1A1 fluorescent signals. Inset displays cells in the dashed white box. (D) 4,6-Diamidino-2-phenylindole (DAPI) staining of the section depicted in (E) Negative control section in which primary antibodies were replaced with an isotype control. (F) DAPI staining of section in (E). Scale bars $50 \mu \mathrm{m}$ (F) and $10 \mu \mathrm{m}$ ([C], inset). Republished with permission from: Orwig, K., Ryu, B., Master, S., Phillips, B., Mack, M., Avarbock, M. Chodosh, L., Brinster, R. Stem Cells, 2008. 26(4):927-938.

translation, examples of which have been discovered in the male germ cell. DAZAP1 is a protein essential for spermatogenesis, as evidenced by the infertile knockout mouse [142, 143]. It is an hnRNP (heterogeneous nuclear ribonucleoprotein), and is responsible for shuttling 
transcripts into the cytoplasm for translation, and interestingly its shuttling abilities require active transcription of new mRNAs [144]. Similarly, GRTH (gonadotropin-regulated testicular RNA helicase, also known as DDX25) null mice are infertile. This protein has two isoforms: the cytoplasmic isoform regulates efficiency of translation, while the nuclear isoform directs mRNA export for translation [145, 146]. Not only does GRTH serve as an example of regulated transport in the germline, but also provides an example of the multifunctional activities of RNA regulatory proteins.

In addition to the tremendous amount of testis-specific alternative splicing, there is also abundant post-transcriptional regulation in male germ cells that takes place in the cytoplasm. Once exported from the nucleus, male germ cell mRNAs are generally segregated into one of two places: ribosomes for active translation, or ribonucleoprotein particles (RNPs) for storage [147]. Where the mRNA is situated obviously controls its translational efficiency [148, 149]. The RNP storage controls the timing of translation and protects mRNAs from rapid degradation typical of most cell types [149]. One unique occurrence in spermatogenic cells that necessitates mRNA storage is the condensation of the chromatin in late spermatogenesis. In spermatids, transcription ceases, as does RNA processing, because histones are replaced by transition proteins and then protamines which tightly condense the DNA to fit in the sperm head [150-153]. Simultaneously, proteins necessary in spermiogenesis are still being produced through the translation of previously produced stored mRNAs. This explains why global RNA production is high in undifferentiated spermatogonia, and decreases as they differentiate from type A to type B spermatogonia and further still in spermatocytes [8]. The distinctive nature of chromatin condensation during spermatogenesis compels germ cells to temporally separate transcription 
and translation, and it is through unique RNA binding proteins that this process of mRNA storage and regulation of translation timing occurs.

Translational control mechanisms, like splicing, require unique male germ cell mechanisms of action. Conserved small RNAs, families of proteins, and subcellular structures are involved in controlling the timing and efficiency of translation. Whether mechanisms other than mRNA storage through germline development necessitating translational regulation exist is not known, but whatever the cause, the extent of post-transcriptional regulation is high in male germ cells; nearly $70 \%$ of testis mRNAs are found in non-translated ribonucleoprotein particles (RNPs) [150].

The mechanisms of translational regulation in the male germline are in part conserved because the families of proteins which regulate RNA in germ cells are evolutionarily conserved. Two such protein families, the DAZ and VASA families of proteins, include some of the most commonly used markers of germ cells, since they are expressed exclusively in germ cells. In Drosophila, Xenopus and Mus musculus, loss of members of the DAZ family can cause a loss of male germ cells resulting in infertility [154-156]. DAZ member proteins are stimulators of translation. The target mRNAs of DAZ family member DAZL, include MVH (mouse VASA homologue), another gene critical for spermatogenesis [2-4, 157].

Like the DAZ family, VASA and its homologues are well conserved proteins expressed in the germ cells of numerous evolutionarily diverged species [158-161]. Mouse Vasa homolog (MVH) is necessary for the male germline; the MVH null mouse exhibits male specific infertility [162]. The defect is in the germline, and not the niche for instance, because it is expressed specifically in the cytoplasm of germ cells, where it interacts with other RNA binding proteins to regulate translation, though its RNA regulatory targets have not been globally identified [7, 163]. 
In addition to conserved families of proteins, numerous individual proteins have been identified that are involved in driving germ cell translational efficiency, some of which are necessary for normal spermatogenesis. SAM68, GRTH and MILI, for instance promote translation of germ cell mRNA, while MSY2, MVH and NANOS2 act as inhibitors [6, 142, 145, 146, 164-167]. As a result, the balance of proteins promoting and inhibiting translation is crucial to germ cell function. The balance is maintained by developmental timing of action of these regulatory proteins as well as by what specific mRNA species they bind.

One of the unique characteristics of male germ cells, in addition to a unique protein profile, which coordinate this complex network of RNA regulation is the chromatoid body. Similar to the processing body (P body) of somatic cells, the chromatoid body is an electron dense cloud-like structure described as a central mRNA regulatory center [6]. It is also thought to help contribute to the coordinated homogeneity of germ cell clones (seen in chains) because of its ability to move across intracytoplasmic bridges [74]. While the specifics of how the chromatoid body works are still under investigation, it is considered important for regulating translation in germ cells because of its constituents: mRNA, transcript-storing proteins $\mathrm{MVH}$ and MIWI and miRNA machinery [5, 6].

Another germ cell-conserved RNA-mediated regulation is that of silencing transposable elements through a class of small germline specific RNAs known as PIWI-interacting RNAs (piRNAs) [168]. This is an especially important mechanism in the germline, because transposable element insertions can be deleterious, and their regulation is necessary for maintaining the integrity of heritable information [169]. MILI, a translational promotion factor is in the PIWI protein family of proteins, which interact with piRNAs. These proteins as well as piRNAS, which are small non-protein coding RNAs distinct from miRNAs, are expressed 
specifically in the male germ line [170]. The PIWI protein family is extremely well conserved from plants to humans and in the male germline, two of the proteins from this family, MIWI and PIWIL2, are necessary for mouse spermatogenesis [163, 171-173]. Furthermore, the PIWI proteins are thought to control expression of genes necessary for spermatogenesis, as exhibited by PIWIL2 in mouse, which modulates expression of spermatogonial genes including Thy-1 and Stra8 [174].

Collectively, these data build a narrative of spermatogenesis with deep layers of RNA regulation. Conserved proteins and protein families as well as sub-cellular structures work to control the expression of genes through highly active mechanisms such as RNA splicing, storage, degradation and translational control. These mechanisms and activities are often necessary for spermatogenesis, and the explanation of how these activities regulate SSCs and spermatogenesis in general requires further investigation. We hypothesized that a way to undertake this investigation would be to identify RNA binding proteins that correlated with SSC activity, which would subsequently identify RNA regulatory mechanisms that are unique to SSCs. These mechanistic insights progress the fields of SSC biology and RNA regulation with understanding that may elucidate idiopathic male infertility.

\subsection{IDENTIFYING SPERMATOGONIAL GENES}

The testis is a heterogeneous collection of cells, including SSCs and all of their differentiating germ lineage as well as the various types of somatic cells supporting spermatogenesis through function and structure (see Figure 4A). Because the SSC represents such a small portion of the 
total testis population, about 1 in 3,000 cells in the adult mouse [72], and because the SSC is not distinguishable by any physical or molecular phenotype, identifying genes expressed by SSCs in vivo requires thoughtful experimental design.

To get a global landscape of gene expression in stem cells, many studies have used microarray analysis. Two studies in particular compared stem cells (hematopoietic, neural and embryonic) to identify unique stem cell characteristics $[175,176]$. While debatable in their goal of finding unique genes defining "stemness," these studies helped show the usefulness of microarray experiments in identifying intrinsic regulation of adult tissue stem cells.

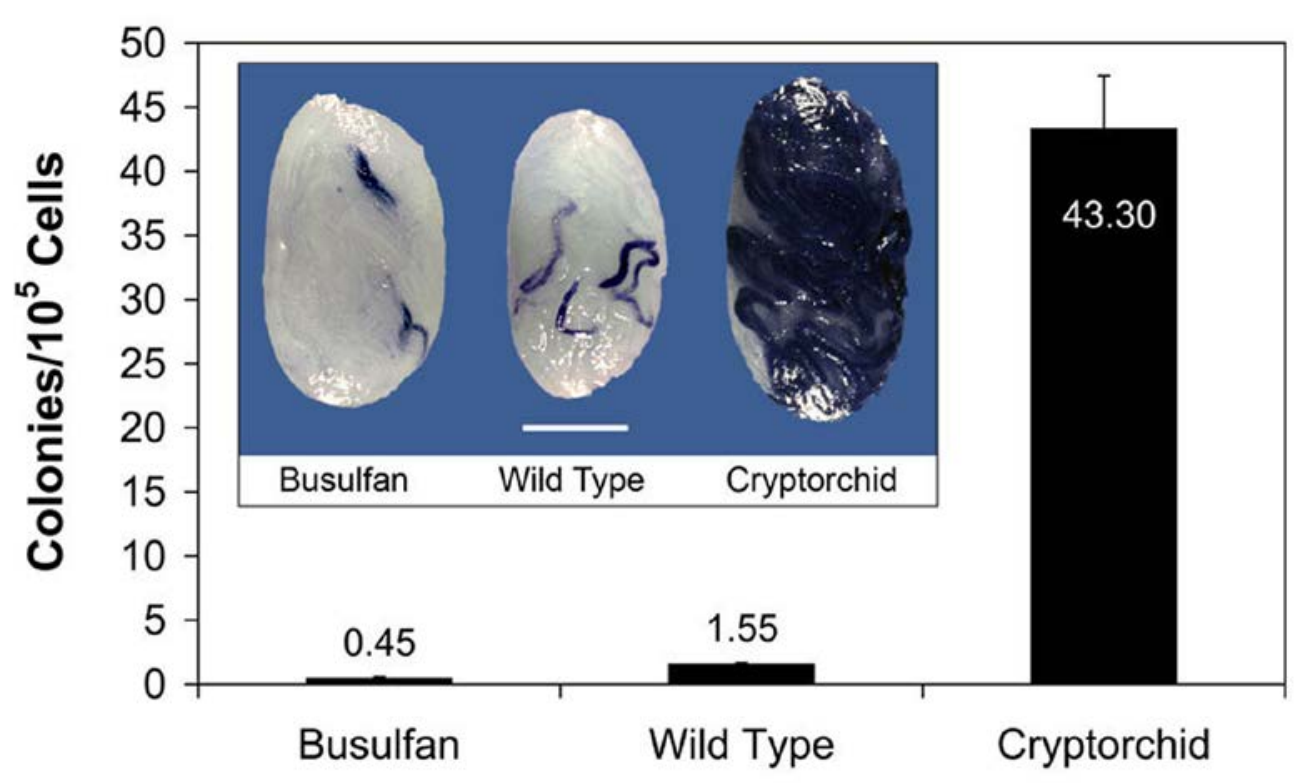

Figure 8: In vivo testis models have variable SSC activity. Mouse testes were transplanted with whole cell suspensions from transgenic (lacZ) donor testis. Insets show colonizing activity of donor cells (stained blue) from busulfan-treated, wild-type and cryptorchid mice. The SSC transplant assay is quantifiable and the SSC activity of each is as follows: Busulfan $\left(0.45 \pm 0.13\right.$ colonies per $10^{5}$ cells transplanted), Wild Type $(1.55 \pm 0.13$ colonies per $10^{5}$ cells transplanted) and Cryptorchid (43.30 \pm 4.17 colonies per $10^{5}$ cells transplanted). Republished with permission from: Orwig, K., Ryu, B., Master, S., Phillips, B., Mack, M., Avarbock, M. Chodosh, L., Brinster, R. Stem Cells, 2008. 26(4):927-938. 
Microarrays have also been used to compare gene expression in mouse spermatogonia to other tissues to identify spermatogenesis related genes [121], compare developmentally timed testis samples [122], conduct germline development analysis [123], and analyze the effects of growth factor conditions on gene expression in SSC cultures [124]. These studies have all proven useful in the identification of genes important to spermatogenesis and/or SSC biology. We compared gene expression in three in vivo testis models containing different concentrations of SSCs.

The three models we used were wild type testis, cryptorchid testis, and the testis of busulfan-treated mice. The wild type mouse testis, as described, has the full complement of spermatogenesis containing all germ cell types from SSC to sperm along with the total somatic compartment. Cryptorchid testes are surgically fixed in the abdomen of the mouse. Exposure to the high core body temperature (the scrotum is $2-4^{\circ} \mathrm{C}$ cooler than the abdomen) causes the death of differenting germ cells, but the SSCs remain [177]. By virtue of having lost most germ cells (the majority percentage of cells in the testis), cryptorchid mouse testes are enriched for SSCs. Busulfan, on the other hand, is a chemotherapeutic agent which kills rapidly dividing cells and can abolish all germ cells including SSCs from a mouse testis with a non-lethal dose [178]. The busulfan-treated mouse testis then has little to no germ cells, but the somatic environment is fairly unaltered.

To prove that the SSC activity of these three testis models was in fact different, recipient mice were transplanted with whole testis cell suspensions from each model and tested for SSC activity as measured by the number of spermatogenic colonies formed (Figure 8). Busulfantreated testis produced about a third of the number of colonies in the SSC transplantation assay as an equal number of transplanted wild type testis. Conversely, cells transplanted from a 


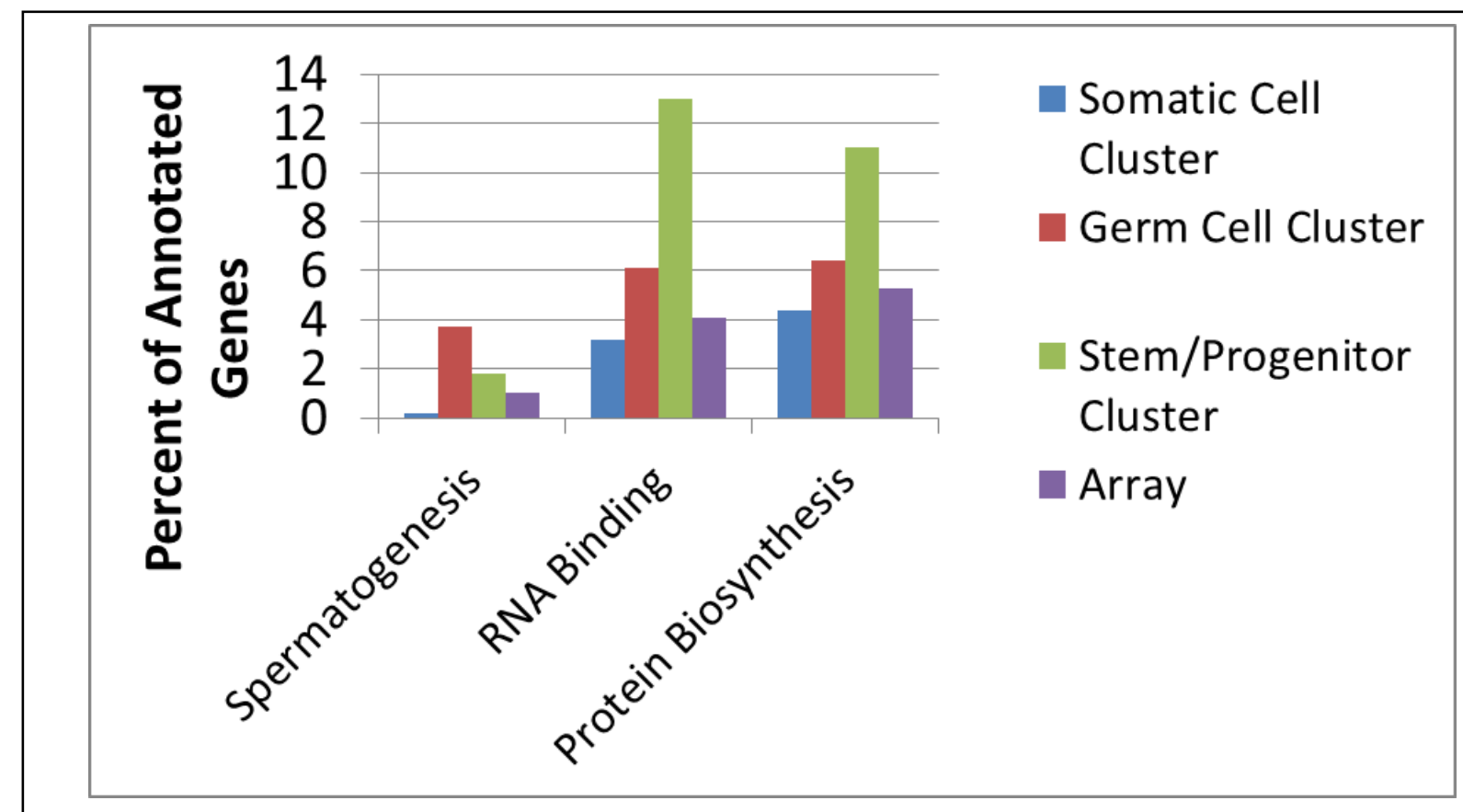

Figure 9: Functional annotation of gene list from microarray. Somatic Cell Cluster (blue), Germ Cell Cluster (red) and Stem/Progenitor Cluster (green) contain genes which were annotated on the basis of functional categories in Gene Ontology and compared with the distribution of genes on the U74Av2 array (purple). Results for genes categorized by function into Spermatogenesis, RNA Binding and Protein Biosynthesis are shown. The percentage of genes in each cluster that fall in the functional categories is indicated by the y-axis.

cryptorchid testis produced nearly 28 times more colonies of spermatogenesis than wild type (Figure 8). These data confirm that compared to wild type testis, the busulfan-treated mouse testis is depleted of SSCs and the cryptorchid mouse testis is enriched for SSCs [67].

To identify genes that correlate with SSC activity, and as a result are presumably expressed uniquely by SSCs, Affymetrix MGU74Av2 arrays were used to analyze global transcription profiles of wild type, cryptorchid and busulfan-treated mouse testis. The comparison of the profiles allowed us to cluster genes according to cells present in each model. For instance, somatic cells are greatly enriched in the busulfan-treated and cryptorchid testis over the wild type because they are each depleted of all or nearly all germ cells respectively. As a result a gene expressed lower in the wild type than the other two groups would fit a somatic cell 
expressed profile. Inversely, a gene with higher expression in wild type than in the cryptorchid and buslfan-treated groups would correspond to differentiating germ cells, which are absent in both cryptorchid and busulfan-treated testes. Predictably, this "germ cell" cluster is enriched for genes involved in spermatogenesis (Figure 9) and these data helped validate the microarray study design.

The somatic cells are relatively unchanged in comparing busulfan-treated and cryptorchid testis, and both lack the multiple layers of spermatogenesis making them collectively very similar in that regard. The most significant difference is the presence of SSCs in the cryptorchid mouse, as shown by the transplant assay, in comparison to the SSC-depleted busulfan-treated mouse testis. 389 genes were identifies whose expression was greater in the cryptorchid than the busulfan-treated mouse testis (Stem/Progenitor cluster) (Figure 9); in other words, expression of 389 genes correlated with SSC activity. This gene list was the foundation for the thesis research described herein. 


\subsection{CHARACTERIZING RNA BINDING PROTEINS IN THE MOUSE TESTIS}

\subsection{INTRODUCTION}

Understanding the basic mechanisms of spermatogenesis can provide clinical options to the $15 \%$ of infertile couples worldwide in addition to producing potential male contraceptives [54]. While myriad genetic and environmental pathologies can contribute to a decrease or loss of male fertility, maintenance of spermatogenic potential is fundamental. Spermatogonial stem cells (SSCs) are the basis of mammalian spermatogenesis and provide an obvious clinical option for fertility restoration [59]. SSCs balance self-renewal (maintaining the stem cell pool) with differentiation (ultimately producing spermatozoa). An imbalance of self-renewal/differentiation can result in azoospermia, yet the genetic regulators of these processes are poorly understood. Thus, understanding the factors that govern SSC fate decisions will elucidate the biology of spermatogenesis and instruct clinical assessment and treatment of male infertility.

Our previous microarray analyses identified 389 genes that were correlated with SSC functional activity in busulfan-treated, wild type and cryptorchid mouse testes. Functional annotation of the 389 candidate genes revealed that genes encoding proteins involved in RNA regulation and protein biosynthesis were over-represented. Based on our knowledge of RNA regulation in the male germline, it was no surprise that genes involved in post-transcriptional regulation were enriched about 2-3-fold over the total percentage of such genes on the array itself. This includes a marked increase in their expression over other clusters (germ and somatic) 
as well (Figure 9). These data have provided us with a list of 27 candidate RNA binding proteins with which to dissect the post-transcriptional regulation landscape of mouse spermatogonia. Based on function and availability of antibodies, we focused on the 14 candidates listed in Tables 1 and 2. We hypothesized that the analysis of RNA binding proteins of the testis would lead to the identification of specific proteins and pathways regulating the self-renewal and differentiation of mouse SSCs. In this chapter, we validated the testis expression and localization of 14 candidate genes that encode RNA binding proteins by RT-PCR and immunohistochemistry of wild-type, busulfan-treated and cryptorchid mouse testes.

\subsection{MATERIALS AND METHODS}

\section{Testis Models}

Testes were collected from wild-type, busulfan treated and cryptorchid adult C57BL/6 mice between 3 and 4 months of age. Busulfan (50 mg/kg, i.p., (Sigma-Aldrich, St. Louis, MO, http://www.sigmaaldrich.com) was injected into six week old animals and testes were collected 5-6 weeks after busulfan treatment. Cryptorchid mice were produced by fixing the testes surgically in the upper abdomen when animals were 8 weeks old and testes were collected 8 weeks later. Testes and all other organs indicated in Figure 2.4 were collected at 4 months of age.

$R T-P C R$

The RNA from all organs, including busulfan-treated, cryptorchid and wild type testes, 


\begin{tabular}{|c|c|c|c|}
\hline GENE & Forward Primer & Reverse Primer & Cycle \# \\
\hline$\beta$-Actin & CTCTAGGCACCAAGGTGTGATG & CACGATTTCCCTCTCAGCTGTG & 30 \\
\hline Dazl & CTCAACAGTCCAATCAGTGGG & GGTACAAAGGTTCTCTGCTGTC & 30 \\
\hline $\mathrm{Ddx} 4$ & GGCAAGAGAAAAGCTGCAGTCTTC & GAAGACTGCAGCTTTTCTCTTGCC & 30 \\
\hline Ewsr1 & CAGCCTAGGATATGGACAG & CAGAGTCTTCATCGGGATC & 30 \\
\hline Fbl & GTAGAGGAGGTGGAAGAG & GCCACATCGGCAAAGATG & 32 \\
\hline Gfral & CCAAAGGGAACAACTGCC & CAGCGAGACCATCCTTTC & 36 \\
\hline Hnrpa2b1 & GAGGAACACCACCTTAGAG & CTACССССАААGTТTССАС & 30 \\
\hline Lsm4 & GCAGAATCACCCCATGCTG & GTGGGGCTTCACACAAAGG & 32 \\
\hline Lsm8 & CGTCTGCTTTGGAGAACTAC & CССТАAACATCACTCTCAGG & 32 \\
\hline $\mathrm{Ncl}$ & GGAGGAAGATGACTCTGAGG & CTCCAAGTGCTGGTCTTTCC & 30 \\
\hline Ngn3 & CGTGCAGTGACCTCTAAG & CCAGACAGGTCTCTTCAC & 36 \\
\hline Pabpc1 & GGTCTGCAGGGACATGATCAC & GACGCTCATCATCAATCCCG & 30 \\
\hline$\overline{\mathrm{Plzf}}$ & GAAGAGGACCGTAAGGCTC & CAGTTTCCTGTGCTGCTCC & 36 \\
\hline Rbmy & GATTTGGACCAGTAGCACGTG & GATACTCATCTCTTCTGGAAG & 30 \\
\hline Refbp1 & GCCGTACAGCAGACCGAAACAAC & GCGTCCAACTCCTCTGCAGAAAG & 30 \\
\hline Sfrs6 & GCCTGCACGAACTGAGGTTTTG & CGAAAAGCAGACTCGAAATGCGCC & 32 \\
\hline Sfrs10 & CCGAAGATCCAAGTCCAAGTC & CCTTATTAAGTCAGGAGGCCAC & 30 \\
\hline Ybx1 & GGGACAAGAAGGTCATCGCAAC & GTCTCACTGGTCTACCTTGCTC & 30 \\
\hline
\end{tabular}

Table 1: Forward and reverse primers for RNA binding protein encoding genes. Cycle denotes the number of cycles for PCR.

was extracted using Trizol (Invitrogen, Camarillo, CA, http://www.invitrogen.com). We used 0.1-1.0 ug of RNA in reverse transcription with oligo-dT primers to produce cDNA. We used Taq (Invitrogen 10342-020) in PCR for the target genes gene. For each gene we used specific primers and an empirically deduced number of cycles, both of which are found in Table 1. 


\section{Immunohistochemistry}

Paraffin embedded $5 \mu \mathrm{M}$ sections of $\mathrm{C} 57 \mathrm{Bl} / 6$ mouse adult testes were used for immunohistochemistry (IHC). Briefly, slides were treated with two 15 minute xylene washes, rehydrated through a graded ethanol series (100\%, 100\%, 95\%, 80\%, 70\%, 50\%, 25\%, PBS) and incubated at $95^{\circ} \mathrm{C}$ for 20 minutes in sodium citrate buffer for antigen retrieval. We blocked with buffer containing serum for 30 minutes at room temperature. Slides were washed ( $3 \times 5$ minutes with PBS with $1 \%$ Tween20) and incubated with primary antibody at $20^{\circ} \mathrm{C}$ for 90 minutes. Slides were washed (3x5 minutes) and incubated with secondary antibody for 60 minutes. Slides were then washed and mounted with VectaShield mounting medium containing 4,6-diamidino-2phenylindole (DAPI, Vector Laboratories, Burlingame, CA, http://www.vectorlabs.com). Primary antibodies and dilutions were used as follows: Dazl, 1:150 (Abcam, Cambridge, MA, http://www.abcam.com, ab17224), Ddx4, 1:300 (Abcam, ab13840), Ewsr1, 1:800 (Abcam, ab36796), Fbl, 1:800 (Abcam, ab5821), Hnrpa2b1, 1:200 (Abcam ab31645), Lsm4, 1:800 (Abcam, ab19101), Lsm8, 1:500 (Abcam, ab53220), Ncl, 1:800 (Abcam, ab16940), Pabpc1, 1:800 (Abcam, ab21060), PLZF, 1:500 (R\&D Systems, Minneapolis, MN, http://www.rndsystems.com, Af2944), Rbmy1a1, 1:200 (gift from Dr. David Elliott, University of Newcastle upon Tyne, Newcastle upon Tyne, U.K.), Refbp1, 1:800 (Abcam, ab6141), Sfrs6, 1:500 (Abcam, ab28428), Sfrs10, 1:200 (Abcam, ab50513), Ybx1, 1:1600 (Abcam, ab12148). For secondary antibodies we used donkey anti-goat alexa-flour 568 (Invitrogen, A-11057), donkey anti-rabbit alexa-flour 488 (Invitrogen, A-21206), donkey anti-mouse alexa-flour 488 (Invitrogen, A-21202), donkey anti goat alexa-flour 488 (Invitrogen, A-11055). All secondary antibodies were used at a 1:200 dilution. 


\subsection{RESULTS AND DISCUSSION}

\subsubsection{Testis RNA Binding Proteins}

Our microarray functional annotation analyses identified 27 genes encoding RNA binding proteins with expression patterns that correlated with SSC activity in busulfan treated, wild type and cryptorchid testis. We chose to focus on fourteen of the RNA binding protein encoding genes identified in the microarray, which are listed in Table 2. The genes vary in RNA regulatory function, and some serve multiple functions, probably due to the pleiotropic activities of RNA binding proteins and their regulatory centers $[126,179,180]$. The most common functions of these 14 genes are splicing and translational control. Included on the list are two known pan-germ cell markers DAZL and DDX4 (VASA), RNA binding proteins expressed exclusively by germ cells including SSCs, which are necessary for spermatogenesis [156, 158, 162, 181]. These established germ cell markers serve as internal controls and help to validate the microarray experimental design. Also of note is that the RNA binding proteins we identified vary in function, offering distinct regulatory steps, including export, splicing and translational control of mRNA among others.

\subsubsection{Characterization of the 14 RNA Binding Proteins of Interest}

To begin analyzing the genes of interest, we performed RT-PCR for each gene in the three testis models (cryptorchid, wild type and busulfan-treated testis) from the microarray study. This was the initial step in validating the microarray study and surveying the RNA binding protein landscape of the testis in greater detail. All 14 genes were expressed in the wild type and 


\begin{tabular}{|l|l|l|}
\hline Gene & \multicolumn{1}{|c|}{ Function } & \multicolumn{1}{c|}{ References } \\
\hline Dazl & Translational control & {$[1-4]$} \\
\hline Ddx4 & Translational control & {$[5-8]$} \\
\hline Ewsr1 & Splicing & {$[9-11]$} \\
\hline Fbl & rRNA/snoRNA processing & {$[12-14]$} \\
\hline Hnrpa2b1 & Splicing, Translational Control & {$[9,15-17]$} \\
\hline Lsm4 & Splicing & {$[18,19]$} \\
\hline Lsm8 & Splicing & {$[18]$} \\
\hline Ncl & Translational control & {$[20]$} \\
\hline Pabpc1 & Translational control & {$[2,21-25]$} \\
\hline Rbmy1a1 & Splicing & {$[26-28]$} \\
\hline Refbp1 & Export & {$[29,30]$} \\
\hline Sfrs6 & Splicing & {$[31,32]$} \\
\hline Sfrs10 & Splicing & {$[33-35]$} \\
\hline Ybx1 & Trans control, splicing, transp & {$[11,24,36-53]$} \\
\hline
\end{tabular}

Table 2: RNA Binding Proteins Identified in Differential Testis Microarray

cryptorchid testis cells, which validated that the genes are expressed in testes containing SSCs (Figure 10). Ten of the genes (Ewsr1, Fbl, Hnrpa2b1, Lsm4, Lsm8, Ncl, Pabpc1, Refbp1, Sfrs6, Sfrs10) were additionally expressed by the busulfan-treated mouse testis, which is nearly depleted of germ cells. The four remaining genes (Dazl, Ddx4, Rbmy1a1, Ybx1) were exclusively expressed in wild-type and cryptorchid testes, suggesting expression in germ. As expected, Dazl and Ddx4, previously found specifically in germ cells were in this group [7, 182]. Rbmy1a1 has also been initially characterized in the testis and was also unsurprisingly found to have a germ cell-specific expression pattern [26, 27, 67, 138]. The final gene, Ybx1, has no known testis function, but shared the expression pattern of germ cell-specific genes because its expression is not detected via RT-PCR of the busulfan-treated testis. Therefore, Ybx1 was the primary focus of our studies. 


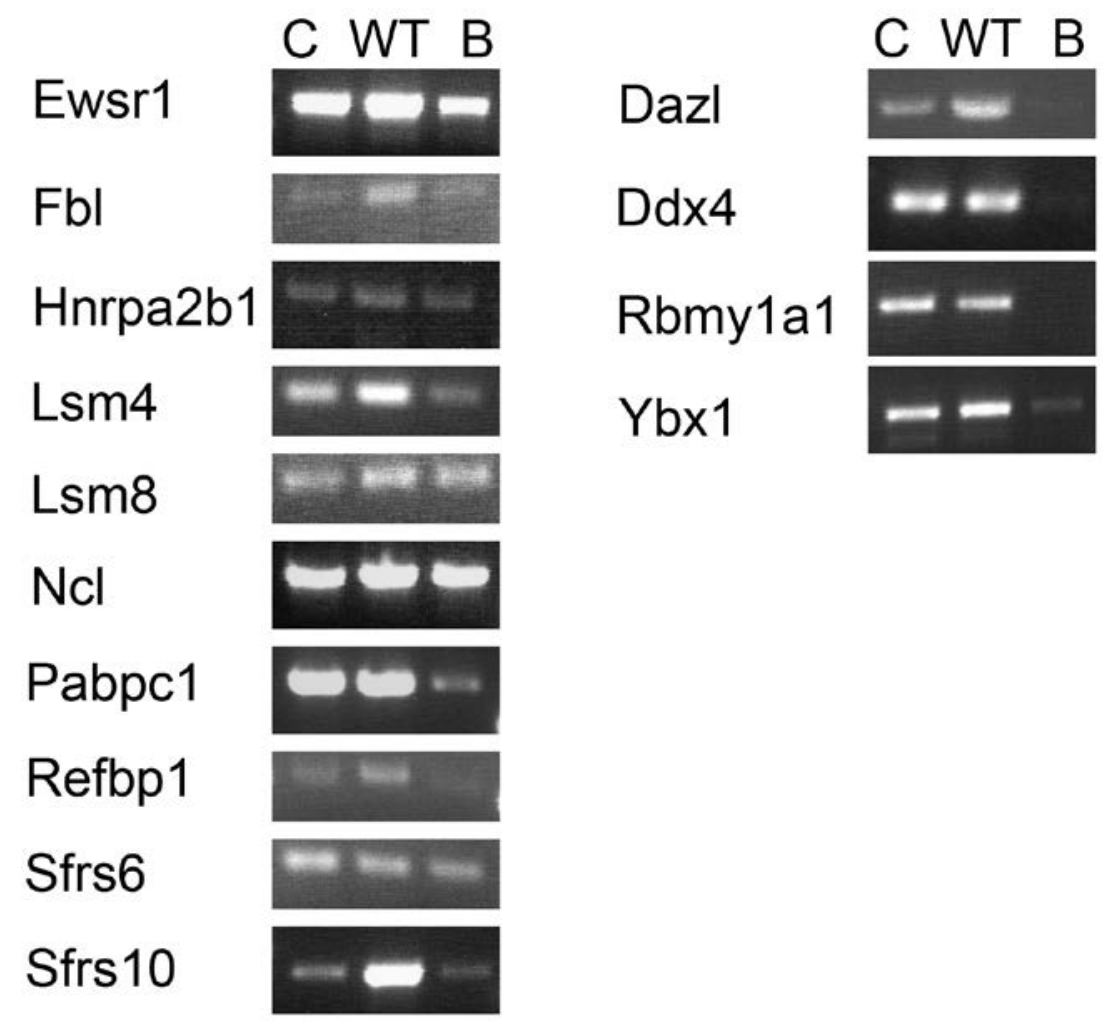

Figure 10: RNA binding protein expression in testis models. RT-PCR was performed on cDNA produced from three distinct mouse testis cell models: crytporchid (C), wild type (W) and busulfantreated mice (B). Of the 14 genes tested, all were present in the cryptorchid and wild type mouse testis. Four of the genes (on the right) were not detected in the busulfan-treated mouse testis, which is germ cell depleted. Three replicates of these data were generated, and those shown are representative.

A primary aim of the RNA binding process screen was to identify genes important for germ cell function, specifically undifferentiated germ cells. 10 of the 14 genes screen using RTPCR were expressed in testes lacking germ cells (busulfan-treated testis), indicating that other cells in the testis (i.e., somatic cells) express these 10 genes. Based on the RT-PCR analyses, we cannot exclude the possibility that these ten genes are also expressed by germ cells. It is fallacious to conclude that these genes are not intrinsically essential for germ cell, including SSC, activity though simply because they are more widespread in testis expression. However, 
the broad expression pattern would have to be considered in the interpretation of results from downstream studies.

RT-PCR of whole testes does not establish whether candidate genes are expressed by undifferentiated germ cells. Therefore, we performed immunohistochemistry (IHC) for all 14 candidate RNA binding proteins in wild type adult mouse testis sections. Additionally, we costained with consensus stem and progenitor spermatogonia marker PLZF to determine the expression of the target genes in undifferentiated spermatogonia.

The cellular expression patterns in the testis of the 14 genes fell into three categories based on IHC. Ten genes were expressed broadly by most or all germ cells (Class I, Figure 11). This group included germ cell-specific proteins (DAZL, DDX4, SFRS6, NCL, PABPC1, LSM8, SFRS10, REFPB1), as well as proteins that were observed in germ and somatic cells, such as those located in the interstitium (FBL and LSM4). These ten genes were all expressed by stem and/or progenitor spermatogonia, as indicated by their co-expression with PLZF (see Figure 11 Class I insets). Class II genes, Hnrpa2b1 and Ewsr1, were expressed by germ cells but expression in undifferentiated spermatogonia could not be confirmed by PLZF co-staining. We can conclude this because PLZF+ cells (marking undifferentiated germ cells) are HNRPA2B1 and EWSR1 negative (see Class II insets Figure 11). As a result, we conclude that HNRPA2B1 and EWSR1 may have an important function in spermatogenesis, but are not expressed by SSCs and thus are not intrinsically necessary for SSC function.

Two genes, identified here as Class III, had expression patterns restricted to germ cells located on the basement membrane of seminiferous tubules, including PLZF+ spermatogonia. The first was previously described RBMY1A1 [26, 27, 67, 138]. RBMY1A1 is a well conserved RNA binding protein expressed specifically by spermatogonia in the male germline (Figure 11) 


\section{Class I}
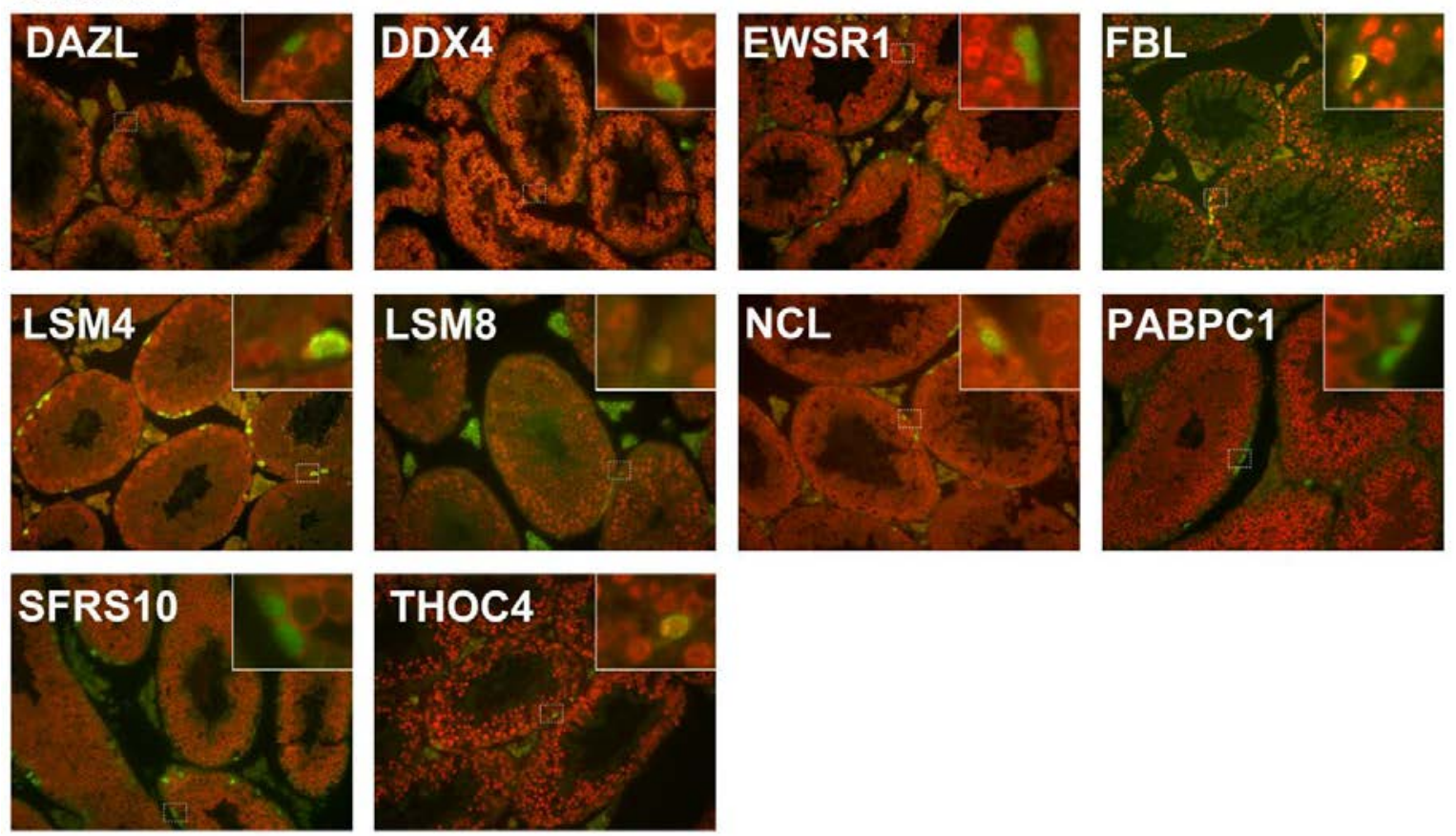

\section{Class II}
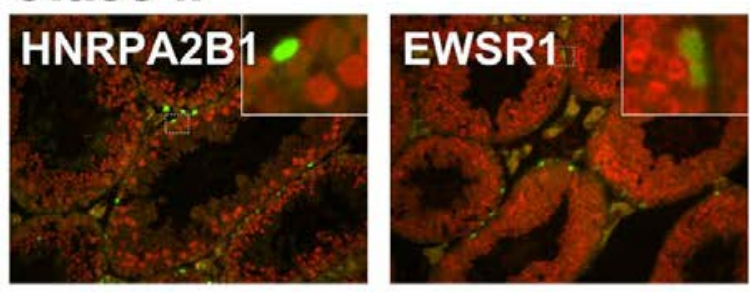

\section{Class III}
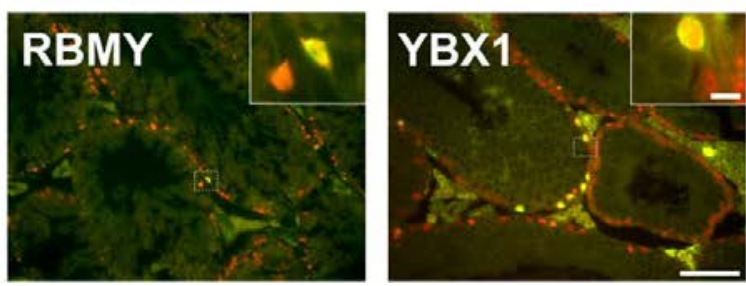

Figure 11: RNA binding protein expression in the testis. Immunohistochemistry was performed on the candidate 14 RNA binding proteins (labeled in red). Co-staining was performed with PLZF (green) to determine the overlap with stem/progenitor spermatogonia. Expression patterns are divided into three general classes. Class I genes are broadly expressed in most or all male germ cells. Class II genes have broad expression in germ cells, excluding PLZF+ spermatogonia. Class III genes are restricted in expression to undifferentiated germ cells, including PLZF+ cells. Scale bars equal $100 \mu \mathrm{m}$ and $10 \mu \mathrm{m}$ in figure insets. Three replicates of these data were generated, and those shown are representative.

[138, 183-185]. It further is an attractive candidate for clinical study of male infertility, because mutations in its genomic locus are associated with oliogospermgia and sperm abnormalities [137, 
139]. Known for its role in mRNA splicing, studies in both mouse and human have identified RBMY1A1 target transcripts, many of which are alternatively spliced and some of which are testis specific, such as Tex14 [140, 141]. These data imply a splicing role for RBMY1A1 in spermatogonia, and again, validate the study design.

Unlike RBMY1A1, YBX1, the other Class III gene identified via IHC, has hardly been examined in germ cells. Its expression in the testis is restricted to those cells located on the basement membrane of seminiferous tubules including PLZF+ spermatogonia (Figure 11).

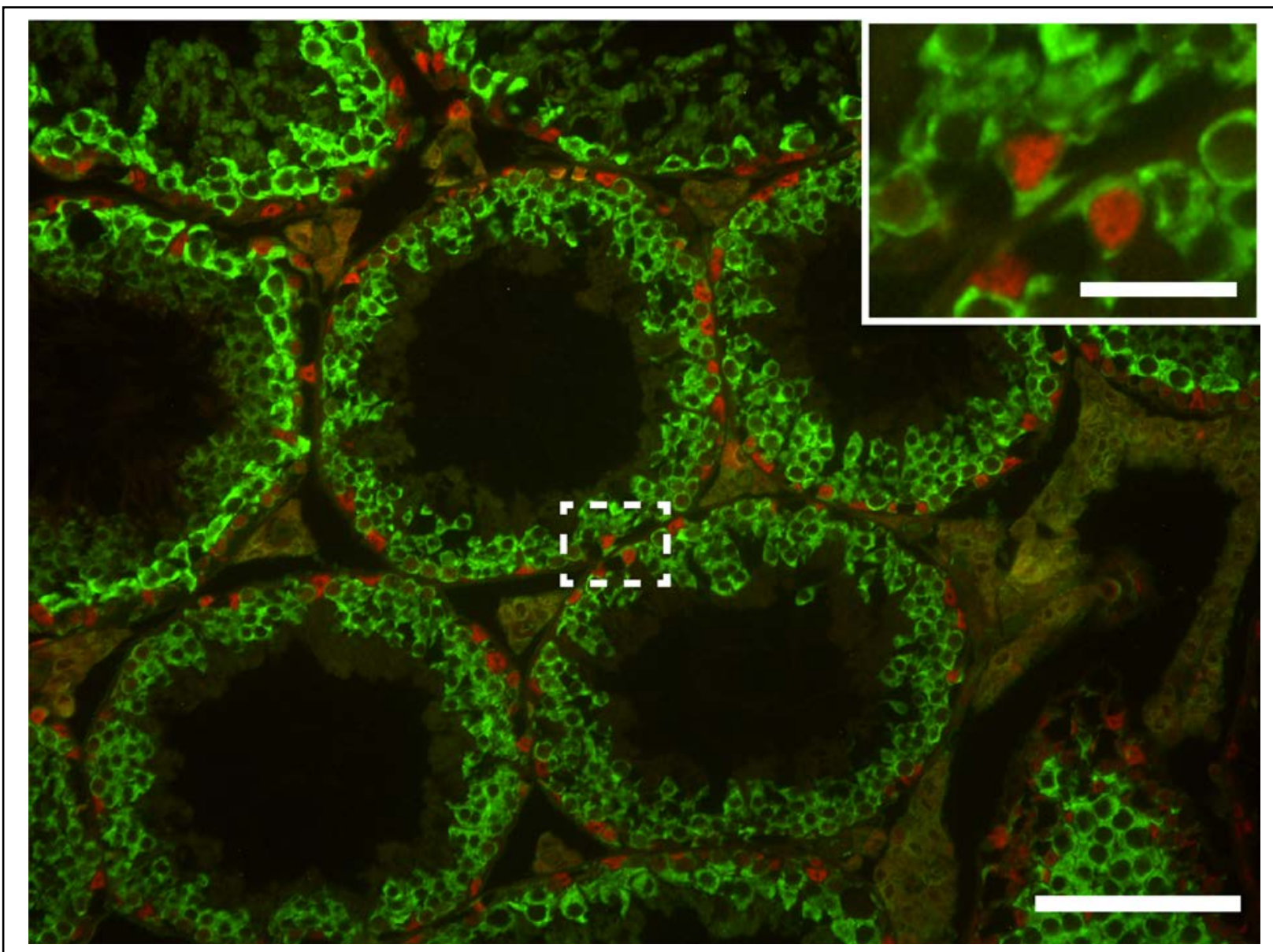

Figure 12: YBX1 co-expression with DAZL. Co-staining immunohistochemistry was performed on adult mouse testis. YBX1-positive cells, red, co-label with a subset of DAZL-positive (green) cells. The inset, which is zoomed in of the highlighted box, shows double-positive cells. Scale bar is $100 \mu \mathrm{m}$, and $20 \mu \mathrm{m}$ in insets. 


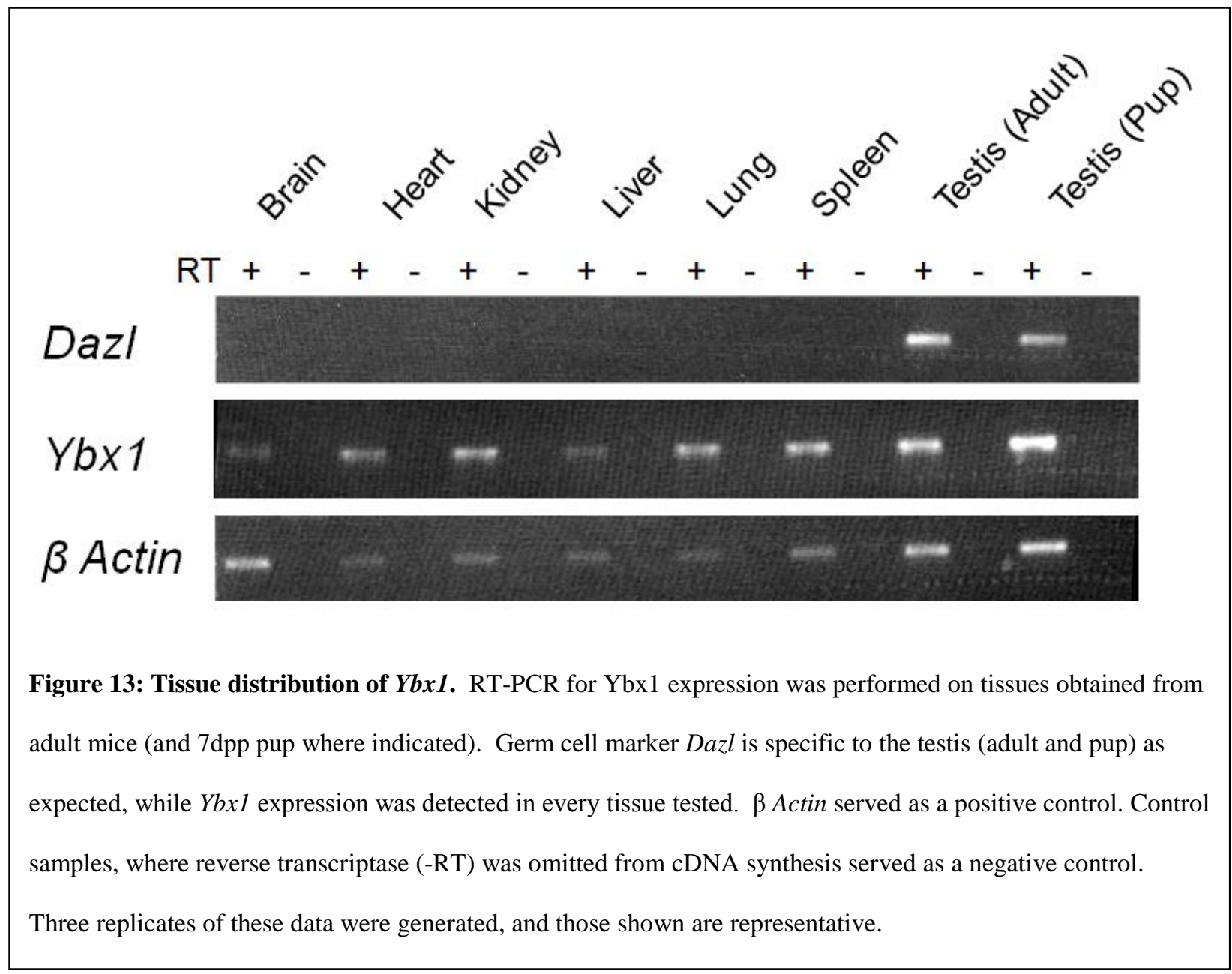

Because there are no PLZF+ cells that are YBX1-, we conclude that all undifferentiated germ cells, including SSCs, express YBX1. Further, we examined the overlap of YBX1 and DAZL expression and found that all YBX1+ cells are also DAZL+ (Figure 12). This indicates that only a subset of germ cells of the testis express YBX1, but no somatic cells. The restricted expression of YBX1 in the germline leads us to hypothesize that YBX1 provides critical RNA regulation in undifferentiated germ cells of the testis, including SSCs. Furthermore, the YBX1 expression pattern is consistent with other adult tissue stem cells. Hematopoietic and neural stem cells both express YBX1, but upon their differentiation, expression is lost [186, 187].

Using RT-PCR on RNA extracted from various adult mouse tissues (brain, heart, kidney, liver, lung, spleen, adult and pup testis), we confirm previous data that YBX1 is broad in tissue 
expression (Figure 13) and [188, 189]. However, the restricted testis expression to a subtotal of germ cells is a potentially important observation, as specificity in expression for spermatogonia could imply specificity in function. We therefore proceeded with further investigation of YBX1 in mouse SSCs. 


\subsection{GDNF SIGNALING THROUGH PI3K/AKT REGULATES YBX1 PHOSPHORYLATION IN SSCS}

\subsection{INTRODUCTION}

The previous chapter described the testis expression of 14 RNA binding proteins identified by microarray analysis of busulfan-treated, wild type and cryptorchid testes. We chose to focus our studies on YBX1 because its expression in undifferentiated germ cells led us to hypothesize that it plays a role in regulating SSC function.

Ybx1 (Y-box binding protein 1) is a gene encoding the DNA/RNA binding protein YBX1, a cold shock protein that is evolutionarily conserved $[180,190,191]$. It is widely expressed across a broad range of tissues, but in vivo data on the biological function of YBX1 is limited because the Ybx1 null mouse is embryonic lethal [192, 193]. YBX1 is as broad in its cellular function as in its expression, involved in transcription, translational control and splicing depending on the cell type expressing it and post-translational modifications $[11,24,36,39,41$, 42, 48-51, 193-196]. Perhaps because of its myriad cellular roles, there is little consistency about when developmentally it is expressed across tissues, or where inside the cell it is located, with it being reported in the nucleus, cytoplasm, or shuttling between the two based on post-

transcriptional modifications [41, 188, 194, 196-198]. The role of YBX1 in the male germline is unknown. 
The mechanisms by which YBX1 is regulated are of increasing interest because YBX1 has been discovered to play a role in progression and drug resistance of numerous types of cancer [43, 186, 187, 196, 199-202]. One mode of YBX1 regulation is AKT-mediated phosphorylation at Serine102, which is in the cold shock domain [202]. The effects of YBX1 phosphorylation are numerous. In Xenopus germ cells, phosphorylation of Y box proteins drives mRNA storage [203]. YBX1 does not have a known nuclear localization sequence (NLS), however YBX1 phosphorylation can also coordinate its nuclear translocation [47, 194, 198]. Additionally, the protein and DNA/RNA binding partners of YBX1 can change when it is phosphorylated [42]. Taken together, these data show that AKT can mediate extrinsic signaling through phosphorylation of YBX1 [42, 44].

In mouse spermatogonia, the AKT signaling cascade is active and necessary for stem cell function [90-92]. It is activated by GDNF (glial cell line derived neurotrophic factor), which signals through its receptor and co-receptor, GFR $\alpha 1$ and RET respectively, to activate phosphoinosited-3 kinase (PI3K), which then activates AKT. This signaling is reversible; brief GDNF withdrawal decreases AKT phosphorylation, but it can be recovered with GDNF replacement, and with no adverse effect to SSC activity [90]. Because GDNF is a growth factor essential for maintaining mouse SSCs in culture and in vivo, the AKT pathway is clearly crucial to the activities of SSCs $[66,88,108]$. There are some known downstream targets of GDNF signaling (including NANOS2, ID4 and POU3F1), but the complete signaling cascade of GDNF responsible for maintaining SSC activity is yet to be entirely elucidated [204-206].

Taken together, published work shows that YBX1 can be phosphorylated by AKT, and that phosphorylation can alter the ability of YBX1 to interact with other molecules, such as RNA. In spermatogonia, we do not know if YBX1 is phosphorylated and if so, by what 
pathway. We do know however that in spermatogonia, AKT signaling is activated by GDNF. We therefore hypothesize that one mechanism by which GDNF exerts its essential influence is via AKT and YBX1 phosphorylation and modulation of YBX1/RNA interactions in SSCs. We analyze the first half of that hypothesis in this chapter and show that GDNF signals through the PI3K/AKT pathway to phosphorylate YBX1.

\subsection{MATERIALS AND METHODS}

\section{Cell Culture and Treatments}

Primary SSC cultures were established as previously described from the testis of DBA/2 mice, ages 6-9 dpp [88, 108, 110]. Briefly, the testes were isolated and the tunica removed. A single cell suspension was produced by enzymatic digestion with $0.25 \%$ Trypsin (Invitrogen 25200-114) and DNaseI (Sigma DN25). We used a three part sorting strategy to isolate an SSCenriched population. First, we isolated cells pelleted through a 30\% Percoll gradient (Sigma p4937). Second, we used MACS to isolate Thy1+ cells (Miltenyi Biotec, Auburn, CA, http://www.miltenyibiotec.com, 130-049-101). Finally, using 0.1\% gelatin-coated plates, we performed differential plating. After 4 hours on gelatin-coated plates, floating cells were collected and re-seeded on plates coated with STO mouse embryonic fibroblast feeder cells and passaged weekly. They were grown in established mouse SSC media containing growth factors

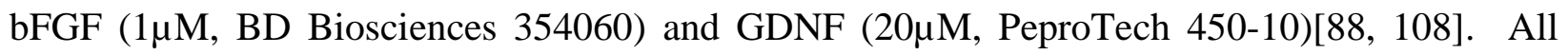
lines used in experiments were between passages four and sixteen.

For growth factor withdrawal or drug treatment experiments, media was removed and cells were washed with HBSS. $20 \mu \mathrm{M}$ LY294002 (Invitrogen, PHZZ1144) or vehicle control 
DMSO was added to standard culture medium and cells were incubated for 4 hours. $5 \mu \mathrm{M}$ MK2206 (Selleck Chemicals, S1078) or vehicle control DMSO was added to standard culture conditions and incubated for 18-24 hours. In growth factor withdrawal experiments, cells were washed and media replaced with fresh medium lacking the given factor per experiment and grown for 18 hours before lysis and Western blot analysis.

\section{Immunocytochemistry}

For immunocytochemical analysis of protein expression, primary mouse SSC cultures were washed with PBS and fixed in 1\% PFA for 20 minutes. They were then washed with PBS 2x10 minutes. Primary antibody incubations were performed at room temperature for 90 minutes, followed by PBS washes ( $3 \mathrm{x}$ five minutes). Secondary antibodies were incubated for 60 minutes at room temperature, followed by PBS washes ( $3 \mathrm{x}$ five minutes). Antibodies used were Phospho(Ser102)-Ybx1, 1:150 (Assay Biotech, A8481), Ybx1, 1:100 (Abcam ab12148) Dazl, 1:200 (Abcam ab17224), Plzf, 1:100 (R\&D Systems, Af2944) and secondaries donkey anti-rabbit alexa-flour 488 (Invitrogen, A-21206), donkey anti-mouse alexa-flour 568 (Invitrogen, A-10037), donkey anti-goat alexa-flour 568 (Invitrogen, A-11057).

\section{Western Blot}

For testis protein isolation, the testis was removed from the tunica and homogenized in lysis buffer: RIPA containing proteinase inhibitor and phosphatase inhibitor (Thermo Scientific, Rockford, IL, www.therm.com/pierce). For cultured cell protein isolation, germ cells were removed from feeder cells using vigorous pipetting and pelleted. Cells were then placed in the lysis buffer for 8 minutes on ice, and centrifuged to remove debris. Protein concentrations were determined using the Bradford assay. Proteins were separated on $10 \%$ polyacrylamide gels 
(BioRad) and transferred onto nitrocellulose membranes. Blots were blocked with 5\% Blotto blocking buffer for one hour at $20^{\circ} \mathrm{C}$. (Santa Cruz). Primary antibody incubation was performed for 90 minutes at $20^{\circ} \mathrm{C}$, followed by $3 \times 10$ minute washes in PBS; secondary antibody incubation was 60 minutes also at $20^{\circ} \mathrm{C}$, again followed by $3 \times 10$ minute washes. Western blots were visualized using SuperSingal Chemiluminescent Substrate (Thermo Scientific). Blots were stripped using Restore Western Blot Buffer (Thermo Scientific), washed in PBS, and then blocked before reapplication of primary antibody. Antibodies used were as follows: $\beta$ Actin, 1:3000 (Sigma, A1978), phospho(Ser102)-Ybx1, 1:333 (Assay Biotech), Ybx1, 1:1000 (Abcam, ab12148), Dazl, 1:200 (Abcam, ab17224), Plzf, 1:200 (R\&D Systems, Af294), phospho(Ser473)-Akt, 1:3000 (Abcam, ab66138), Akt, 1:1000 (Millipore, Billerica, MA, 05-

591). Secondary antibodies were all used at 1:2000 dilutions and are as follows: Goat antiMouse HRP (Santa Cruz Biotechnology, sc-2055) Donkey anti-Goat HRP (Santa Cruz Biotechnology, sc-2056).

\subsection{RESULTS AND DISCUSSION}

\subsubsection{YBX1 is Expressed in Mouse SSC Cultures}

YBX1 is restricted in expression to undifferentiated germ cells, including stem and progenitor spermatogonia, in the mouse testis (see Chapter 2). We hypothesize that this restricted expression reveals an important function necessary for the activity of undifferentiated spermatogonia. We employed SSC culture, which is amenable to experimental manipulation, to examine the mechanisms regulating YBX1 in SSCs. 


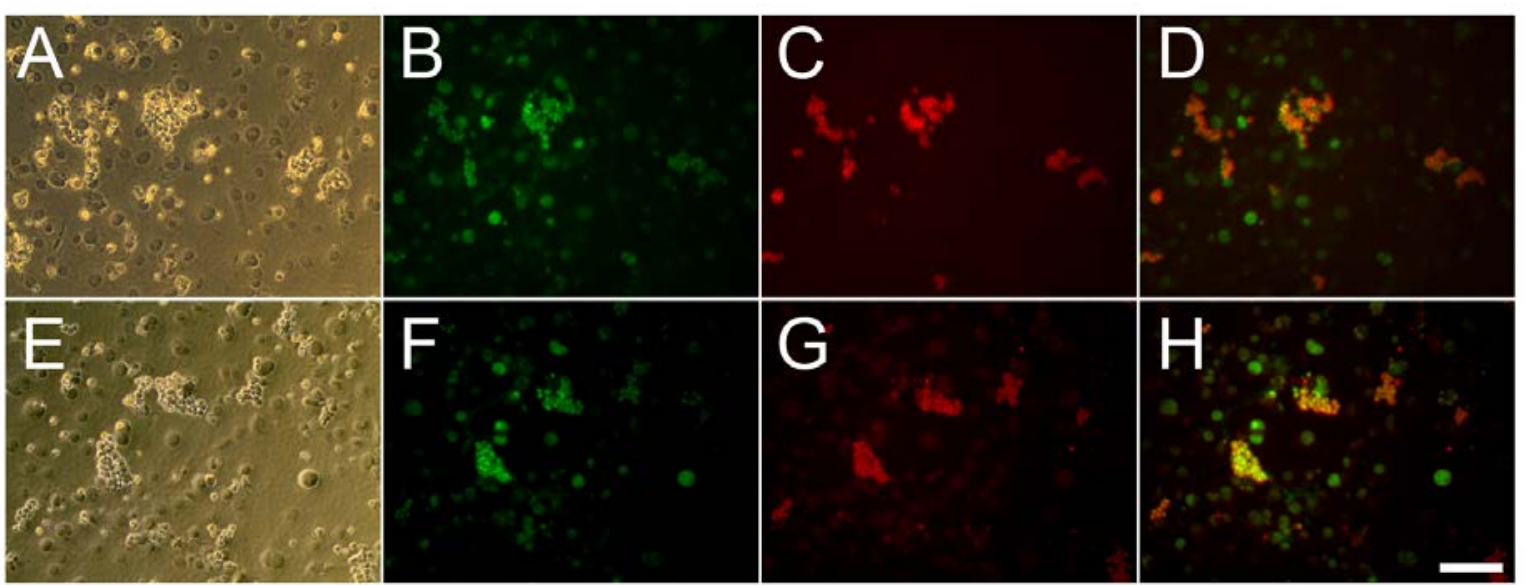

Figure 14: YBX1 protein is detected in mouse SSC culture. We performed immunocytochemistry on primary mSSCs, shown in brightfield (A and E). YBX1, labeled in green (B and F), localized to germ cell clusters expressing DAZL and PLZF, labeled in red ( $\mathrm{C}$ and G respectively). Double positive cells are seen in the merge images (D and H). Scale bar is $100 \mu \mathrm{m}$. Three replicates of these data were generated, and those shown are representative.

SSC culture is a well-established tool useful for dissecting the regulatory mechanisms of mouse spermatogonia. Numerous studies have elucidated the necessary components of SSC culture and have shown that the cultured cells in fact do accurately represent in vivo SSCs [87, 88, 108, 112]. SSCs grow in clusters on STO feeder cells (Figure 14A and E), and express the pan germ cell marker DAZL and stem and progenitor marker PLZF, which can be seen localized to the SSC containing clusters (Figure $14 \mathrm{C}$ and G respectively). To verify that YBX1 is faithfully expressed in SSCs in vitro, we performed immunocytochemistry (ICC) on cultured mouse SSCs and show that YBX1 protein is detected in germ cell clusters, overlapping with DAZL and PLZF (Figure 14). 


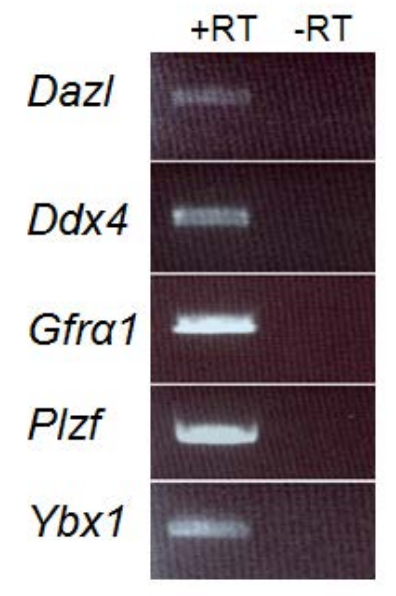

Figure 15: YBX1 mRNA is detected in mouse SSC culture. We performed RT-PCR on cDNA from the SSC cultures to confirm expression of pan germ cell markers (Dazl and Ddx4) and spermatogonial markers (Gfra1 and Plzf). In addition to expressing these expected markers, cultured mouse SSCs express Ybx1. Control samples, where reverse transcriptase (-RT) was omitted from cDNA synthesis served as a negative control. Three replicates of these data were generated, and those shown are representative.

To further confirm YBX1 expression in SSC cultures, we isolated RNA from established cell lines and performed RT-PCR, as described in Section 2. We detected YBX1 mRNA in cultured SSCs, and we additionally verified expression of control genes: germ cell markers Dazl and $D d x 4$, and undifferentiated spermatogonia markers Gfral and Plzf (Figure15). Together with the ICC data, we have confirmed that mouse SSCs in culture, express YBX1, as they do in vivo.

\subsubsection{YBX1 is Phosphorylated in vivo and in vitro}

We hypothesize that YBX1 is phosphorylated in spermatogonia due to GDNF signaling, but there is no data on the phosphorylation status of YBX1 in the testis. We performed Western blot 

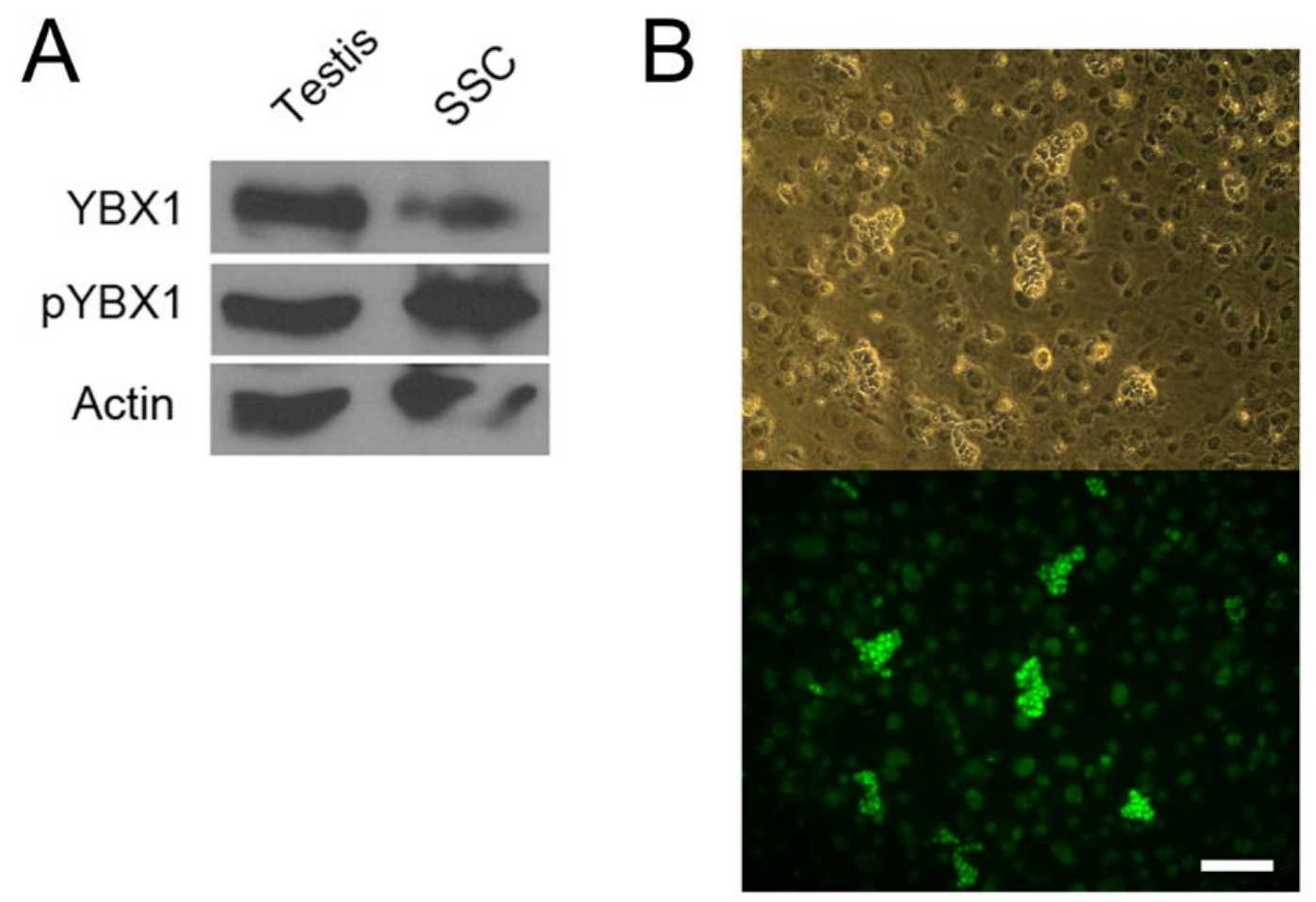

Figure 16: Phospho-YBX1 is expressed in adult mouse testis and SSCs in vitro. (A)We performed a Western Blot on whole testis lysate from adult mouse and on lysate from cultured mouse SSCs to confirm the presence of YBX1 and its phosphorylated form (pYBX1) in vivo and in vitro. Actin served as a loading control. (B) We then performed immunocytochemistry on mouse SSC cultures (shown in brightfield on top) to confirm the presence of the pYBX1 in these cells. Positive cells are labeled green. Scale bar is equal to $100 \mu \mathrm{m}$. Three replicates of these data were generated, and those shown are representative.

analysis on whole testis lysate using an antibody specific for YBX1 phosphorylated at Serine 102 and show that YBX1 is phosphorylated in vivo (Figure 16A). Because the only testis cells expressing YBX1 are undifferentiated spermatogonia, we can conclude that YBX1 in some or all of these cells is phosphorylated.

Again, we needed to confirm that our cell culture system correctly recapitulated the in vivo scenario, so we performed Western blot analysis on cultured SSC extracts. Like the testis, we see that YBX1 is present and phosphorylated in these cells (Figure 16A). To further validate 
phosphorylation of YBX1 in SSC cultures, we performed ICC using the same phospho-Ser102 YBX1 (p-YBX1) antibody. Positive signals located specifically in the germ cell clusters confirm that YBX1 is phosphorylated in the cultured SSCs (Figure 16B). In conclusion, YBX1 is expressed by SSCs, in vivo and in vitro, where it is phosphorylated. These data validate cultured mouse SSCs as a model for analyzing YBX1.

\subsubsection{GDNF Directs YBX1 Phosphorylation}

The two major growth factors necessary in maintaining and expanding mouse SSCs in long term culture are GDNF and bFGF, and while GDNF is necessary for SSC maintenance, bFGF is thought to be a mitogen driving proliferation in vitro [110]. We hypothesized that GDNF would be critical for directing YBX1 phosphorylation through AKT, but tested the withdrawal of each growth factor (GDNF and bFGF) individually or in concert to more completely dissect the signaling.

Under normal mouse SSC growth conditions, containing bFGF and GDNF (referred to hereafter as $+\mathrm{F} /+\mathrm{G}$ respectively) both $\mathrm{AKT}$ and $\mathrm{YBX} 1$ were phosphorylated (Figure 17). Growing cells for 18 hours in the absence of of GDNF (+F/-G) caused a loss of AKT and YBX1 phosphorylation, though no change in total protein levels were observed. Conversely, loss of bFGF signaling $(-\mathrm{F} /+\mathrm{G})$ for 18 hours resulted in no phosphorylation or protein level changes for either AKT or YBX1. Removing both factors (-F/-G) mimics GDNF alone withdrawal in terms of phosphorylation changes. These results indicated that GDNF, not bFGF, regulates the phosphorylation of $\mathrm{AKT}$ and $\mathrm{YBX} 1$, though how AKT signaling is linked to YBX1 phosphorylation requires further experimentation. 


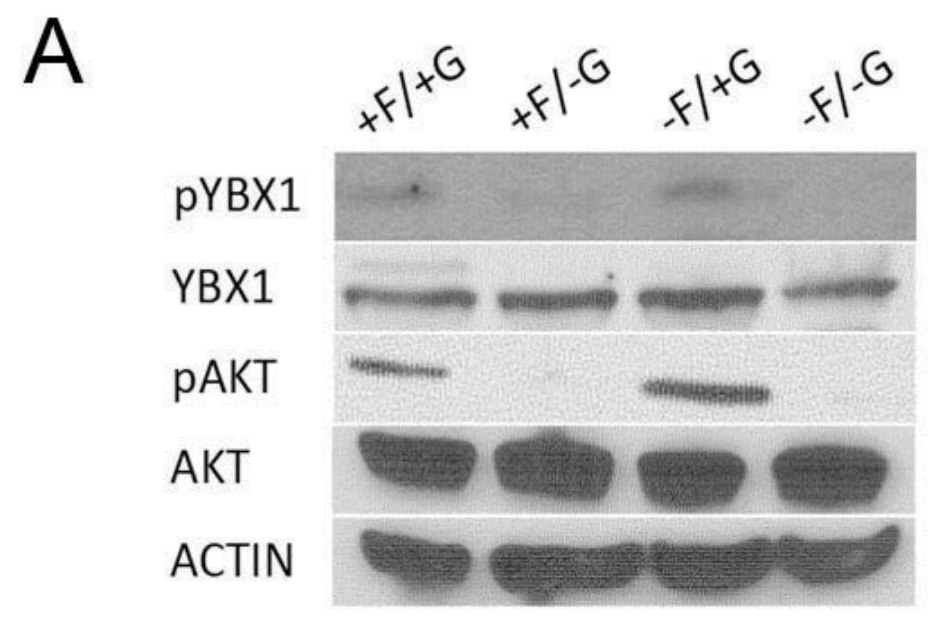

B

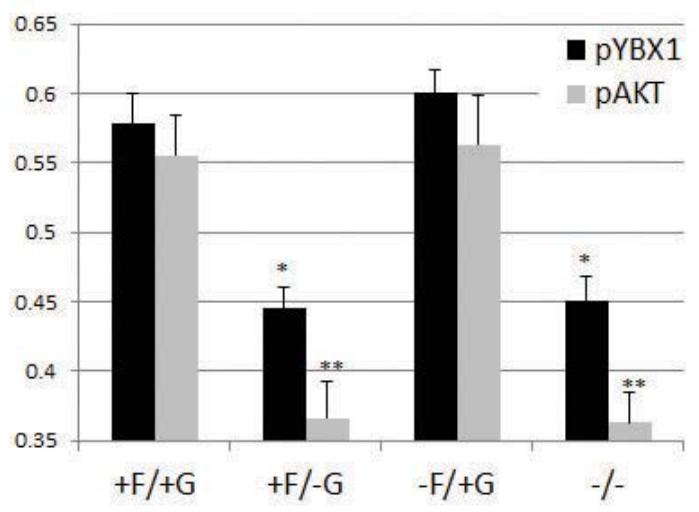

Figure 17: YBX1 phosphorylation is mediated by GDNF signaling in mSSCs cultures. (A) We performed Western blots on the lysates of SSCs grown in four different conditions. Antibodies specific to phosphorylated YBX1 and AKT (pYBX1 and pAKT respectively) indicate that YBX1 and AKT are phosphorylated when cells are cultured with GDNF, while bFGF does not affect their phosphorylation. Total YBX1 and AKT protein levels remain unchanged. Actin serves as a loading control. Three replicates of these data were generated, and those shown are representative. (B) Quantification of phosphorylation for the four treatment groups. Error bars indicate standard error of mean. All data normalized to total protein ACTIN, and YBX1 or AKT. *P=<.05 compared to $+\mathrm{F} /+\mathrm{G}$ pYBX1, $* * \mathrm{P}=<.05$ compared to $+\mathrm{F} /+\mathrm{G}$ pAKT.

To dissect the signaling pathway responsible for YBX1 phosphorylation, we blocked PI3K signaling with the inhibitor LY294002, which has previously been published as an efficient 


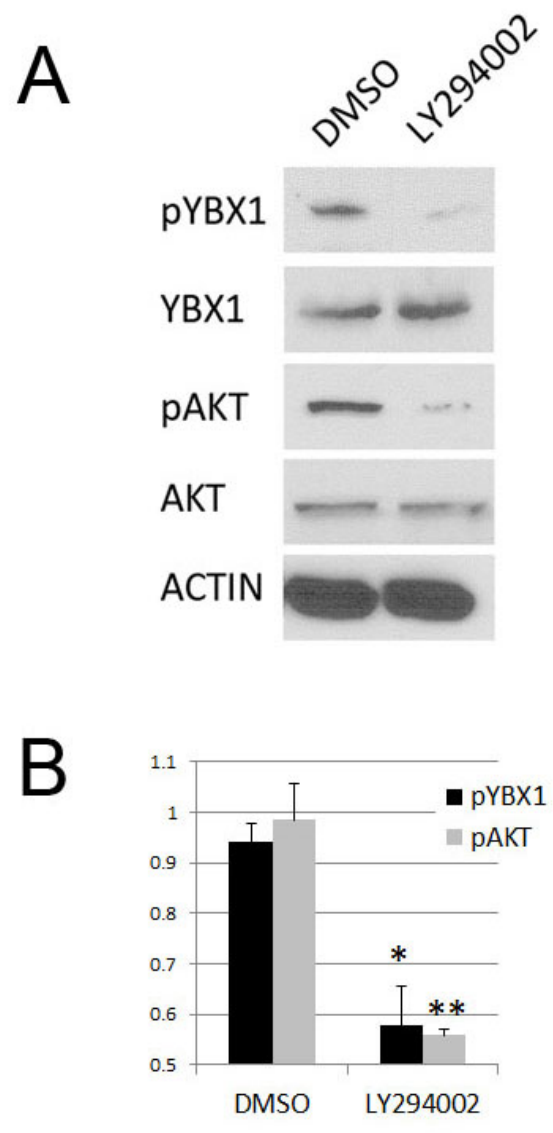

Figure 18: YBX1 phosphorylation is mediated by PI3K signaling in SSCs cultures. (A)Western blots were performed on SSCs grown in normal growth conditions $(+F /+G)$ treated fo four hours with either PI3Kinase inhibitor LY294002 or vehicle control treatment, DMSO. Phosporylated YBX1 and AKT (pYBX1 and pAKT respectively) were depleted in drug treatment in comparison to vehicle control. Total YBX1 and AKT protein levels remain unchanged. Actin serves as a loading control. Three replicates of these data were generated, and those shown are representative. (B) Error bars indicate standard error of mean. All data normalized to total protein ACTIN, and YBX1 or AKT. $* \mathrm{P}=<.05$ comparing $\mathrm{pYBX} 1, * * \mathrm{P}=<.05$ comparing $\mathrm{pAKT}$.

inhibitor of PI3K activity in mouse SSCs. PI3K is activated upon GDNF signaling and is upstream of the AKT pathway [90, 92]. Mouse SSCs grown under standard growth conditions $(+F /+G)$, were treated with LY294002 or vehicle control (DMSO). Inhibition of PI3K resulted in decreased phosphorylation of both AKT and YBX1 without changes in total protein levels 
(Figure 18A and B). These data indicate that AKT and YBX1 are downstream of PI3K signaling.

To test the direct activity of AKT in YBX1 phosphorylation, we employed the AKT

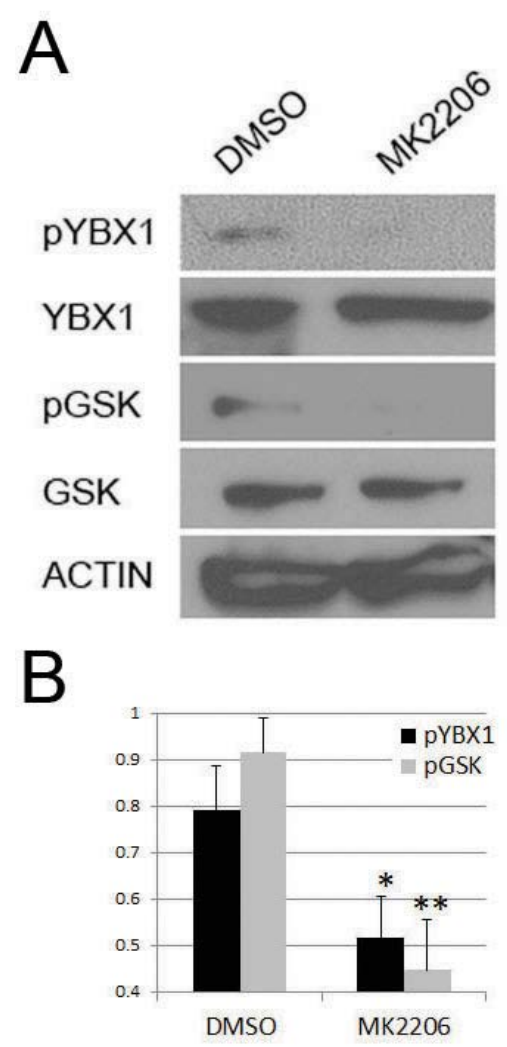

Figure 19: YBX1 phosphorylation is mediated by PI3K signaling in SSCs cultures. (A)Western blots were performed on SSCs treated with either MK2206 or vehicle control DMSO. MK2206 blocks AKT kinase activity, though not its phosphorylation. Thus we confirmed MK2206 inhibitory effect on known AKT target GSK (pGSK), and show that YBX1 phosphorylation (pYBX1) is similarly lost when AKT is specifically inhibited. Neither total protein level changes. Actin served as a loading control. Three replicates of these data were generated, and those shown are representative. (B)Error bars indicate standard error of mean. All data normalized to total protein ACTIN, and YBX1 or GSK. $* \mathrm{P}=<.05$ comparing $\mathrm{pYBX} 1,{ }^{* *} \mathrm{P}=<.05$ comparing pGSK. 
allosteric inhibitor MK2206. MK2206 blocks AKT from phosphorylating its targets, but it does not block phosphorylation of AKT itself. Therefore, to confirm the efficacy of the compound on blocking AKT phosphorylation ability in cultured SSCs, we performed Western blots on the known AKT target GSK-3 (glycogen synthase kinase 3) [207, 208]. Mouse SSC cultures treated with MK2206 predictably showed a loss of GSK-3 phosphorylation, although not total protein levels as compared to vehicle control, confirming inhibition of AKT kinase activity (Figure 19A and B). Likewise, YBX1 phosphorylation was decreased in the presence of MK2206 (Figure 19A and B). These data confirm that AKT is upstream of YBX1 and responsible for its phosphorylation.

Collectively, the data presented in this section show that YBX1 is phosphorylated in response to GDNF signaling in mouse SSCs. PI3K and AKT inhibition show that this is the pathway through which GDNF works to ultimately phosphorylate YBX1. While these data do not show that YBX1 is directly phosphorylated by AKT in SSCs, studies in other cell types where AKT directly acts upon YBX1 lead us to believe this is the probable mechanism in SSCs as well $[42,194,198,202]$. These data provide a downstream regulatory target for GDNF, a factor critical to spermatogonial maintenance. Further studies are necessary to determine what the importance of GDNF-directed YBX1 phosphorylation is, and how it could contribute to balancing self-renewal and differentiation in SSCs. 


\subsection{GROWTH FACTOR STIMULI DIRECT YBX1/MRNA INTERACTION}

\subsection{INTRODUCTION}

The regulatory mechanisms driving SSC activity are poorly understood. RNA regulatory pathways are a significant part of SSC maintenance and spermatogenesis (see Section 1.5). Analysis of genes associated with mouse SSC activity revealed 14 RNA binding proteins that we screened for testis location (see Chapter 2). One protein, YBX1 was observed only in undifferentiated germ cells, including stem and progenitor spermatogonia. Interest in the mechanism of YBX1 activity led us to study the signaling pathway responsible for its regulation (see Chapter 3). We showed that GDNF signaling through the PI3K/AKT pathway results in the phosphorylation of YBX1 in mouse SSCs, but what this phosphorylation means for YBX1 function is not known.

As discussed, $Y b x 1$ is a gene encoding the DNA/RNA binding protein YBX1, which is evolutionarily conserved and widely expressed [180, 188-191]. In vivo data on the biological function of YBX1 is limited because the $Y b x 1$ null mouse is embryonic lethal and $Y b x 1$ null embryonic stem cells are not viable [192, 193, 209]. A YBX1 homologue, MSY2, is expressed in differentiating germ cells. MSY2 is involved in RNA stability, and when it is knocked out, mice are viable but males and females are infertile, giving us further evidence for the importance of the Y box family of proteins in spermatogenesis [210, 211]. 


\begin{tabular}{|l|l|l|l|}
\hline GENE & Forward Primer & Reverse Primer & Cycle \\
\hline Dazl & CTCAACAGTCCAATCAGTGGG & GGTACAAAGTTCTCTGCTGTC & 30 \\
\hline Dazl: N & GGTTGGGATGGTAATTAGG & CCAATGATCTCATGTCCATC & 36 \\
\hline Ddx4 & GGCAAGAGAAAAGCTGCAGTCTTC & GAAGACTGCAGCTTTTCTCTTGCC & 30 \\
\hline Ddx4: N & GGCCTTTTTGGTTCTAGG & GTTTGAGCACAAGCCATC & 36 \\
\hline Gfra1 & CCAAAGGGAACAACTGCC & CAGCGAGACCATCCTTTC & 36 \\
\hline Gfra1: N & CAGCTACGGGATGCTCTTC & GAAGGCAGTGGTAGTCGTG & 36 \\
\hline Ngn3 & CGTGCAGTGACCTCTAAG & CCAGACAGGTCTCTTCAC & 36 \\
\hline Ngn3: N & CTAGCCCCACTCTCATAC & GTAGATAGAGCCCCAGTC & 36 \\
\hline PIzf & GAAGAGGACCGTAAGGCTC & CAGTTTCCTGTGCTGCTCC & 36 \\
\hline Plzf: N & GAACTCTTCAGCCACCTGC & CAGACGTCACTGAAGACGG & 36 \\
\hline
\end{tabular}

Table 3: Forward and reverse primers for PCR and nested PCR (denoted with N). Cycle denotes the number of cycles for PCR and nested PCR

YBX1 has a broad range of reported functions including transcriptional regulation and splicing depending on the cell type expressing it and post-translational modifications [11, 49, 51, 193-199, 212]. The other major function of YBX1 is in RNA translational control, generally through mRNA sequestration and prevention of transcript degradation, although some studies suggest that it can positively regulate translation as well [24, 36, 39-42, 45-48, 50, 52, 53]. Identifying conserved RNA targets of YBX1 has proven difficult, because it does not seem to bind with sequence or structure specificity, and yet it does not act globally on mRNA (perhaps binding $20 \%$ of all transcripts), suggesting some mechanisms of target preference [41, 42, 189, 213]. The in vivo mRNA targets of YBX1 in germ cells and its role in SSCs remain unknown. 
However, because of its reported regulation of genes important for undifferentiated cells, we hypothesize that YBX1 will modulate expression of SSC regulatory genes [41, 199].

We have shown in the previous chapter that YBX1 phosphorylation is mediated by GDNF through the PI3K/AKT pathway. This is an important finding, as the phosphorylation of YBX1 can potentially affect its activity and binding partners. In regard to translational regulation, phosphorylation of YBX1 by AKT can affect its ability to interact with mRNA, thus providing a signaling mechanism for translational modulation [41, 42]. We hypothesize that GDNF-directed phosphorylation of YBX1 regulates the mRNA species with which it interacts to regulate protein levels of genes important for SSC function.

\subsection{MATERIALS AND METHODS}

Ribonucleoprotein Immunoprecipitation

Mouse SSCs were grown in culture as previously described (section 3.2). Media was removed from primary mSSC cultures and cells were washed with HBSS. We then replaced media with one of four media treatments: SSC media +GDNF/+bFGF, -GDNF/+bFGF, +GDNF/-bFGF or -GDNF/-bFGF. After 18 hours germ cells were rinsed off of feeders with vigorous pipetting, pelleted and lysed in RIPA lysis buffer containing protease inhibitor, phosphatase inhibitor and RNAse inhibitor (Invitrogen, 10777-019). We used 250-500 $\mu$ g lysate and $2 \mu \mathrm{g}$ Ybx1 antibody (Abcam, ab12148) or IgG isotype control (Santa Cruz Biotechnology, sc-2027) for immunoprecipitation, which we performed using the Pierce Classic Immunoprecipitation Kit (Thermo Scientific, 26146). Following IP, RNA was isolated using Trizol, then DNAseI treated to remove potentially contaminating DNA. We then used 0.1-1 $\mathrm{gg}$ 
of RNA in cDNA synthesis. Finally, we performed nested PCR for five target genes (Dazl, Ddx4, Gfral, Ngn3 and Plzf), empirically determining PCR cycle number for each (see Table 3).

\section{Western Blot}

For SSC culture protein isolation, cells were grown in the absence of growth factor(s), as in the four RNP-IP treatment groups from Chapter 3 (+GDNF/+bFGF, -GDNF/+bFGF, +GDNF/-bFGF or - GDNF/-bFGF). Cells were then rinsed off of feeder cells using vigorous pipetting and pelleted for lysis (as before, see Section 3.2) and protein isolation. Protein concentration from lysate was determined via Bradford assay. Proteins were separated on $10 \%$ polyacrylamide gels and transferred onto nitrocellulose membranes (Biorad, 456-1034). Primary and secondary incubations and Western blot visualization were performed as previously described (see Section 3.2). Antibodies used were as follows: $\beta$ Actin, 1:3000 (Sigma, A1978), Dazl, 1:200 (Abcam, ab17224), Plzf, 1:200 (R\&D Systems, Af294). Secondary antibodies were used in the following concentrations: Goat anti-Mouse HRP (Santa Cruz Biotechnology, sc2055) Donkey anti-Goat HRP (Santa Cruz Biotechnology, sc-2056).

\subsection{RESULTS AND DISCUSSION}

\subsubsection{Growth Factor Mediated YBX1 Association with mRNA}

GDNF signaling is required for maintenance of SSCs in vivo as well as survival and expansion of SSCs in vitro $[66,108]$. The mechanisms by which GDNF regulates SSC function are not fully understood, but GDNF function is mediated through the PI3K/AKT signaling pathway [90-92]. 


\begin{tabular}{|c|c|c|c|c|c|c|c|c|c|c|c|c|c|c|c|c|c|c|c|}
\hline \multirow[b]{2}{*}{ bFGF } & \multicolumn{3}{|l|}{ Input } & \multicolumn{4}{|c|}{ YBX1 IP } & \multicolumn{4}{|c|}{ YBX1 FT } & \multicolumn{4}{|c|}{ IgG IP } & \multicolumn{4}{|c|}{ IgG FT } \\
\hline & + & - & - & + & + & - & - & + & + & - & - & + & + & - & - & + & + & - & - \\
\hline GDNF & + & + & - & + & - & + & - & + & - & + & - & + & - & + & - & + & - & + & - \\
\hline
\end{tabular}

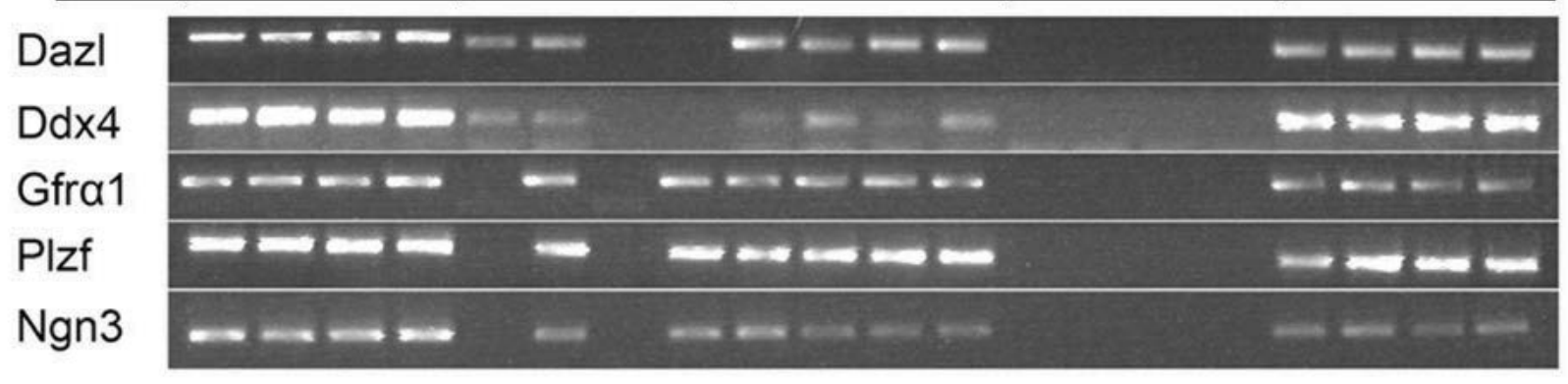

Figure 20: YBX1 association with mRNA is mediated by growth factor stimuli. We performed RNP IP on SSC lysates grown under four distinct conditions $(+F /+G,+F /-G,-F /+G,-F /-G)$. We ensured that all transcripts were present before immunoprecipitation by performing RT-PCR on the five target genes with input RNA (Input). When we immunoprecipitated YBX1 from + F/+G treated cells, only RT-PCR for Dazl and Ddx4 yielded a positive signal. All five transcripts were detected YBX1 immunoprecipitate following GDNF withdrawal (+F/-G), whereas in the absence of bFGF, none of the five co-immunoprecipitated. In the absence of both factors (-F/-G), the binding pattern is inverse of when both are present. The flow through controls (YBX1 FT) show that all RNA species maintained integrity through the RNP-IP process. The isotype controls (IgG IP) show that the RNA association is specific to YBX1, while the isotype flow through (IgG FT) ensure that the lack of isotype interaction is not due to RNA degradation. Three replicates of these data were generated, and those shown are representative.

We show that GDNF signaling through PI3K/AKT is responsible for the phosphorylation of YBX1. Because phosphorylation has been shown to affect YBX1 interaction with mRNA, we hypothesized that GDNF signaling would alter YBX1/mRNA interactions in cultured spermatogonia. As with signaling studies, we took advantage of the fact that SSCs are maintained in a defined media, so we tested the effects of both major growth factors in SSC media (bFGF and GDNF) on YBX1 association with specific mRNAs. To do so we performed

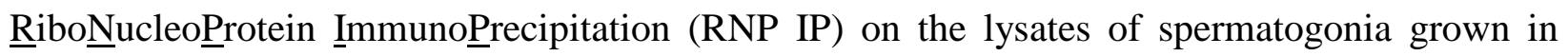
conditions containing different growth factor stimuli: 1) +bFGF/+GDNF, 2) +bFGF/-GDNF, 3)- 
bFGF/+GDNF and 4)-bFGF/-GDNF (or +F/+G, +F/-G, -F/+G and -F/-G respectively). YBX1 was immunoprecipitated from each condition and co-immunoprecipitating transcripts were isolated for RT-PCR. We tested the resultant RNA populations for presence (indicating YBX1 association) of pan germ cell markers (Dazl and $D d \times 4$ ), undifferentiated germ cell markers (Gfr $\alpha 1$ and Plzf) and a differentiating spermatogonia marker (Ngn3).

As expected for SSC cultures, all five genes are expressed by the cultured spermatogonia under all four conditions before immunoprecipitation (see Input Figure 20). The mRNA integrity for all genes was maintained under all conditions of the RNP IP process (YBX1 FT Figure 20). However, only genes expressed broadly in germ cells, Dazl and $D d x 4$, coimmunoprecipitated with YBX1 under normal growth conditions $(+F /+G)$, while association with genes restricted to more spermatogonia, Gfr $\alpha 1$, Plzf, and $N g n 3$, was not detected under these conditions (see YBX1 IP +F/+G Figure 20). These associations were YBX1-specific, as isotype control immunoprecipitation had no observed association with the tested RNAs (see IgG IP and FT Figure 20). These results confirm that in spermatogonia, YBX1 shows some preference in mRNA binding. While we are not certain what confers mRNA binding specificity, there is clearly some growth factor mediated mechanism or mechanisms that cause YBX1 to interact with a subset of total RNA. What is curious about the subset of YBX1-interacting mRNAs (Dazl and Ddx4) is that they differ in their testis expression from the non-bound genes (Gfr 1 1, Ngn3 and Plzf). DAZL and DDX4 are proteins found in all male germ cells, while the non-YBX1 interacting species (Gfra1, Plzf and Ngn3) are restricted in expression to undifferentiated or differentiating spermatogonia [65]. Whether germ lineage expression is the cause of this differential YBX1 interaction is unknown, but that the genes are segregated by spermatogenic lineage development expression profile is cause for further investigation. 
To determine how GDNF signaling alters these YBX1/mRNA interactions, we grew SSCs in the absence of GDNF or bFGF or both factors and then performed the same RNP IP. All five genes co-immunoprecipitated with YBX1 in the absence of GDNF (+F/-G). When bFGF was withdrawn $(-F /+G)$, none of the five genes analyzed were detected (see YBX1 IP Figure 20). GDNF appears to be inhibiting YBX1/mRNA association, or bFGF is promoting it, or some combination of the two. These 'all or none' results for mRNA interaction with YBX1 in bFGF or GDNF absence indicate that there is a balance maintained by these two factors in SSCs which directs YBX1 association with certain mRNA species. These conclusions are bolstered by the observation that in the absence of both factors (-F/-G), the YBX1-associating mRNAs are opposite those associating when both factors are present (see YBX1 IP Figure 20). The significance of YBX1 association with certain transcripts requires further investigation, but these data show that extrinsic signals influence YBX1 binding to specific mRNAs in mouse SSCs.

\subsubsection{YBX1 Association with RNA Correlates with Protein Levels}

YBX1 has a well-documented role in translational control, promoting or inhibiting depending on its cellular environment. To test if YBX1 might be effecting the translation of the transcripts with which it interacts in mouse SSCs, we performed Western Blots on one of the pan germ cell markers (DAZL) and one of the undifferentiated germ cell markers (PLZF) which we tested for RNA association with YBX1. To do this, we grew cells under the same conditions used for RNP IP $(+F /+G,+F /-G,-F /+G$ and $-F /-G)$, then lysed the cells and probed protein levels. Interestingly, the pattern of protein levels positively correlated with YBX1/mRNA binding. YBX1 interacts with DAZL mRNA under two of the four conditions tested (+F/+G, +F/-G), and 
under these two conditions DAZL protein levels were increased relative to the other conditions where the transcript failed to co-immunoprecipitate with YBX1 (Figure 21A and B). Likewise, YBX1 interacts with PLZF mRNA under two conditions (+F/-G and $-\mathrm{F} /-\mathrm{G})$, and under those conditions protein levels were increased over the conditions under which YBX1 did not coimmunoprecipitate with the PLZF transcript $(+F /+G,-F /+G)$ (Figure 21A and B). These data suggest that YBX1 promotes the translation, directly or indirectly, of its associated transcripts.

Based on withdrawal, we can conclude that bFGF plays a role in DAZL protein levels,

A

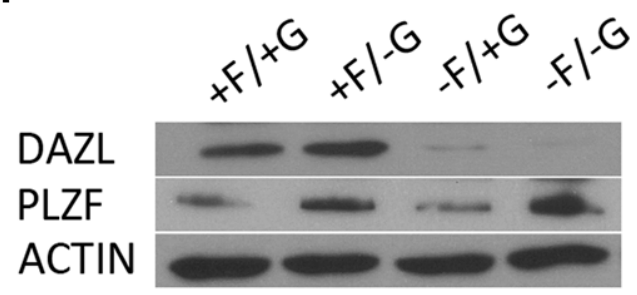

B

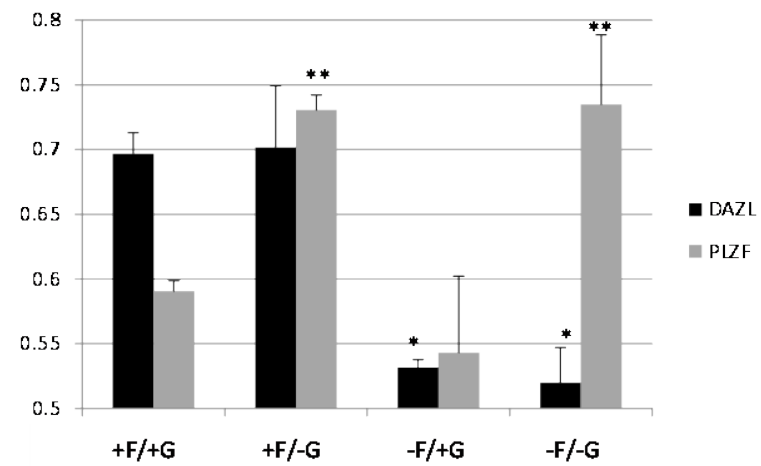

Figure 21: Protein levels correlate with YBX1 association with mRNA. A. We performed Western blots for DAZL and PLZF on mouse SSC lysates grown under four different growth conditions: containing bFGF and GDNF (+F/+G), GDNF withdrawn (+F/-G), bFGF withdrawn (-F/+G) and both factors withdrawn (-F/-G). Protein levels for DAZL decrease in bFGF absence, regardless of GDNF presence. Conversely, GDNF withdrawal causes an increase in PLZF protein levels regardless of bFGF presence. Protein levels for DAZL and PLZF correlate with YBX1 association with each. When YBX1 associates with DAZL or PLZF mRNA (see Figure 7), it is under those identical conditions that the protein levels of DAZL or PLZF or the highest. Three replicates of these data were generated, and those shown are representative. B. Quantification of protein levels for the four treatment groups in A. Error bars indicate standard error of mean. All data normalized to total protein ACTIN. * $\mathrm{P}=<.05$ compared to $+\mathrm{F} /+\mathrm{G}$ DAZL, **P=<.05 compared to $+\mathrm{F} /+\mathrm{G}$ PLZF. 
since in its presence, regardless of GDNF, DAZL protein is more abundant than in its absence (compare - and + bFGF lanes, Figure 21A and B). PLZF, conversely, is more responsive to GDNF, as its protein is diminished in GDNF presence, regardless of bFGF status (compare - and + GDNF lanes, Figure 21A and B). These data suggest a balance of YBX1 mediated regulation, where different external stimuli may use the same RNA binding protein to differentially regulate genes involved in unique cellular functions.

Previous studies show that PLZF mRNA levels in mouse SSCs do not change following changes in GDNF exposure [90]. Our data are interesting because they show that PLZF protein levels do change following withdrawal of GDNF. One explanation for this discrepancy is posttranscriptional regulation of PLZF mRNA. We propose, based on the above data, that YBX1 is responsible for this regulation. We further show that DAZL is under what appears to be similar, but not identical regulation by YBX1. It is similar because SSCs treated with GDNF alone (F/+G) contain YBX1 that is not associating with either Plzf or Dazl transcripts and thus produce lower protein levels for these genes. Nor is there a difference with bFGF alone $(+F /-G)$ in that both RNAs associate with YBX1 and show an increase in protein levels. The difference is in the presence or absence of both factors. When both bFGF and GDNF are present $(+F /+G), Y B X 1$ associates with Dazl and not Plzf mRNA, and thus the protein levels are reflective of that (high DAZL, low PLZF). Likewise, protein analysis shows that in the absence of both (-F/-G) the protein levels of DAZL and PLZF are inverted from when both growth factors are present (low DAZL, high PLZF). These results are not caused by changes in YBX1 protein levels, as we showed previously that while phosphorylation of YBX1 changes in response to growth factor signaling, the protein levels are consistent across all four treatment groups (Figure 17A and B). 
These data provides us with two conclusions about YBX1 association with mRNA. First, there is some mechanism of specificity under normal growth conditions $(+F /+G)$ that is lost upon removal of the normal maintenance paradigm. Secondly, YBX1 appears to be positively regulating translation of genes important for spermatogenesis. There are reports of YBX1 being both a positive and negative regulator of translation depending on the specific cell type expressing it. When YBX1 is in SSCs, we show that it is a nuclear protein which positively regulates the translation of mRNAs important for SSC function and/or spermatogenesis. 


\subsection{SUMMARY AND CONCLUSIONS}

Spermatogonial stem cells are essential for male fertility, maintaining spermatozoal output through a balance of self-renewal and differentiation. However, the mechanisms that regulate self-renewal versus differentiation fate decisions are still being elucidated. Previous studies have identified an essential role for RNA regulation in male germline development. Likewise, GDNF has been recognized as the critical growth factor required for driving SSC self-renewal [66, 87, 88]. The goal of this work was to gain new insights into SSC regulation by determining whether RNA binding proteins mediate GDNF signaling in SSCs.

The RNA regulatory proteins we analyzed were identified using in vivo transcriptome mining. We found 14 genes encoding RNA regulatory proteins and expression correlated with SSC activity that became the basis of this current study. We determined the testis expression pattern of each gene, and categorized them based on their testis distribution and co-expression with stem and progenitor spermatogonia marker PLZF. Their distribution fell into three groups. Ten genes were widely expressed in most or all germ cells, including PLZF-positive spermatogonia (which include $\mathrm{A}_{\text {single, }} \mathrm{A}_{\text {paired }}$ and $\mathrm{A}_{\text {aligned}}$ ) through haploid gametes (Class I). Two genes were expressed preferentially by differentiating germ cells, but not PLZF-positive spermatogonia, with expression appearing in spermatocytes on the basement membrane (Class

II). These two Class II genes were not expressed by all cells on the basement membrane though, and their expression began roughly as cells were transitioning into meiosis. Finally, two genes 
were expressed preferentially by undifferentiated germ cells, including PLZF-positive spermatogonia, (Class III).

The 14 genes encode proteins involved in different steps of RNA regulation, and the most functionally prevalent group (7 of 14 genes) was splicing regulators. There is little to no data on most of these 14 genes regarding roles specific to germline development. One that has been described, RBMY1A1 (RNA binding motif protein, Y chromosome, family 1, member A1), is expressed only in early stage male germ cells (Class III), confirming previous data [137, 138, 184, 185]. It is of special interest because of its clinical link to oliogspermic males [139]. The intricacies of its function in the germline are unknown, but it does interact with splicing regulators, including another protein we identified on this list (SFRS10), leading some to hypothesize its tissue specific role in alternative splicing [26, 27]. Coincidentally, SFRS10 (serine/arginine-rich splicing factor 10), a Class I protein, is the other splicing regulatory protein from our list that has been described in germ cells, where it has been shown to be excluded from condensed germ chromatin [153]. SFRS10 is a general splicing regulator, though its interaction with RBMY1A1 may offer it unique regulatory capabilities in SSCs [26].

Further alternative splicing could be mediated by two genes from the Sm-Like family of proteins which were identified in our gene list. LSM4 and LSM8 (both Class I) are best characterized in yeast, where they form complexes involved in RNA splicing and processing [18, 19, 214]. They are predicted to have similar roles in metazoan cells, but there function in mammals is not well described, in part because the LSM4 null mouse is embryonic lethal [215].

The final three candidate RNA binding proteins involved in splicing are SFRS6 (serine/arginine-rich splicing factor 6), EWSR1 (Ewing sarcoma breakpoint region 1) and HNRPA2B1 (heterogeneous nuclear ribonucleoprotein A2/B1). They are linked in that they too 
have no known germ cell function. SFRS6 is a Class I protein and member of a well conserved class of splicing factors involved in promoting mRNA processing [31, 32]. Functionally opposite, aberrant EWSR1 can cause splicing inhibition, while HNRPA2B1 can promote exon skipping to produce alternative protein isoforms [9, 10, 17]. It is of interest that these represent different mechanisms of regulating alternative splicing (promotion, inhibition, exon skipping), which may work in combinatorial or antagonistic ways. HNRPA2B1 and EWSR1 are both Class II proteins though, so their function is primarily post-meiotic, whereas the other splicing regulators are expressed earlier or throughout germ cell development. HNRPA2B1 and EWSR1 may then be acting antagonistically towards other splicing regulators, such as SFRS6, or they may provide unique splicing events necessary for differentiating germ cells. What, if any, role these proteins have in SSC biology or spermatogenesis is yet to be discovered and is merely speculation.

In addition to splicing, another step of RNA regulation inside the nucleus involves the processing of small non-coding RNAs. FBL (fibrillarin), a Class I protein, is a component of small nucleolar RNPs, where it directs processing of ribosomal RNA (rRNAs) and is also important for ribosome assembly, interacting with small nucleolar RNAs (snoRNAs) [12, 13]. It is a ubiquitous protein, although it is preferentially expressed in tissues with high cellular proliferation (including the testis) and is necessary for viability, as the FBL knockout mouse is embryonic lethal [13].

Following nuclear events, RNA binding proteins are next responsible for exporting mRNAs into the cytoplasm. One such export protein, REFBP1 (RNA and export factor-binding protein 1), was identified in our screen. It too is a widely expressed Class I gene. While little is known about how specifically this protein works in mammalian cells, and in what tissues it is 
even expressed, it provides an interesting potential regulatory step in SSCs because of its functional participation with general mRNA export machinery in murine cell lines [29, 30].

Once mRNAs are in the germ cell cytoplasm, translation is highly regulated. Unsurprisingly then, the second largest functional class we investigated comprised 6 genes involved in translational control. Two of these genes, Hnrpa2b1 (which was also mentioned earlier as a splicing regulator) and Pabpc1 (poly(A) binding protein, cytoplasmic 1)(Class I), encode proteins which are positive regulators of translation and are ubiquitous, though PABPC1 is more abundant in the testis than other tissues [15, 22, 216, 217]. PABPC1 may hold special interest in the germline, as the Xenopus homologue interacts pan-germ cell marker DAZL, and further data suggests its physical interaction with YBX1, also found on this list [2, 23, 50].

In contrast to these translation promoting proteins, NCL (nucleolin) is a negative regulator of translation [20]. This is a multi-functional protein that is expressed by spermatogonia but decreases in expression during spermatogenesis [218]. In Drosophila, the NCL homologue is necessary for germ cell function, though whether or not that is related to aberrant regulation of translation is not clear [219]. It is noteworthy that NCL, like PABPC1, can function in concert with YBX1, further building the case for YBX1 as a central signal mediator of RNA regulation in the germline [38].

The final three genes on the list, also translational regulators, are DAZL (deleted in azoospermia-like), DDX4 (DEAD (Asp-Glu-Ala-Asp) box polypeptide 4) and YBX1. As previously discussed, DAZL and DDX4 (both Class I) are known germ cell markers required for spermatogenesis $[156,162,220]$. DAZL is suggested to positively regulate the translation of the mRNA it binds, including DDX4 mRNA. DDX4 is a part of chromatoid bodies where RNA can be stored; there the transcripts DDX4 binds can be regulated by its acetylation [3, 6, 7]. 
YBX1 became the focus for our work because its expression was restricted to spermatogonia located on the basement membrane of seminiferous tubules in the testis (Class III). We further hypothesized that YBX1 activity was under GDNF-mediated regulation. YBX1 is a pleiotropic protein involved in numerous DNA and RNA regulatory functions. In fact, YBX1 interacts with several other RNA regulatory proteins identified in our microarray analyses. For instance, YBX1 can work in concert with NCL to stabilize mRNA [38]. Additionally, YBX1 has been shown to bind independent sequences from, but still work together with PABPC1 in controlling translation [24, 46, 50, 52, 221]. YBX1 also has splicing related defects that are synergistically decreased when co-depleted along with EWSR1 [11]. This suggests that YBX1 works with other SSC-associated RNA binding proteins to regulate RNA in a variety of ways in the male germline. However, the specific mechanisms of YBX1 regulation and function in spermatogonia were not known and this was the focus of our studies.

GDNF is critical to SSC maintenance and self-renewal [66, 87, 88], but the mechanisms that regulate GDNF signaling are incompletely characterized. Considering the potentially broad role for YBX1 in many steps of RNA regulation, we hypothesized that it may be a regulator of GDNF signaling in SSCs. We show that phosphorylation of YBX1 is dependent on GDNF signaling through the PI3K/AKT pathway. This is a significant result, as GDNF signaling is only initiated in those germ cells containing its receptor GFR $\alpha 1$ and co-receptor RET [89]. The only cells expressing this receptor complex in the testis are undifferentiated germ cells, including SSCs [65]. This means that in the most undifferentiated germ cells, GDNF signaling regulates YBX1 is phosphorylation and therefore possibly its function. Interestingly, YBX1 is restricted in expression to undifferentiated germ cells through spermatocytes, meaning that there are differentiating germ cells which are expressing YBX1 but are not capable of responding to 
GDNF because they lack that receptor. In these cells lacking GDNF signaling, YBX1 would presumably not be phosphorylated. We hypothesize a stepwise progression then of GDNF/YBX1 activity. First, YBX1 is phosphorylated in stem and progenitor spermatogonia. Then, GDNF signaling is lost during differentiation, and YBX1 is still present, but not phosphorylated. Then, at or soon after meiosis I, the expression of YBX is lost as well. The stepwise progression of 1) presence of phosho-YBX1, 2) presence of YBX1 without phosphorylation and 3) absence of any YBX1 through germline development allows multiple regulatory mechanisms for controlling translation of mRNAs involved in spermatogenic lineage development. Loss of YBX1 phosphorylation, followed by total loss of YBX1 expression coordinates with hallmarks of germ cell differentiation: SSC commitment to differentiate and then germ cell entry into meiosis respectively.

We show that YBX1 does associate with multiple mRNA species in SSCs. We have not shown that YBX1 is directly binding the mRNA, simply that they are in complex together. YBX1 contains conserved RNA binding domains, and its nucleic acid binding properties are well documented, so we hypothesize a direct YBX1/mRNA interaction [37, 39, 41, 42, 45-48, 51, $180,190,222]$. Whether other molecules play a role in the interaction is not known, but a complex of YBX1/mRNA interacting proteins does offer a potential mechanism for selective binding to specific mRNAs.

We show that YBX1 interaction with mRNA can be mediated by GDNF and bFGF signaling. In steady state mouse SSC cultures (+GDNF/+bFGF), presumably where the balance favors SSC self-renewal over differentiation, there are certain transcripts bound by YBX1. Those transcripts that associate with YBX1 are highly translated, whereas YBX1-free mRNAs are poorly expressed at the protein level. However, when GDNF is removed (-GDNF/+bFGF) 
YBX1 is not phosphorylated and all tested mRNAs are bound, the result is an increase in translation. This suggests that YBX1 specifically binds mRNA to stimulate its efficiency of protein synthesis. What is unusual about this observation is that under self-renewal conditions (+GDNF/+bFGF) YBX1 does not bind and does not promote the translation of, genes specifically associated with SSC function such as PLZF. Conversely, it does promote translation of the general germ cell marker DAZL, but this appears to be a bFGF regulated process (compare +GDNF/+bFGF and -GDNF/+bFGF lanes to +GDNF/-bFGF and -GDNF/-bFGF lanes in Fig. 21A).

This is a counter-intuitive result, but may be consistent with previously published data. We would have hypothesized that if YBX1 is regulated by GDNF and GDNF is required for maintenance of SSCs, then YBX1 would promote the translation of SSC-specific proteins (like PLZF), while more widely expressed germ cell genes (like DAZL) would be independent of GDNF signaling mechanisms. The DAZL results were consistent with this hypothesis, but not the PLZF results. Previous studies by Oatley et al [124] provided valuable insights by demonstrating that SSC activity actually increases in the short-term after GDNF withdrawal, however PLZF mRNA [90] levels did not change during this interval. We show here that the same treatment causes an increase in PLZF protein. Based on our data, we speculate that YBX1 mediates a rapid post-transcriptional response (increased PLZF protein levels) to loss of GDNF signaling that results in a temporary increase in SSC activity. Future studies are needed to determine whether YBX1 is necessary for normal SSC function.

A number of factors suggest a critical role for YBX1 in SSC regulation. First, the phosphorylation status of YBX1 is regulated by GDNF, which is necessary for SSC maintenance. Second, YBX1 is expressed in undifferentiated cell types in the spermatogenic 


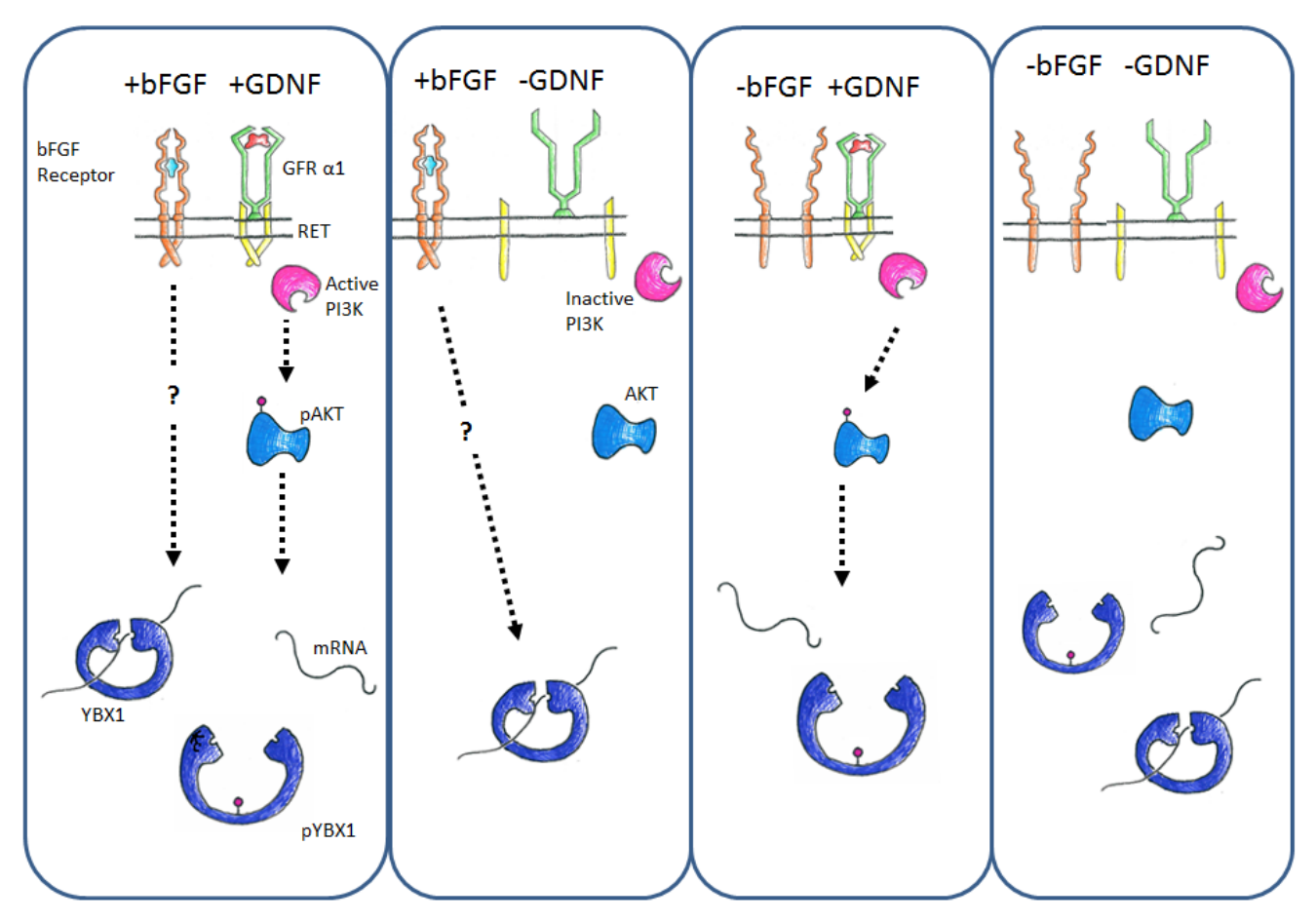

Figure 22: Model of GDNF/bFGF action on YBX1 in SSCs. SSCs grown in the presence of bFGF and GDNF (far left) have competing signals. GDNF signals through its receptor to activate PI3K, which activates AKT and ultimately phosphorylates YBX1, disrupting its ability to interact with mRNA. In this model, a subset of total YBX1 under these conditions is left unphosphorylated due to an unknown bFGF activated antagonist to YBX1 phosphorylation, allowing it to associate specifically with some RNA species, promoting their translation. Unassociated mRNAs are poorly translated. Upon GDNF withdrawal (left center), YBX1 is no longer phosphorylated and the whole population of YBX1 is available for bFGF directed mRNA binding. It binds then with less specificity, but it still promotes translation of bound transcripts. Conversely, when bFGF is removed in the presence of GDNF (right center), the entire population of YBX1 is phosphorylated, causing it to be unable to bind any mRNA species. When both growth factors are removed (far right), YBX1 lacks the GDNF activated phosphorylation but bFGF still promotes binding mRNA inverse of what is bound in the presence of both factors.

lineage (current study) and in other tissues [186, 187]. Third, YBX1 shows distinct binding patterns for genes necessary for spermatogenesis, including DAZL, DDX4 and PLZF, and it modulates the translation of these essential genes. We predict therefore that a loss of GDNF 
signaling promotes germ cell differentiation, which is mediated by changes in YBX1/mRNA interactions that impact translation of critical proteins.

Further conclusions can be drawn from these molecular interaction experiments. First, YBX1 is a multi-functional RNA/DNA binding protein, but in mouse SSCs it is binding mRNA. We did not evaluate YBX1 binding to DNA in mouse spermatogonia in this study. Second, we show that YBX1 interaction with mRNA increases levels of the encoded protein, suggesting a role in translational regulation. Finally, we show that YBX1 binds with specificity, which changes under different growth factor conditions.

A number of possibilities exist for how YBX1 binds with specificity to certain mRNAs and not others. Briefly, SSCs grown in the presence of GDNF and absence of bFGF exhibit high levels of phosphorylated YBX1 that correlates with no YBX1/mRNA binding. However, in the presence of bFGF as well, YBX1 interacts specifically with certain transcripts. In the absence of GDNF, YBX1 interacts with every transcript tested. This tells us that the mechanism of YBX1 binding mRNA with specificity comes from the balance of bFGF and GDNF signaling. Basic FGF appears then to be modulating the YBX1 response to GDNF.

The model we propose for YBX1/mRNA interaction is depicted in Figure 22. In self renewing SSCs, there is a balance between phosphorylated and unphosphorylated YBX1. In this scenario, these two populations act distinctly, and phosphorylated YBX1 does not interact with mRNA, while the phosphate-free protein does. Here, bFGF antagonizes, to some extent and by some unknown mechanism, the phosphorylation of YBX1 initiated by GDNF (Figure 22 left panel). When GDNF is withdrawn, all YBX1 is free to bind mRNA and it does so without preference (Figure 22 left center panel). When bFGF is withdrawn, all YBX1 is phosphorylated and no mRNA is bound (Figure 22 right center panel). When both factors are missing, YBX1 
binds mRNA to promote its translation (Figure 22 right panel). The transcripts it associates with inverse of those it binds when both growth factors are present. YBX1 selectivity of mRNA association is therefore not growth factor dependent, but the identity of the YBX1-bound population is growth factor dependent. When transitioned from normal conditions (+GDNF/+bFGF) to no growth factor input conditions (-bFGF/-GDNF), YBX1 switches from binding and promoting translation of general germ cell transcripts to spermatogonia-specific transcripts. In short term GDNF withdrawal, SSC self-renewal has been reported to increase [124], so when YBX1 is not being modulated by bFGF signaling, it may be acting as the signal which interprets GDNF absence in a time of brief SSC expansion. Further functional studies are necessary to determine how the specific relationship between YBX1 and GDNF affect SSC activity.

In this model, the self-renewing SSC has both signals and some sub-population of total YBX1 is unphosphorylated. Phosphorylated YBX1 is the limiting reagent, and so cannot bind all mRNA, and so binds certain transcripts with higher affinity to promote their translation. This model requires a downstream actor from bFGF signaling that de-phosphorylates YBX1 or prevents its total phosphorylation. This model would require a change in total phospo-YBX1 levels in differing growth factor conditions. We do not observe dramatic change of YBX1 phosphorylation relative to total YBX1 when comparing SSCs treated with GDNF and those treated with a combination of GDNF and bFGF (Figure 17). Nevertheless, subtle changes could be possible that produce dramatic differences in mRNA regulatory activities of YBX1.

We recognize the possibility of other plausible modes of YBX1/mRNA interaction. Generally, we would classify other models as requiring phosphorylation status of YBX1 to alter its protein binding partners resulting in altered mRNA affinity depending on the constituents of 
the RNA binding complex. Further studies defining protein-protein interactions of YBX1 in spermatogonia would elucidate the validity of this model.

Regardless of which of these models, or some yet uncharacterized mechanism of action, is real, it is clear that more work is necessary to dissect the roles of bFGF and GDNF signaling, and potentially other cellular events, in YBX1 mediated translational control in SSCs. Identifying mechanisms of SSC function are important for basic stem cell and spermatogenic biology but may also prove to have clinical implications. Because YBX1 is regulating the translation of genes that are known to be important for spermatogenesis (such as DAZL and PLZF), we predict that this protein is critical to normal SSC function. While we cannot discount the possibility that YBX1 is redundant in function, there is significance that another Y-box protein, MSY2, is only expressed in later spermatogenic cells and is necessary for spermatogenesis because of its function in translational regulation [210, 223, 224]. It occurs to us that YBX1 and MSY2 may be performing similar functions in different cells. Therefore, as MSY2 is critical for differentiating germ cells, so too may YBX1 be critical for undifferentiated germ cells. Future studies designed to reduce endogenous YBX1 levels in mouse SSCs before transplanting them into infertile recipient testis would elucidate the functional necessity of YBX1 in the male germline.

We have characterized the expression of 14 regulatory proteins in the testis, many of which have not been described in the male germline. There are countless studies yet to be undertaken with these genes with clinical and therapeutic implications. Further, if YBX1 proves to have an essential role in spermatogenesis, then there are multiple steps of regulation in the GDNF signaling to YBX1 pathway that could be disrupted to negatively impact male fertility. Any mutation that alters the phosphorylation site on YBX1 would clearly disrupt the mRNA 
regulatory balance, as its phosphorylation directs its molecular interactions. Additionally, if in fact YBX1 does have other binding partners in this regulatory scheme, any mutation that disrupts their interaction would be deleterious to the critically timed translation of germ cell specific genes. While much is yet to be discovered about how YBX1 functions in SSCs, it remains an attractive target for study of SSC biology because of its potential to elucidate SSC biology, spermatogenesis and male infertility. 


\section{BIBLIOGRAPHY}

1. Fox, M., J. Urano, and R.A. Reijo Pera, Identification and characterization of RNA sequences to which human PUMILIO-2 (PUM2) and deleted in Azoospermia-like (DAZL) bind. Genomics, 2005. 85(1): p. 92-105.

2. $\quad$ Collier, B., et al., The DAZL family proteins are PABP-binding proteins that regulate translation in germ cells. EMBO J, 2005. 24(14): p. 2656-66.

3. Reynolds, N., et al., Dazl binds in vivo to specific transcripts and can regulate the premeiotic translation of Mvh in germ cells. Hum Mol Genet, 2005. 14(24): p. 3899-909.

4. Jiao, X., P. Trifillis, and M. Kiledjian, Identification of target messenger RNA substrates for the murine deleted in azoospermia-like RNA-binding protein. Biol Reprod, 2002. 66(2): p. 475-85.

5. Kotaja, N. and P. Sassone-Corsi, The chromatoid body: a germ-cell-specific RNAprocessing centre. Nat Rev Mol Cell Biol, 2007. 8(1): p. 85-90.

6. Nagamori, I. and P. Sassone-Corsi, The chromatoid body of male germ cells: epigenetic control and miRNA pathway. Cell Cycle, 2008. 7(22): p. 3503-8.

7. Toyooka, Y., et al., Expression and intracellular localization of mouse Vasa-homologue protein during germ cell development. Mech Dev, 2000. 93(1-2): p. 139-49.

8. Parvinen, M., The chromatoid body in spermatogenesis. International Journal of Andrology, 2005. 28(4): p. 189-201.

9. Mayeda, A., D.M. Helfman, and A.R. Krainer, Modulation of exon skipping and inclusion by heterogeneous nuclear ribonucleoprotein A1 and pre-mRNA splicing factor SF2/ASF. Mol Cell Biol, 1993. 13(5): p. 2993-3001.

10. Chansky, H.A., et al., Oncogenic TLS/ERG and EWS/Fli-1 fusion proteins inhibit RNA splicing mediated by YB-1 protein. Cancer Res, 2001. 61(9): p. 3586-90.

11. Dutertre, M., et al., Cotranscriptional exon skipping in the genotoxic stress response. Nat Struct Mol Biol, 2010. 17(11): p. 1358-66.

12. Fatica, A., et al., Fibrillarin binds directly and specifically to U16 box C/D snoRNA. RNA, 2000. 6(1): p. 88-95.

13. Newton, K., et al., Fibrillarin is essential for early development and required for accumulation of an intron-encoded small nucleolar RNA in the mouse. Mol Cell Biol, 2003. 23(23): p. 8519-27.

14. Tollervey, D., et al., Temperature-sensitive mutations demonstrate roles for yeast fibrillarin in pre-rRNA processing, pre-rRNA methylation, and ribosome assembly. Cell, 1993. 72(3): p. 443-57. 
15. Kozu, T., B. Henrich, and K.P. Schafer, Structure and expression of the gene (HNRPA2B1) encoding the human hnRNP protein A2/B1. Genomics, 1995. 25(2): p. 36571.

16. Hou, V.C., et al., Decrease in hnRNP A/B expression during erythropoiesis mediates a pre-mRNA splicing switch. EMBO J, 2002. 21(22): p. 6195-204.

17. Shyu, A.B. and M.F. Wilkinson, The double lives of shuttling mRNA binding proteins. Cell, 2000. 102(2): p. 135-8.

18. Kufel, J., et al., Lsm Proteins are required for normal processing and stability of ribosomal RNAs. J Biol Chem, 2003. 278(4): p. 2147-56.

19. Ingelfinger, D., et al., The human LSm1-7 proteins colocalize with the mRNA-degrading enzymes Dcp1/2 and Xrnl in distinct cytoplasmic foci. RNA, 2002. 8(12): p. 1489-501.

20. Takagi, M., et al., Regulation of p53 translation and induction after DNA damage by ribosomal protein L26 and nucleolin. Cell, 2005. 123(1): p. 49-63.

21. Cheng, S. and D.R. Gallie, eIF4G, eIFiso4G, and eIF4B bind the poly(A)-binding protein through overlapping sites within the RNA recognition motif domains. J Biol Chem, 2007. 282(35): p. 25247-58.

22. Gu, W., et al., Poly (A) binding protein is bound to both stored and polysomal mRNAs in the mammalian testis. Mol Reprod Dev, 1995. 40(3): p. 273-85.

23. Paynton, B.V., RNA-binding proteins in mouse oocytes and embryos: expression of genes encoding Y box, DEAD box RNA helicase, and polyA binding proteins. Dev Genet, 1998. 23(4): p. 285-98.

24. Skabkina, O.V., et al., Poly(A)-binding protein positively affects YB-1 mRNA translation through specific interaction with YB-1 mRNA. J Biol Chem, 2003. 278(20): p. 18191-8.

25. Tenenbaum, S.A., et al., Identifying mRNA subsets in messenger ribonucleoprotein complexes by using cDNA arrays. Proc Natl Acad Sci U S A, 2000. 97(26): p. 14085-90.

26. Elliott, D.J., The role of potential splicing factors including RBMY, RBMX, hnRNPG-T and STAR proteins in spermatogenesis. Int J Androl, 2004. 27(6): p. 328-34.

27. Elliott, D.J., et al., A mammalian germ cell-specific RNA-binding protein interacts with ubiquitously expressed proteins involved in splice site selection. Proc Natl Acad Sci U S A, 2000. 97(11): p. 5717-22.

28. Elliott, D.J., et al., Dynamic changes in the subnuclear organisation of pre-mRNA splicing proteins and RBM during human germ cell development. J Cell Sci, 1998. 111 ( Pt 9): p. 1255-65.

29. Perez-Alvarado, G.C., et al., Structure of the nuclear factor ALY: insights into posttranscriptional regulatory and mRNA nuclear export processes. Biochemistry, 2003. 42(24): p. 7348-57.

30. Zhou, Z., et al., The protein Aly links pre-messenger-RNA splicing to nuclear export in metazoans. Nature, 2000. 407(6802): p. 401-405.

31. Zahler, A.M., et al., SR proteins: a conserved family of pre-mRNA splicing factors. Genes Dev, 1992. 6(5): p. 837-47.

32. Graveley, B.R., Sorting out the complexity of SR protein functions. RNA, 2000. 6(9): p. 1197-211.

33. Fu, X.D., et al., General splicing factors SF2 and SC35 have equivalent activities in vitro, and both affect alternative 5' and 3' splice site selection. Proc Natl Acad Sci U S A, 1992. 89(23): p. 11224-8. 
34. Bermingham, J.R., Jr., et al., Chromosomal localization of mouse and human genes encoding the splicing factors ASF/SF2 (SFRS1) and SC-35 (SFRS2). Genomics, 1995. 29(1): p. 70-9.

35. Wang, H.Y., et al., SC35 plays a role in T cell development and alternative splicing of CD45. Mol Cell, 2001. 7(2): p. 331-42.

36. Ashizuka, M., et al., Novel translational control through an iron-responsive element by interaction of multifunctional protein YB-1 and IRP2. Mol Cell Biol, 2002. 22(18): p. 6375-83.

37. Bouvet, P., K. Matsumoto, and A.P. Wolffe, Sequence-specific RNA recognition by the Xenopus Y-box proteins. An essential role for the cold shock domain. J Biol Chem, 1995. 270(47): p. 28297-303.

38. Chen, C.Y., et al., Nucleolin and YB-1 are required for JNK-mediated interleukin-2 mRNA stabilization during T-cell activation. Genes Dev, 2000. 14(10): p. 1236-48.

39. Cobbold, L.C., et al., Upregulated c-myc expression in multiple myeloma by internal ribosome entry results from increased interactions with and expression of PTB-1 and YB1. Oncogene, 2010. 29(19): p. 2884-91.

40. Evdokimova, V.M., et al., The major core protein of messenger ribonucleoprotein particles (p50) promotes initiation of protein biosynthesis in vitro. J Biol Chem, 1998. 273(6): p. 3574-81.

41. Evdokimova, V., L.P. Ovchinnikov, and P.H. Sorensen, Y-box binding protein 1: providing a new angle on translational regulation. Cell Cycle, 2006. 5(11): p. 1143-7.

42. Evdokimova, V., et al., Akt-mediated YB-1 phosphorylation activates translation of silent mRNA species. Mol Cell Biol, 2006. 26(1): p. 277-92.

43. Evdokimova, V., et al., Translational activation of snail1 and other developmentally regulated transcription factors by $Y B-1$ promotes an epithelial-mesenchymal transition. Cancer Cell, 2009. 15(5): p. 402-15.

44. Evdokimova, V., et al., Reduced proliferation and enhanced migration: two sides of the same coin? Molecular mechanisms of metastatic progression by YB-1. Cell Cycle, 2009. 8(18): p. 2901-6.

45. Fukuda, T., et al., Characterization of the 5'-untranslated region of YB-1 mRNA and autoregulation of translation by YB-1 protein. Nucleic Acids Res, 2004. 32(2): p. 611-22.

46. Lyabin, D.N., et al., Interplay between Y-box-binding protein 1 (YB-1) and poly(A) binding protein $(\mathrm{PABP})$ in specific regulation of YB-1 mRNA translation. RNA Biol, 2011. 8(5).

47. Matsumoto, K. and A.P. Wolffe, Gene regulation by Y-box proteins: coupling control of transcription and translation. Trends Cell Biol, 1998. 8(8): p. 318-23.

48. Nekrasov, M.P., et al., The mRNA-binding protein $Y B-1$ ( $p 50)$ prevents association of the eukaryotic initiation factor eIF4G with mRNA and inhibits protein synthesis at the initiation stage. J Biol Chem, 2003. 278(16): p. 13936-43.

49. Raffetseder, U., et al., Splicing factor SRp30c interaction with Y-box protein-1 confers nuclear YB-1 shuttling and alternative splice site selection. J Biol Chem, 2003. 278(20): p. 18241-8.

50. Skabkina, O.V., et al., YB-1 autoregulates translation of its own mRNA at or prior to the step of 40S ribosomal subunit joining. Mol Cell Biol, 2005. 25(8): p. 3317-23.

51. Stickeler, E., et al., The RNA binding protein YB-1 binds A/C-rich exon enhancers and stimulates splicing of the CD44 alternative exon v4. EMBO J, 2001. 20(14): p. 3821-30. 
52. Svitkin, Y.V., et al., General RNA-binding proteins have a function in poly(A)-binding protein-dependent translation. EMBO J, 2009. 28(1): p. 58-68.

53. Tanaka, T., et al., YB-1 binds to GluR2 mRNA and CaM1 mRNA in the brain and regulates their translational levels in an activity-dependent manner. Cell Mol Neurobiol, 2010. 30(7): p. 1089-100.

54. Carrell, D.T., C. De Jonge, and D.J. Lamb, The genetics of male infertility: a field of study whose time is now. Arch Androl, 2006. 52(4): p. 269-74.

55. Stewart, A.F. and E.D. Kim, Fertility Concerns for the Aging Male. Urology, 2011. 78(3): p. 496-499.

56. Holoch, P. and M. Wald, Current options for preservation of fertility in the male. Fertil Steril, 2011. 96(2): p. 286-290.

57. Singh, K. and D. Jaiswal, Human Male infertility. Reproductive Sciences, 2011. 18(5): p. 418-425.

58. O'Flynn O'Brien, K.L., A.C. Varghese, and A. Agarwal, The genetic causes of male factor infertility: A review. Fertil Steril, 2010. 93(1): p. 1-12.

59. Orwig, K.E. and S. Schlatt, Cryopreservation and transplantation of spermatogonia and testicular tissue for preservation of male fertility. J Natl Cancer Inst Monogr, 2005. 34(34): p. 51-6.

60. de Rooij, D.G., Stem cells in the testis. Int J Exp Pathol, 1998. 79(2): p. 67-80.

61. McLaren, A., Primordial germ cells in the mouse. Dev Biol, 2003. 262(1): p. 1-15.

62. Kluin, P.M. and D.G. Derooij, A Comparison between the Morphology and Cell-Kinetics of Gonocytes and Adult Type Undifferentiated Spermatogonia in the Mouse. International Journal of Andrology, 1981. 4(4): p. 475-493.

63. McCarrey, J.R., Development of the germ cell, in Cell and Molecular Biology of the Testis, C. Desjardins and L.L. Ewing, Editors. 1993, Oxford University Press: New York. p. 58-89.

64. Yoshida, S., et al., The first round of mouse spermatogenesis is a distinctive program that lacks the self-renewing spermatogonia stage. Development, 2006. 133(8): p. 1495-1505.

65. Phillips, B.T., K. Gassei, and K.E. Orwig, Spermatogonial stem cell regulation and spermatogenesis. Philos Trans R Soc Lond B Biol Sci, 2010. 365(1546): p. 1663-78.

66. Meng, X., et al., Regulation of cell fate decision of undifferentiated spermatogonia by GDNF. Science, 2000. 287(5457): p. 1489-93.

67. Orwig, K.E., et al., Genes involved in post-transcriptional regulation are overrepresented in stem/progenitor spermatogonia of cryptorchid mouse testes. Stem Cells, 2008. 26(4): p. 927-38.

68. $\quad$ Oakberg, E.F., Spermatogonial stem-cell renewal in the mouse. Anat.Rec., 1971. 169(3): p. 515-531.

69. Yoshida, S., Y. Nabeshima, and T. Nakagawa, Stem cell heterogeneity: actual and potential stem cell compartments in mouse spermatogenesis. Ann N Y Acad Sci, 2007. 1120: p. 47-58.

70. Morimoto, H., et al., Phenotypic plasticity of mouse spermatogonial stem cells. PLoS One, 2009. 4(11): p. e7909.

71. Olive, V. and F. Cuzin, The spermatogonial stem cell: from basic knowledge to transgenic technology. The International Journal of Biochemistry \&amp; Cell Biology, 2005. 37(2): p. 246-250. 
72. Tegelenbosch, R.A. and D.G. de Rooij, A quantitative study of spermatogonial multiplication and stem cell renewal in the C3H/101 F1 hybrid mouse. Mutat Res, 1993. 290(2): p. 193-200.

73. Braun, R.E., et al., Genetically haploid spermatids are phenotypically diploid. Nature, 1989. 337(6205): p. 373-6.

74. Ventela, S., J. Toppari, and M. Parvinen, Intercellular organelle traffic through cytoplasmic bridges in early spermatids of the rat: mechanisms of haploid gene product sharing. Mol Biol Cell, 2003. 14(7): p. 2768-80.

75. Oakberg, E.F., A description of spermiogenesis in the mouse and its use in analysis of the cycle of the seminiferous epithelium and germ cell renewal. Am J Anat, 1956. 99(3): p. 391-413.

76. Oakberg, E.F., Duration of spermatogenesis in the mouse and timing of stages of the cycle of the seminiferous epithelium. Am J Anat, 1956. 99(3): p. 507-16.

77. Ogawa, T., M. Ohmura, and K. Ohbo, The niche for spermatogonial stem cells in the mammalian testis. Int J Hematol, 2005. 82(5): p. 381-8.

78. Dadoune, J.P., New insights into male gametogenesis: what about the spermatogonial stem cell niche? Folia Histochem Cytobiol, 2007. 45(3): p. 141-7.

79. Griswold, M.D., The central role of Sertoli cells in spermatogenesis. Seminars in Cell \&amp; Developmental Biology, 1998. 9(4): p. 411-416.

80. Chen, C., et al., ERM is required for transcriptional control of the spermatogonial stem cell niche. Nature, 2005. 436(7053): p. 1030-4.

81. Gow, A., et al., CNS myelin and sertoli cell tight junction strands are absent in Osp/claudin-11 null mice. Cell, 1999. 99(6): p. 649-59.

82. Holdcraft, R.W. and R.E. Braun, Androgen receptor function is required in Sertoli cells for the terminal differentiation of haploid spermatids. Development, 2004. 131(2): p. 459-67.

83. Shinohara, T., et al., Restoration of spermatogenesis in infertile mice by Sertoli cell transplantation. Biol Reprod, 2003. 68(3): p. 1064-71.

84. Oatley, J.M., et al., Colony stimulating factor 1 is an extrinsic stimulator of mouse spermatogonial stem cell self-renewal. Development, 2009. 136(7): p. 1191-1199.

85. Yoshida, S., M. Sukeno, and Y. Nabeshima, A vasculature-associated niche for undifferentiated spermatogonia in the mouse testis. Science, 2007. 317(5845): p. 1722-6.

86. Tadokoro, Y., et al., Homeostatic regulation of germinal stem cell proliferation by the GDNF/FSH pathway. Mech Dev, 2002. 113(1): p. 29-39.

87. Kanatsu-Shinohara, M., et al., Long-term proliferation in culture and germline transmission of mouse male germline stem cells. Biol Reprod, 2003. 69(2): p. 612-6.

88. Kubota, H., M.R. Avarbock, and R.L. Brinster, Culture conditions and single growth factors affect fate determination of mouse spermatogonial stem cells. Biol Reprod, 2004. 71(3): p. 722-31.

89. Sariola, H. and M. Saarma, Novel functions and signalling pathways for GDNF. J Cell Sci, 2003. 116(Pt 19): p. 3855-62.

90. Oatley, J.M., M.R. Avarbock, and R.L. Brinster, Glial cell line-derived neurotrophic factor regulation of genes essential for self-renewal of mouse spermatogonial stem cells is dependent on Src family kinase signaling. J Biol Chem, 2007. 282(35): p. 25842-51.

91. Braydich-Stolle, L., et al., Role of Src family kinases and N-Myc in spermatogonial stem cell proliferation. Dev Biol, 2007. 304(1): p. 34-45. 
92. Lee, J., et al., Akt mediates self-renewal division of mouse spermatogonial stem cells. Development, 2007. 134(10): p. 1853-9.

93. Brinster, R.L. and J.W. Zimmermann, Spermatogenesis following male germ-cell transplantation. Proc Natl Acad Sci U S A, 1994. 91(24): p. 11298-302.

94. Shinohara, T., et al., Germ line stem cell competition in postnatal mouse testes. Biol Reprod, 2002. 66(5): p. 1491-7.

95. Ogawa, T., et al., Transplantation of male germ line stem cells restores fertility in infertile mice. Nat Med, 2000. 6(1): p. 29-34.

96. Zhang, X., K.T. Ebata, and M.C. Nagano, Genetic analysis of the clonal origin of regenerating mouse spermatogenesis following transplantation. Biol Reprod, 2003. 69(6): p. 1872-8.

97. Kanatsu-Shinohara, M., et al., Clonal origin of germ cell colonies after spermatogonial transplantation in mice. Biol Reprod, 2006. 75(1): p. 68-74.

98. Ogawa, T., et al., Expansion of murine spermatogonial stem cells through serial transplantation. Biology of Reproduction, 2003. 68(1): p. 316-322.

99. Shinohara, T., et al., Remodeling of the postnatal mouse testis is accompanied by dramatic changes in stem cell number and niche accessibility. Proceedings Of The National Academy Of Sciences Of The United States Of America, 2001. 98(11): p. 61866191.

100. Shinohara, T., M.R. Avarbock, and R.L. Brinster, á1- and à6-integrin are surface markers on mouse spermatogonial stem cells. Proc.Natl.Acad.Sci.U.S.A., 1999. 96(10): p. 5504-5509.

101. Shinohara, T., et al., Spermatogonial stem cell enrichment by multiparameter selection of mouse testis cells. Proc Natl Acad Sci U S A, 2000. 97(15): p. 8346-51.

102. Kubota, H., M.R. Avarbock, and R.L. Brinster, Spermatogonial stem cells share some, but not all, phenotypic and functional characteristics with other stem cells. Proc.Natl.Acad.Sci.U.S.A., 2003. 100(11): p. 6487-6492.

103. Kanatsu-Shinohara, M., S. Toyokuni, and T. Shinohara, CD9 is a surface marker on mouse and rat male germline stem cells. Biology of Reproduction, 2004. 70(1): p. 70-75.

104. Buageaw, A., et al., GDNF family receptor alpha1 phenotype of spermatogonial stem cells in immature mouse testes. Biol Reprod, 2005. 73(5): p. 1011-6.

105. Fujita, K., et al., Transplantation of spermatogonial stem cells isolated from leukemic mice restores fertility without inducing leukemia. Journal of Clinical Investigation, 2005. 115(7): p. 1855-1861.

106. Hofmann, M.C., L. Braydich-Stolle, and M. Dym, Isolation of male germ-line stem cells; influence of GDNF. Dev Biol, 2005. 279(1): p. 114-24.

107. Tokuda, M., et al., CDH1 Is a Specific Marker for Undifferentiated Spermatogonia in Mouse Testes. Biology of Reproduction, 2007. 76(1): p. 130-141.

108. Kubota, H., M.R. Avarbock, and R.L. Brinster, Growth factors essential for self-renewal and expansion of mouse spermatogonial stem cells. Proceedings of the National Academy of Sciences of the United States of America, 2004. 101(47): p. 16489-16494.

109. Shinohara, T., M.R. Avarbock, and R.L. Brinster, Functional analysis of spermatogonial stem cells in Steel and cryptorchid infertile mouse models. Dev Biol, 2000. 220(2): p. 401-11.

110. Oatley, J.M. and R.L. Brinster, Spermatogonial stem cells. Methods Enzymol, 2006. 419: p. 259-82. 
111. Nagano, M.C., Homing efficiency and proliferation kinetics of male germ line stem cells following transplantation in mice. Biol Reprod, 2003. 69(2): p. 701-7.

112. Kanatsu-Shinohara, M., et al., Long-term culture of mouse male germline stem cells under serum-or feeder-free conditions. Biol Reprod, 2005. 72(4): p. 985-91.

113. Ryu, B.-Y., et al., Conservation of spermatogonial stem cell self-renewal signaling between mouse and rat. Proceedings of the National Academy of Sciences of the United States of America, 2005. 102(40): p. 14302-14307.

114. Filipponi, D., et al., Repression of kit expression by Plzf in germ cells. Mol Cell Biol, 2007. 27(19): p. 6770-81.

115. Costoya, J.A., et al., Essential role of Plzf in maintenance of spermatogonial stem cells. Nat Genet, 2004. 36(6): p. 653-9.

116. Buaas, F.W., et al., Plzf is required in adult male germ cells for stem cell self-renewal. Nature Genetics, 2004. 36(6): p. 647-652.

117. Yoshimizu, T., et al., Germline-specific expression of the Oct-4/green fluorescent protein (GFP) transgene in mice. Dev.Growth Differ., 1999. 41(6): p. 675-684.

118. Pesce, M., et al., Differential expression of the Oct-4 transcription factor during mouse germ cell differentiation. Mech Dev, 1998. 71(1-2): p. 89-98.

119. Ballow, D.J., et al., Sohlh2 is a germ cell-specific bHLH transcription factor. Gene Expr Patterns, 2006. 6(8): p. 1014-8.

120. Hao, J., et al., Sohlh2 knockout mice are male-sterile because of degeneration of differentiating type A spermatogonia. Stem Cells, 2008. 26(6): p. 1587-97.

121. Wang, P.J., et al., An abundance of X-linked genes expressed in spermatogonia. Nat Genet, 2001. 27(4): p. 422-6.

122. Shima, J.E., et al., The murine testicular transcriptome: characterizing gene expression in the testis during the progression of spermatogenesis. Biol Reprod, 2004. 71(1): p. 31930.

123. Roy Choudhury, D., et al., Microarray-based analysis of cell-cycle gene expression during spermatogenesis in the mouse. Biol Reprod, 2010. 83(4): p. 663-75.

124. Oatley, J.M., et al., Identifying genes important for spermatogonial stem cell self-renewal and survival. Proc Natl Acad Sci U S A, 2006. 103(25): p. 9524-9.

125. Kong, J. and P. Lasko, Translational control in cellular and developmental processes. Nat Rev Genet, 2012. 13(6): p. 383-394.

126. Wilkinson, M.F. and A.-B. Shyu, Multifunctional regulatory proteins that control gene expression in both the nucleus and the cytoplasm. BioEssays, 2001. 23(9): p. 775-787.

127. Lander, E.S., et al., Initial sequencing and analysis of the human genome. Nature, 2001. 409(6822): p. 860-921.

128. Venter, J.C., et al., The Sequence of the Human Genome. Science, 2001. 291(5507): p. 1304-1351.

129. Johnson, J.M., et al., Genome-Wide Survey of Human Alternative Pre-mRNA Splicing with Exon Junction Microarrays. Science, 2003. 302(5653): p. 2141-2144.

130. Sammeth, M., S. Foissac, and R. Guigó, A General Definition and Nomenclature for Alternative Splicing Events. PLoS Comput Biol, 2008. 4(8): p. e1000147.

131. Black, D.L., MECHANISMS OF ALTERNATIVE PRE-MESSENGER RNA SPLICING. Annual Review of Biochemistry, 2003. 72(1): p. 291-336.

132. Matlin, A.J., F. Clark, and C.W.J. Smith, Understanding alternative splicing: towards a cellular code. Nat Rev Mol Cell Biol, 2005. 6(5): p. 386-398. 
133. Yeo, G., et al., Variation in alternative splicing across human tissues. Genome Biol, 2004. 5(10): p. R74.

134. Kan, Z., et al., Evolutionarily conserved and diverged alternative splicing events show different expression and functional profiles. Nucleic Acids Research. 33(17): p. 56595666.

135. Foulkes, N.S., et al., Developmental switch of CREM function during spermatogenesis: from antagonist to activator. Nature, 1992. 355(6355): p. 80-84.

136. Elliott, D.J., et al., Expression of RBM in the nuclei of human germ cells is dependent on a critical region of the $Y$ chromosome long arm. Proceedings of the National Academy of Sciences, 1997. 94(8): p. 3848-3853.

137. Mahadevaiah, S.K., et al., Mouse homologues of the human AZF candidate gene RBM are expressed in spermatogonia and spermatids, and map to a $Y$ chromosome deletion interval associated with a high incidence of sperm abnormalities. Hum Mol Genet, 1998. 7(4): p. 715-27.

138. Elliott, D.J., et al., An RBM Homologue Maps to the Mouse Y Chromosome and is Expressed in Germ Cells. Human Molecular Genetics, 1996. 5(7): p. 869-874.

139. Ma, K., et al., A Y chromosome gene family with RNA-binding protein homology: Candidates for the azoospermia factor AZF controlling human spermatogenesis. Cell, 1993. 75(7): p. 1287-1295.

140. Zeng, M., et al., Identification of target messenger RNA substrates for mouse RBMY. Molecular Human Reproduction, 2008. 14(6): p. 331-336.

141. Zeng, M., et al., Identifying mRNAs Bound by Human RBMY Protein in the Testis. Journal of Reproduction and Development, 2011. 57(1): p. 107-112.

142. Bettegowda, A. and M.F. Wilkinson, Transcription and post-transcriptional regulation of spermatogenesis. Philosophical Transactions of the Royal Society B: Biological Sciences, 2010. 365(1546): p. 1637-1651.

143. Hsu, L.C., et al., DAZAP1, an hnRNP protein, is required for normal growth and spermatogenesis in mice. RNA, 2008. 14(9): p. 1814-22.

144. Lin, Y.T. and P.H. Yen, A novel nucleocytoplasmic shuttling sequence of DAZAP1, a testis-abundant RNA-binding protein. RNA, 2006. 12(8): p. 1486-93.

145. Tsai-Morris, C.H., et al., Gonadotropin-regulated testicular RNA helicase (GRTH/Ddx25) is essential for spermatid development and completion of spermatogenesis. Proc Natl Acad Sci U S A, 2004. 101(17): p. 6373-8.

146. Sheng, Y., et al., Gonadotropin-regulated testicular RNA helicase (GRTH/Ddx25) is a transport protein involved in gene-specific mRNA export and protein translation during spermatogenesis. J Biol Chem, 2006. 281(46): p. 35048-56.

147. Iguchi, N., J.W. Tobias, and N.B. Hecht, Expression profiling reveals meiotic male germ cell $m R N A s$ that are translationally up- and down-regulated. Proceedings of the National Academy of Sciences, 2006. 103(20): p. 7712-7717.

148. Kleene, K.C., Multiple Controls over the Efficiency of Translation of the mRNAs Encoding Transition Proteins, Protamines, and the Mitochondrial Capsule Selenoprotein in Late Spermatids in Mice. Developmental Biology, 1993. 159(2): p. 720-731.

149. Stern, L., B. Gold, and N.B. Hecht, Gene expression during mammalian spermatogenesis. I. Evidence for stage-specific synthesis of polypeptides in vivo. Biol Reprod, 1983. 28(2): p. 483-496. 
150. Steger, K., Transcriptional and translational regulation of gene expression in haploid spermatids. Anat Embryol (Berl), 1999. 199(6): p. 471-87.

151. Pogany, G.C., et al., DNA and protein content of mouse sperm. Implications regarding sperm chromatin structure. Exp Cell Res, 1981. 136(1): p. 127-36.

152. Ward, W.S. and D.S. Coffey, DNA packaging and organization in mammalian spermatozoa: comparison with somatic cells. Biol Reprod, 1991. 44(4): p. 569-74.

153. Richler, C., et al., Splicing components are excluded from the transcriptionally inactive XY body in male meiotic nuclei. Mol Biol Cell, 1994. 5(12): p. 1341-52.

154. Eberhart, C.G., J.Z. Maines, and S.A. Wasserman, Meiotic cell cycle requirement for a fly homologue of human Deleted in Azoospermia. Nature, 1996. 381(6585): p. 783-5.

155. Houston, D.W. and M.L. King, A critical role for Xdazl, a germ plasm-localized RNA, in the differentiation of primordial germ cells in Xenopus. Development, 2000. 127(3): p. 447-56.

156. Ruggiu, M., et al., The mouse Dazla gene encodes a cytoplasmic protein essential for gametogenesis. Nature, 1997. 389(6646): p. 73-7.

157. Yen, P.H., Putative biological functions of the DAZ family. Int J Androl, 2004. 27(3): p. 125-9.

158. Fujiwara, Y., et al., Isolation of a DEAD-family protein gene that encodes a murine homolog of Drosophila vasa and its specific expression in germ cell lineage. Proc Natl Acad Sci U S A, 1994. 91(25): p. 12258-62.

159. Komiya, T., et al., Isolation and characterization of a novel gene of the DEAD box protein family which is specifically expressed in germ cells of Xenopus laevis. Dev Biol, 1994. 162(2): p. 354-63.

160. Roussell, D.L. and K.L. Bennett, glh-1, a germ-line putative RNA helicase from Caenorhabditis, has four zinc fingers. Proc Natl Acad Sci U S A, 1993. 90(20): p. 93004.

161. Yoon, C., K. Kawakami, and N. Hopkins, Zebrafish vasa homologue RNA is localized to the cleavage planes of 2- and 4-cell-stage embryos and is expressed in the primordial germ cells. Development, 1997. 124(16): p. 3157-65.

162. Tanaka, S.S., et al., The mouse homolog of Drosophila Vasa is required for the development of male germ cells. Genes and Development, 2000. 14(7): p. 841-853.

163. Kuramochi-Miyagawa, S., et al., Mili, a mammalian member of piwi family gene, is essential for spermatogenesis. Development, 2004. 131(4): p. 839-849.

164. Paronetto, M.P., et al., The nuclear RNA-binding protein Sam68 translocates to the cytoplasm and associates with the polysomes in mouse spermatocytes. Mol Biol Cell, 2006. 17(1): p. 14-24.

165. Unhavaithaya, Y., et al., MILI, a PIWI-interacting RNA-binding protein, is required for germ line stem cell self-renewal and appears to positively regulate translation. J Biol Chem, 2009. 284(10): p. 6507-19.

166. Suzuki, A., et al., NANOS2 interacts with the CCR4-NOT deadenylation complex and leads to suppression of specific RNAs. Proc Natl Acad Sci U S A, 2010. 107(8): p. 35949.

167. Tsuda, M., et al., Conserved role of nanos proteins in germ cell development. Science, 2003. 301(5637): p. 1239-41. 
168. Xu, M., et al., Mice Deficient for a Small Cluster of Piwi-Interacting RNAs Implicate Piwi-Interacting RNAs in Transposon Control. Biology of Reproduction, 2008. 79(1): p. 51-57.

169. Nellaker, C., et al., The genomic landscape shaped by selection on transposable elements across 18 mouse strains. Genome Biology, 2012. 13(6): p. R45.

170. Beyret, E. and H. Lin, Pinpointing the expression of piRNAs and function of the PIWI protein subfamily during spermatogenesis in the mouse. Dev Biol, 2011. 355(2): p. 21526.

171. Deng, W. and H. Lin, miwi, a murine homolog of piwi, encodes a cytoplasmic protein essential for spermatogenesis. Dev Cell, 2002. 2(6): p. 819-30.

172. Cox, D.N., et al., A novel class of evolutionarily conserved genes defined by piwi are essential for stem cell self-renewal. Genes Dev, 1998. 12(23): p. 3715-27.

173. Qiao, D., et al., Molecular characterization of hiwi, a human member of the piwi gene family whose overexpression is correlated to seminomas. Oncogene, 2002. 21(25): p. 3988-99.

174. Lee, J.H., W. Engel, and K. Nayernia, Stem cell protein Piwil2 modulates expression of murine spermatogonial stem cell expressed genes. Mol Reprod Dev, 2006. 73(2): p. 1739.

175. Ivanova, N.B., et al., A stem cell molecular signature. Science, 2002. 298(5593): p. 6014.

176. Ramalho-Santos, M., et al., "Stemness": transcriptional profiling of embryonic and adult stem cells. Science, 2002. 298(5593): p. 597-600.

177. Nishimune, Y., S. Aizawa, and T. Komatsu, Testicular germ cell differentiation in vivo. Fertil Steril, 1978. 29(1): p. 95-102.

178. Bucci, L.R. and M.L. Meistrich, Effects of busulfan on murine spermatogenesis: cytotoxicity, sterility, sperm abnormalities, and dominant lethal mutations. Mutat Res, 1987. 176(2): p. 259-68.

179. Nguyen-Chi, M. and D. Morello, RNA-binding proteins, RNA granules, and gametes: is unity strength? Reproduction, 2011. 142(6): p. 803-817.

180. Kohno, K., et al., The pleiotropic functions of the Y-box-binding protein, YB-1. BioEssays, 2003. 25(7): p. 691-8.

181. Reijo, R.A., et al., DAZ Family Proteins Exist Throughout Male Germ Cell Development and Transit from Nucleus to Cytoplasm at Meiosis in Humans and Mice. Biology of Reproduction, 2000. 63(5): p. 1490-1496.

182. Cooke, H.J., et al., A murine homologue of the human DAZ gene is autosomal and expressed only in male and female gonads. Hum Mol Genet, 1996. 5(4): p. 513-6.

183. Delbridge, M.L., et al., A human candidate spermatogenesis gene, RBM1, is conserved and amplified on the marsupial Y chromosome. Nat Genet, 1997. 15(2): p. 131-6.

184. Jarvis, S., et al., Molecular markers for the assessment of postnatal male germ cell development in the mouse. Hum Reprod, 2005. 20(1): p. 108-16.

185. Lee, J., et al., Developmental stage-specific expression of Rbm suggests its involvement in early phases of spermatogenesis. Mol Hum Reprod, 2004. 10(4): p. 259-64.

186. Habibi, G., et al., Redefining prognostic factors for breast cancer: YB-1 is a stronger predictor of relapse and disease-specific survival than estrogen receptor or HER-2 across all tumor subtypes. Breast Cancer Res, 2008. 10(5): p. R86. 
187. Fotovati, A., et al., YB-1 bridges neural stem cells and brain tumor-initiating cells via its roles in differentiation and cell growth. Cancer Res, 2011. 71(16): p. 5569-78.

188. Miwa, A., T. Higuchi, and S. Kobayashi, Expression and polysome association of YB-1 in various tissues at different stages in the lifespan of mice. Biochim Biophys Acta, 2006. 1760(11): p. 1675-81.

189. Tafuri, S.R., M. Familari, and A.P. Wolffe, A mouse Y box protein, MSY1, is associated with paternal mRNA in spermatocytes. J Biol Chem, 1993. 268(16): p. 12213-20.

190. Kloks, C.P., et al., The solution structure and DNA-binding properties of the cold-shock domain of the human Y-box protein YB-1. J Mol Biol, 2002. 316(2): p. 317-26.

191. Kudo, S., M.G. Mattei, and M. Fukuda, Characterization of the gene for $d b p A$, a family member of the nucleic-acid-binding proteins containing a cold-shock domain. Eur $\mathrm{J}$ Biochem, 1995. 231(1): p. 72-82.

192. Fan, L., et al., Nuclease sensitive element binding protein 1 gene disruption results in early embryonic lethality. J Cell Biochem, 2006. 99(1): p. 140-5.

193. Lu, Z.H., J.T. Books, and T.J. Ley, YB-1 is important for late-stage embryonic development, optimal cellular stress responses, and the prevention of premature senescence. Mol Cell Biol, 2005. 25(11): p. 4625-37.

194. Basaki, Y., et al., Akt-dependent nuclear localization of Y-box-binding protein 1 in acquisition of malignant characteristics by human ovarian cancer cells. Oncogene, 2007. 26(19): p. 2736-46.

195. Finkbeiner, M.R., et al., Profiling YB-1 target genes uncovers a new mechanism for MET receptor regulation in normal and malignant human mammary cells. Oncogene, 2009. 28(11): p. 1421-31.

196. To, K., et al., Y-box binding protein-1 induces the expression of CD44 and CD49f leading to enhanced self-renewal, mammosphere growth, and drug resistance. Cancer Res, 2010. 70(7): p. 2840-51.

197. Bargou, R.C., et al., Nuclear localization and increased levels of transcription factor YB1 in primary human breast cancers are associated with intrinsic MDR1 gene expression. Nat Med, 1997. 3(4): p. 447-50.

198. Fujii, T., et al., Expression of HER2 and estrogen receptor alpha depends upon nuclear localization of Y-box binding protein-1 in human breast cancers. Cancer Res, 2008. 68(5): p. 1504-12.

199. Dhillon, J., et al., The expression of activated Y-box binding protein-1 serine 102 mediates trastuzumab resistance in breast cancer cells by increasing CD44+ cells. Oncogene, 2010. 29(47): p. 6294-300.

200. Lee, C., et al., Targeting YB-1 in HER-2 overexpressing breast cancer cells induces apoptosis via the mTOR/STAT3 pathway and suppresses tumor growth in mice. Cancer Res, 2008. 68(21): p. 8661-6.

201. Oda, Y., et al., Prognostic implications of the nuclear localization of Y-box-binding protein-1 and CXCR4 expression in ovarian cancer: their correlation with activated Akt, LRP/MVP and P-glycoprotein expression. Cancer Sci, 2007. 98(7): p. 1020-6.

202. Sutherland, B.W., et al., Akt phosphorylates the Y-box binding protein 1 at Ser102 located in the cold shock domain and affects the anchorage-independent growth of breast cancer cells. Oncogene, 2005. 24(26): p. 4281-92.

203. Sommerville, J. and M. Ladomery, Masking of mRNA by Y-box proteins. FASEB J, 1996. 10(4): p. 435-43. 
204. Sada, A., et al., NANOS2 acts downstream of glial cell line-derived neurotrophic factor signaling to suppress differentiation of spermatogonial stem cells. Stem Cells, 2012. 30(2): p. 280-91.

205. Oatley, M.J., et al., Inhibitor of DNA binding 4 is expressed selectively by single spermatogonia in the male germline and regulates the self-renewal of spermatogonial stem cells in mice. Biol Reprod, 2011. 85(2): p. 347-56.

206. Wu, X., et al., The POU Domain Transcription Factor POU3F1 Is an Important Intrinsic Regulator of GDNF-Induced Survival and Self-Renewal of Mouse Spermatogonial Stem Cells. Biol Reprod, 2010. 82(6): p. 1103-1111.

207. Delcommenne, M., et al., Phosphoinositide-3-OH kinase-dependent regulation of glycogen synthase kinase 3 and protein kinase B/AKT by the integrin-linked kinase. Proc Natl Acad Sci U S A, 1998. 95(19): p. 11211-6.

208. Cross, D.A., et al., Inhibition of glycogen synthase kinase-3 by insulin mediated by protein kinase B. Nature, 1995. 378(6559): p. 785-9.

209. Shibahara, K., et al., Targeted disruption of one allele of the Y-box binding protein-1 (YB-1) gene in mouse embryonic stem cells and increased sensitivity to cisplatin and mitomycin C. Cancer Sci, 2004. 95(4): p. 348-53.

210. Yang, J., et al., Absence of the DNA-/RNA-binding protein MSY2 results in male and female infertility. Proc Natl Acad Sci U S A, 2005. 102(16): p. 5755-60.

211. Yang, J., et al., In the absence of the mouse DNA/RNA-binding protein MSY2, messenger RNA instability leads to spermatogenic arrest. Biol Reprod, 2007. 76(1): p. 48-54.

212. Wu, J., et al., Disruption of the Y-box binding protein-1 results in suppression of the epidermal growth factor receptor and HER-2. Cancer Res, 2006. 66(9): p. 4872-9.

213. Dong, J., et al., RNA-binding specificity of Y-box protein 1. RNA Biol, 2009. 6(1): p. 5964.

214. Mazzoni, C., et al., Yeast caspase 1 links messenger RNA stability to apoptosis in yeast. EMBO Rep, 2005. 6(11): p. 1076-81.

215. Hirsch, E., et al., Peri-implantation lethality in mice lacking the Sm motif-containing protein Lsm4. Mol Cell Biol, 2000. 20(3): p. 1055-62.

216. Feral, C., G. Guellaen, and A. Pawlak, Human testis expresses a specific poly(A)-binding protein. Nucleic Acids Res, 2001. 29(9): p. 1872-83.

217. Kleene, K.C., et al., Developmental expression of poly(A) binding protein mRNAs during spermatogenesis in the mouse. Mol Reprod Dev, 1994. 39(4): p. 355-64.

218. Biggiogera, M., et al., Distribution of nucleolar proteins B23 and nucleolin during mouse spermatogenesis. Chromosoma, 1991. 100(3): p. 162-72.

219. Mikhaylova, L.M., A.M. Boutanaev, and D.I. Nurminsky, Transcriptional regulation by Modulo integrates meiosis and spermatid differentiation in male germ line. Proc Natl Acad Sci U S A, 2006. 103(32): p. 11975-80.

220. Rilianawati, et al., Spermatogenesis in testes of Dazl null mice after transplantation of wild-type germ cells. Reproduction, 2003. 126(5): p. 599-604.

221. Garand, C., et al., An integrative approach to identify YB-1-interacting proteins required for cisplatin resistance in MCF7 and MDA-MB-231 breast cancer cells. Cancer Sci, 2011. 102(7): p. 1410-7.

222. Bader, B.L., et al., Extensive vasculogenesis, angiogenesis, and organogenesis precede lethality in mice lacking all alpha v integrins. Cell, 1998. 95(4): p. 507-519. 
223. Yang, J., et al., The DNA/RNA-binding protein MSY2 marks specific transcripts for cytoplasmic storage in mouse male germ cells. Proc Natl Acad Sci U S A, 2005. 102(5): p. 1513-8.

224. Yang, J., et al., Deletion of the DNA/RNA-binding protein MSY2 leads to post-meiotic arrest. Mol Cell Endocrinol, 2006. 250(1-2): p. 20-4. 